\title{
Thermophysical property anomalies of Baltic seawater
}

\author{
R. Feistel ${ }^{1}$, G. M. Marion ${ }^{2}$, R. Pawlowicz ${ }^{3}$, and D. G. Wright ${ }^{*} \dagger$ \\ ${ }^{1}$ Leibniz-Institut für Ostseeforschung, Seestraße 15, 18119 Warnemünde, Germany \\ ${ }^{2}$ Desert Research Institute, 2215 Raggio Parkway, Reno, NV 89512-1095, USA \\ ${ }^{3}$ Department of Earth and Ocean Sciences, University of British Columbia, Vancouver, BC V6T 1Z4, Canada \\ * formerly at: Bedford Institute of Oceanography, Dartmouth, NS B2Y 4A2, Canada \\ $\dagger$ deceased \\ Received: 26 May 2010 - Published in Ocean Sci. Discuss.: 30 June 2010 \\ Revised: 4 November 2010 - Accepted: 9 November 2010 - Published: 18 November 2010
}

\begin{abstract}
While the thermodynamic properties of Standard Seawater are very well known, the quantitative effect of sea salt composition anomalies on various properties is difficult to estimate since comprehensive lab experiments with the various natural waters are scarce. Coastal and estuarine waters exhibit significant anomalies which also influence to an unknown amount the routine salinity calculation from conductivity measurements.

Recent numerical models of multi-component aqueous electrolytes permit the simulation of physical chemical properties of seawater with variable solute composition. In this paper, the FREZCHEM model is used to derive a Gibbs function for Baltic seawater, and the LSEA_DELS model to provide estimates for the conductivity anomaly relative to Standard Seawater. From additional information such as direct density measurements or empirical salinity anomaly parameterisation, the quantitative deviations of properties between Baltic and Standard Seawater are calculated as functions of salinity and temperature. While several quantities show anomalies that are comparable with their measurement uncertainties and do not demand special improvement, others exhibit more significant deviations from Standard Seawater properties. In particular density and sound speed turn out to be significantly sensitive to the presence of anomalous solute. Suitable general correction methods are suggested to be applied to Baltic Sea samples with known Practical Salinity and, optionally, directly determined density.
\end{abstract}

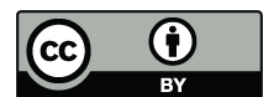

Correspondence to: R. Feistel (rainer.feistel@io-warnemuende.de)

\section{Introduction}

From Knudsen's "Normalwasser VI" (Knudsen, 1903) to the current IAPSO ${ }^{1}$ service, Standard Seawater (SSW) collected from the North Atlantic and processed into sealed bottles has served for the calibration of oceanographic measuring devices for more than a century. This water has also been used to characterise the properties of seawater (Millero et al., 2008). However, the chemical composition of seawater is not exactly constant. Regional deviations of seawater composition and properties were occasionally investigated, in particular in the 1970s (Rohde, 1966; Cox et al., 1967; Kremling, 1969, 1970, 1972; Connors and Kester, 1974; Brewer and Bradshaw, 1975; Millero et al., 1978; Poisson et al., 1981; Millero, 2000), but were generally considered of minor relevance and ignored by previous international oceanographic standards (Forch et al., 1902; Jacobsen and Knudsen, 1940; Lewis, 1981; Millero, 2010). However, the effects of these compositional variations are measureable, and are easily the largest single factor currently limiting the accuracy of empirical formulas for the thermodynamic properties of seawater. It is therefore desirable to investigate the effects of these regional deviations, and to determine how these deviations can be incorporated into routine procedures for obtaining numerical estimates of different seawater properties (Lewis, 1981).

The new TEOS $-10^{2}$ formulation of seawater properties (Feistel, 2008; IAPWS, 2008; IOC et al., 2010) supports the analysis of anomalous seawater properties in a first approximation even though methods and knowledge available for the description of the related effects are still immature. An

\footnotetext{
${ }^{1}$ IAPSO: International Association for the Physical Sciences of the Oceans, http://iapso.sweweb.net

${ }^{2}$ TEOS-10: International Thermodynamic Equation of Seawater 2010, http://www.teos-10.org
}

Published by Copernicus Publications on behalf of the European Geosciences Union. 
important step in this direction was the definition of the Reference Composition (RC) as a standard composition model for sea salt (Millero et al., 2008). The RC can be used to define a Reference Salinity, which represents the actual mass fraction of solute in seawater of Reference Composition. It also defines a baseline relative to which anomalies can be properly quantified in detail. The $\mathrm{RC}$ is defined in the form of exact molar fractions, $x_{a}^{\mathrm{RC}}>0$, for 15 major sea salt constituents, $a$. Deviations of molar fractions, $x_{a} \neq x_{a}^{\mathrm{RC}}$, from the $\mathrm{RC}$ found in samples of natural or artificial seawater are regarded as composition anomalies. A second step towards an analysis procedure for anomalous seawater has been to define a parameter, the Absolute Salinity, which will provide the best estimate of the density of a particular seawater sample whose composition is different than the Reference Composition, when used as a numerical input into the TEOS-10 Gibbs function (Wright et al., 2010b). Under this definition, the Absolute Salinity represents the mass fraction of solute in a seawater of Reference Composition with the same density as that of the sample, and can also be called the Density Salinity. It may therefore be different than the actual mass fraction of solute in the sample, which is termed the Solution Absolute Salinity.

In the past, the thermodynamic properties of freshwater and estuarine systems have been found to be approximately described by a heuristic, referred to as "Millero's Rule" here, that states that these properties depend primarily on the mass of solute, and only secondarily on the composition of the solute (Millero, 1975; Chen and Millero, 1984). If this is true for density, then the Density Salinity is a good approximation for Solution Absolute Salinity, even in the presence of composition anomalies. However, recent analysis (Pawlowicz et al., 2010) suggests that this approximation might have a much narrower range of validity than was previously believed.

The Baltic Sea is an obvious place to study the effects of composition anomalies since the existence of composition anomalies in Baltic seawater has been known since the formulation of Knudsen's equation of state (Knudsen, 1901; Forch et al., 1902) in the form of its salinity intercept at zero Chlorinity. The details of these anomalies were determined by chemical analysis beginning in the 1960s (Rohde, 1965; Kremling, 1969, 1970, 1972; Feistel et al., 2010a), and some empirical evidence has been gathered on the effects on density (Kremling, 1971; Millero and Kremling, 1976).

The electrical conductivity of anomalous solute in Baltic seawater is not negligible and has led in the past to various mutually inconsistent empirical relations between Practical Salinity and Chlorinity (Kwiecinski, 1965; Kremling 1969, 1970, 1972) and to an experimental study of whether Practical Salinity is conservative within its measurement uncertainty (Feistel and Weinreben, 2008). Here, conservative means that the salinity value remains the same when temperature or pressure of the sample are changing. However, there is little theoretical knowledge of the reasons for the mag- nitude of the resulting density and conductivity anomalies, and very little is known at all about the quantitative effect of anomalous solutes on the sound speed, the heat capacities, the freezing point, or many other thermodynamic properties (Feistel, 1998).

One drawback of using the Baltic Sea as a test region is that the relative composition of the water is likely not constant with position or depth. The composition variations derive from the inflow of many rivers, which themselves have a wide range of compositions, and these are not well mixed within the Baltic Sea. In addition, these riverine additions are not constant in time and are involved in complex biogeochemical processes during the water residence time of 2030 years (Feistel et al., 2008b; Reissmann et al., 2009); significant variations apparently occur on at least decadal time scales (Feistel et al., 2010a). Acknowledging this uncertainty, we shall use a highly simplified model of the composition anomaly that represents only the effects arising from the addition of calcium and bicarbonate ions which dominate observed anomalies.

In parallel with the development of TEOS-10, numerical models that can be used to investigate the thermodynamic and transport properties of seawaters from a theoretical basis have been developed and tested (Feistel and Marion, 2007; Pawlowicz, 2010). Known as FREZCHEM (Marion and Kargel, 2008) and LSEA_DELS (Pawlowicz, 2009) respectively, these models have been used to extend the range of validity of the thermodynamic Gibbs function into salinities larger and smaller than have been studied experimentally (IAPWS, 2007; Feistel, 2010), and to investigate the effects of composition anomalies resulting from biogeochemical processes on the conductivity and density of seawater (Pawlowicz et al., 2010). In this paper we combine these numerical approaches to study the properties of Baltic Sea water. We create a correction to the TEOS-10 Gibbs function that can be used to determine all the thermodynamic properties of Baltic Sea water, and a correction to the PSS-78 Practical Salinity Scale that can be used to estimate the conductivity of this water. These analytical models are used to study whether the Density Salinity (i.e. the Absolute Salinity as defined by TEOS-10) is in fact a good estimate of the Solution Absolute Salinity (actual mass fraction of solute), and whether or not the Density Salinity can be used in conjunction with the Gibbs function for SSW to determine other thermodynamic parameters.

The composition anomaly of the Baltic Sea, Fig. 1, is dominated by riverine calcium excess (Rohde, 1965; Millero and Kremling, 1976; Feistel et al., 2010a). The dissolved positive $\mathrm{Ca}^{++}$ions are charge-balanced mainly by dissolved carbon dioxide, $\mathrm{CO}_{2}$, e.g., in the form of two negative bicarbonate $\mathrm{HCO}_{3}^{-}$ions. Baltic carbonate concentrations depend in a complex way on exchange with the atmosphere, seasonal solubility, biological activity as well as various chemical reactions with the sediment under occasionally anoxic conditions (Thomas and Schneider, 1999; Nausch et al., 2008; Omstedt 


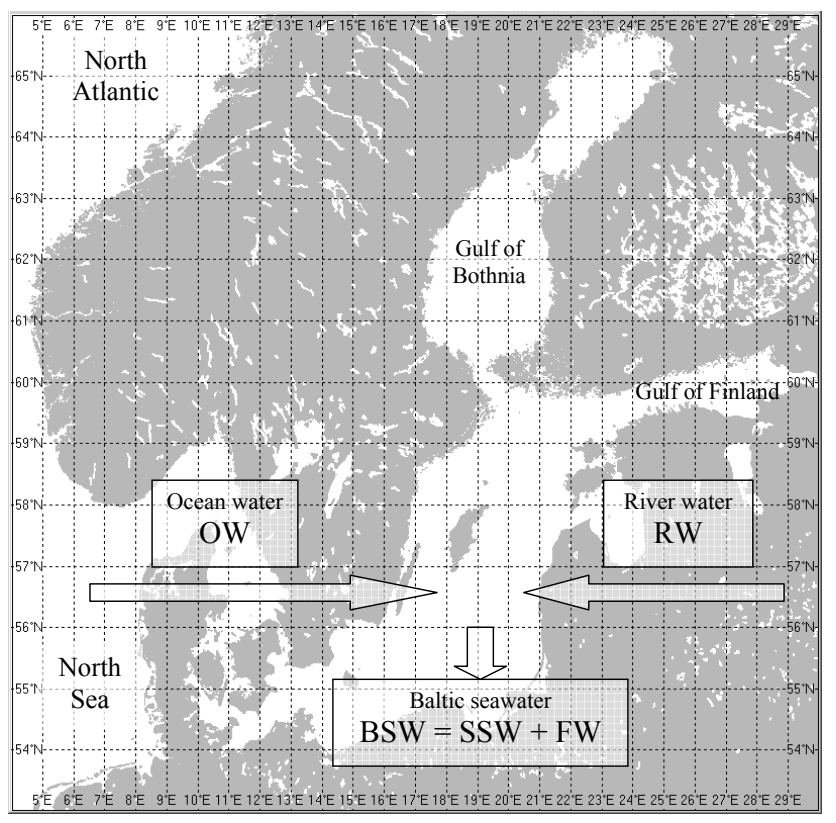

Fig. 1. The Baltic Sea is a semi-enclosed estuary with a volume of about $20000 \mathrm{~km}^{3}$ and an annual freshwater surplus of about $500 \mathrm{~km}^{3} \mathrm{a}^{-1}$; direct precipitation excess accounts for only $10 \%$ of the latter value (Feistel et al., 2008b). Baltic seawater (BSW) is a mixture of ocean water $(\mathrm{OW})$ from the North Atlantic with river water (RW) discharged from the large surrounding drainage area. Regionally and temporally, mixing ratio and RW solute are highly variable. Collected BSW samples consist of Standard Seawater (SSW) with Reference Composition (RC) plus a small amount of anomalous freshwater solute (FW), which we approximate here to be calcium bicarbonate, $\mathrm{Ca}\left(\mathrm{HCO}_{3}\right)_{2}$. In dissolved form, depending on ambient temperature and $\mathrm{pH}, \mathrm{Ca}\left(\mathrm{HCO}_{3}\right)_{2}$ is decomposed into the various compounds of the aqueous carbonate system with mutual equilibrium ratios (Cockell, 2008).

et al., 2009; Schneider et al., 2010). Additions of solute can cause changes in the equilibrium chemistry (e.g., in $\mathrm{pH}$ ), and hence can lead to particles of, say, $\mathrm{HCO}_{3}^{-}$, being converted into particles of $\mathrm{CO}_{3}^{2-}$ by solute-solvent reactions. Such reactions convert $\mathrm{H}_{2} \mathrm{O}$ molecules from being part of the solvent to being part of the solute, or vice versa, such as in the case of Eq. (1.1). A full numerical simulation must model these changes as well, and this requires additional assumptions.

In FREZCHEM an "open system" approach is used. Lime $\left(\mathrm{CaCO}_{3}\right)$ is added, and then the chemical composition is allowed to evolve to an equilibrium state under the restriction that the partial pressure of carbon dioxide $\left(p \mathrm{CO}_{2}\right)$ and the total alkalinity (TA) are fixed. This is a reasonable approach for laboratory studies in which waters at $25^{\circ} \mathrm{C}$ are stirred in contact with air after the addition of a salt, or for wind-mixed river plumes in equilibrium with the atmosphere. In the additions modelled here, a substantial inflow of $\mathrm{CO}_{2}$ gas occurs and increases the mass of anomalous solute, so that the final composition is approximately modelled as an addition of $\mathrm{Ca}^{++}$and $2 \mathrm{HCO}_{3}^{-}$, i.e. a reaction of the form (Cockell, 2008):

$\mathrm{CaCO}_{3}+\mathrm{CO}_{2}+\mathrm{H}_{2} \mathrm{O} \rightarrow \mathrm{Ca}^{++}+2 \mathrm{HCO}_{3}^{-}$.

In LSEA_DELS a "closed system" approach is used. In this case a salt is added, and the chemical composition is allowed to evolve to an equilibrium state under the restriction that the total dissolved inorganic carbon (DIC) is fixed. This is a reasonable approach in situations where a TA and DIC anomaly are known. In the Baltic, these anomalies in TA and DIC are almost equal (Feistel et al., 2010), which indicates that the composition change is approximately modelled as an increase in $\mathrm{Ca}\left(\mathrm{HCO}_{3}\right)_{2}$. This again is consistent with a reaction of the form (1.1).

Although the different assumptions in the two models are potentially a source of discrepancy between the results of our investigation into thermodynamic properties, which requires FREZCHEM, and investigation into conductivity properties, which required LSEA_DELS, there is little difference between the final compositions obtained using the two approaches in this particular case. From another numerical model referred to as LIMBETA (Pawlowicz et al., 2010), an equilibrium model consistent with LSEA_DELS, density is computed for comparison with FREZCHEM in order to quantify the effect of the different boundary conditions. The difference in the predicted density anomalies for a given $\mathrm{Ca}$ anomaly is less than $6 \mathrm{~g} \mathrm{~m}^{-3}$, as discussed in Sect. 6 .

The FREZCHEM model results are used here to develop a Gibbs function for Baltic seawater in the form of a small correction to TEOS-10. A Gibbs function is a thermodynamic potential in terms of temperature, pressure and particle numbers and is therefore consistent with "closed system" conditions. The proper thermodynamic potential for FREZCHEM is a function which takes chemical potentials rather than particle numbers as independent variables, such as the Landau potential, $\Omega=p V$, where $p$ and $V$ are pressure and volume (Landau and Lifschitz, 1987; Goodstein, 1975). The Landau potential is related to the Gibbs potential by a Legendre transform (Alberty, 2001; Feistel et al., 2010c). The chemical potential of water in seawater expressed in terms of the Gibbs function is an example for such a Legendre transform. Since the differences between the open and the closed models are small, we refrain from the relatively complicated conversion procedure between Gibbs and Landau potentials in our generalization of the TEOS-10 Gibbs function with respect to an additional salinity variable. The gain expected from this significantly more demanding model will very likely be minor and at this stage does not warrant the additional effort.

Thermodynamic potentials describe unique equilibrium states at given conditions, e.g., in terms of numbers of atoms of the elements present in the system. These atoms may or may not form mutual bound states, and chemical reactions may occur between those compounds, between the solutes 
or the solvent, without affecting the validity of the thermodynamic potential expressed in terms of the system's elementary composition. This very convenient property is evident from the representation of thermodynamic potentials in statistical mechanics such as the canonical or the grand canonical ensemble. Formally, the atom numbers can also be replaced by suitable fixed stoichiometric combinations, i.e. by numbers of certain molecules as independent variables. Hence, the concentrations of $\mathrm{Ca}^{++}$and $\mathrm{HCO}_{3}^{-}$ions are sufficient to correctly formulate the Gibbs function for Baltic seawater, regardless of any chemical reactions that in reality occur in the marine carbonate system, and which are modelled correspondingly by FREZCHEM and LIMBETA to determine the particular equilibrium states.

The paper is organised as follows. In Sect. 2, several required composition variables and basic thermodynamic terms are introduced. In Sect. 3, a formal expression for the Gibbs function of Baltic seawater is derived. This expression is used in Sect. 4 to obtain a formulation for the Baltic Sea Gibbs function through an empirical correlation of a specified functional form against results estimated using of the FREZCHEM model. This Gibbs function depends on two salinities, the Absolute Salinity of the SSW part, and a correction proportional to the anomalous calcium excess. In Sect. 5 selected property anomalies are computed from the Gibbs function for Baltic seawater and compared with a density-salinity approach taking into account the experimental uncertainty. In Sect. 6, as functions of the two salinity variables, correlation formulas for the conductivity, Practical Salinity and Reference Salinity of Baltic seawater are derived from results based on the LSEA_DELS model. Combining the previous results, Sect. 7 discusses the errors implied by computing seawater properties directly from Practical Salinity readings, and suggests general correction algorithms for error reduction.

\section{Composition variables}

Baltic seawater, BSW, is a mixture of ocean water, OW, from the Atlantic plus a riverine freshwater contribution, RW, which may contain a small amount of salt, Fig. 1. The composition of OW is very close to the RC, i.e., to the composition of IAPSO Standard Seawater (SSW). RW contains various salts with the composition varying strongly in time depending on the different river sources (Perttilä, 2009). On average, the molar ratio of calcium to chloride for RW is significantly higher that for the RC. When RW and OW are mixed to form BSW, the two different origins of the chloride fraction can no longer be distinguished but a measurable calcium excess remains compared to the concentrations seen in SSW of the same Chlorinity and this represents the primary composition anomaly associated with RW inputs to the Baltic. Thus, samples collected from the Baltic Sea can reasonably be regarded as a parent solution of pure-water diluted Stan- dard Seawater, SSW, with Reference Composition, RC, plus a small amount of anomalous freshwater solute, FW, which originates from river discharge and contains mainly the calcium fraction of RW in excess of the expected value based on the $\mathrm{Ca} / \mathrm{Cl}$ ratio of the RC. Note that the SSW contribution includes pure water plus RC solute from both OW and RW whereas FW refers only to the anomalous solute derived from riverine inputs.

The SSW and FW fractions of BSW are usually separated by the definition that FW does not contain any halides, i.e., that the Chlorinity of BSW determines the SSW fraction, independent of whether or not some of the river water entering the Baltic carries a relevant halide load. Because the RW component does in fact contain a small fraction of halides, the use of Chlorinity to estimate the SSW fraction will always result in this component including a small contribution from RW of all species in the RC. However, because the halide concentrations in OW are so large, the relative change in their concentration due to RW solute is very small, as is the corresponding error in the concentrations of all species in RC, and thus can be neglected. Anomalies of BSW, i.e., the composition of the FW fraction, in chemical species other than calcium and carbonates are neglected in our models. They are less relevant and were also found to vary significantly from author to author and between the analysed samples (Feistel et al., 2010a).

We emphasize that the models considered in this paper are formulated in terms of two independent salinity variables representing the SSW and FW fractions of BSW. In contrast, it is a common practice to assume that the FW composition equals that of RW (Millero and Kremling, 1976; Feistel et al., 2010a), which is consistent with the fact that the composition anomaly of BSW increases with decreasing brackish salinity. When results from our models are discussed or compared with observations, we will make use of such empirical salinity-anomaly relations between SSW and FW to conveniently display the typical anomalous properties as functions of a single variable that is routinely observed, the brackish salinity. In particular, the SSW and FW variables of the models will be approximately linked to the OW and RW concentrations, Eq. (2.16). However, it should be noted that the thermophysical equations derived from our models do not rely on any empirical and climatologically varying relation between SSW and FW; they depend separately on the two concentration variables.

In the FREZCHEM and LSEA_DELS models, the FW composition is simplified to consist only of the carbonate equilibrium components that evolve from the dissolution of $\mathrm{Ca}\left(\mathrm{HCO}_{3}\right)_{2}$ in pure water, neglecting any other solutes such as sulfate or magnesium. The Gibbs function derived from FREZCHEM takes only the mass fraction of $\mathrm{Ca}\left(\mathrm{HCO}_{3}\right)_{2}$ as the FW input variable, regardless of the chemical equilibrium composition details after its dissolution in water.

To describe the thermodynamic properties of a given BSW sample, we first introduce a number of terms and variables. 
A set of independent primary variables (considered as known) is required to describe the composition of the solutions corresponding to a particular water sample: the number of water molecules from $\mathrm{OW}, N_{0}^{\mathrm{OW}}$, and from the local freshwater input RW, $N_{0}^{\mathrm{RW}}$, and the number of particles $N_{a}^{\mathrm{OW}}$ and $N_{a}^{\mathrm{RW}}$ of the related solute species, $a$. Their molar masses of the solvent and solute species are denoted by $A_{0}$ and $A_{a}$, respectively. The number of particles per mole is Avogadro's number, $N_{\mathrm{A}}$.

When conservative mixing and a neutral precipitationevaporation balance are assumed, the number of water and solute particles in BSW are,

$N_{0}^{\mathrm{BSW}}=N_{0}^{\mathrm{OW}}+N_{0}^{\mathrm{RW}}, \quad N_{a}^{\mathrm{BSW}}=N_{a}^{\mathrm{OW}}+N_{a}^{\mathrm{RW}}$,

respectively. Regardless of the - usually unknown - precise origin in terms of $N_{a}^{\mathrm{OW}}$ and $N_{a}^{\mathrm{RW}}$ of the particle numbers finally found in the mixture, $N_{0}^{\mathrm{BSW}}, N_{a}^{\mathrm{BSW}}$, they actually define the composition of a given Baltic seawater sample and represent the starting point of our model. The aim of this paper is to estimate the deviation of thermophysical properties of BSW from those of SSW due to the excess of calcium ions in BSW. For this reason we formally divide the BSW particle numbers $N_{0}^{\mathrm{BSW}}, N_{a}^{\mathrm{BSW}}$ into a major SSW fraction with Reference Composition, and a minor fraction of FW solute,

$N_{a}^{\mathrm{BSW}}=x_{a}^{\mathrm{RC}} N_{\mathrm{S}}^{\mathrm{SSW}}+x_{a}^{\mathrm{FW}} N_{\mathrm{S}}^{\mathrm{FW}}$.

Here, the total solute particle numbers of the SSW and the FW fraction, $N_{\mathrm{S}}^{\mathrm{SSW}}$ and $N_{\mathrm{S}}^{\mathrm{FW}}$, respectively, are chosen so that $N_{a}^{\mathrm{SSW}}=x_{a}^{\mathrm{RC}} N_{\mathrm{S}}^{\mathrm{SSW}}>0$ for all species of the RC but $N_{a}^{\mathrm{FW}}=$ $x_{a}^{\mathrm{FW}} N_{\mathrm{S}}^{\mathrm{FW}}=0$ for most of the RC species in the freshwater fraction. The molar fractions of the Reference Composition, $x_{a}^{\mathrm{RC}}>0$, are defined by Millero et al. (2008), and the molar fractions of the anomalous solute, $x_{a}^{\mathrm{FW}} \geq 0$, are inferred from the simplified dissociation reaction Eq. (1.1), as

$x_{\mathrm{Ca}}^{\mathrm{FW}}=1 / 3, \quad x_{\mathrm{HCO}_{3}}^{\mathrm{FW}}=2 / 3$.

Additional basic quantities are derived from the previous variables to determine the related water properties. These quantities include:

- the mass of salt from the SSW part,

$$
M_{\mathrm{S}}^{\mathrm{SSW}}=\frac{1}{N_{\mathrm{A}}} \sum_{a} N_{a}^{\mathrm{SSW}} A_{a},
$$

- the mass of the FW part, which consists of the solute only,

$$
M_{\mathrm{S}}^{\mathrm{FW}}=M^{\mathrm{FW}}=\frac{1}{N_{\mathrm{A}}} \sum_{a} N_{a}^{\mathrm{FW}} A_{a},
$$

- the total mass of solvent, $M_{0}^{\mathrm{BSW}}$, which equals the solvent mass of the SSW part,

$$
M_{0}^{\mathrm{BSW}}=\frac{N_{0}^{\mathrm{BSW}}}{N_{\mathrm{A}}} A_{0}=M_{0}^{\mathrm{SSW}},
$$

- the total mass of solute, $M_{\mathrm{S}}^{\mathrm{BSW}}$,

$$
M_{\mathrm{S}}^{\mathrm{BSW}}=M_{\mathrm{S}}^{\mathrm{SSW}}+M_{\mathrm{S}}^{\mathrm{FW}},
$$

- the total mass of the SSW solution,

$$
M^{\mathrm{SSW}}=M_{0}^{\mathrm{SSW}}+M_{\mathrm{S}}^{\mathrm{SSW}}, \text { and }
$$

- the total mass of the combined BSW sample, $M^{\mathrm{BSW}}$,

$$
M^{\mathrm{BSW}}=M^{\mathrm{SSW}}+M^{\mathrm{FW}} \text {. }
$$

In terms of those basic particle numbers and masses, several other useful properties are defined, such as the total number of water particles, $N_{0}^{\mathrm{SSW}}$, in SSW, and of salt, $N_{\mathrm{S}}^{\mathrm{BSW}}$, in BSW,

$N_{0}^{\mathrm{SSW}}=N_{0}^{\mathrm{BSW}}, \quad N_{\mathrm{S}}^{\mathrm{BSW}}=N_{\mathrm{S}}^{\mathrm{SSW}}+N_{\mathrm{S}}^{\mathrm{FW}}$,

and the Absolute Salinity of BSW,

$S_{\mathrm{A}}^{\mathrm{BSW}}=\frac{M_{\mathrm{S}}^{\mathrm{BSW}}}{M^{\mathrm{BSW}}}=S_{\mathrm{SSW}}^{\mathrm{BSW}}+S_{\mathrm{FW}}^{\mathrm{BSW}}$.

The latter consists of the sum of the mass fractions of sea salt from the SSW, $S_{\mathrm{SSW}}^{\mathrm{BSW}}$, and from the FW, $S_{\mathrm{FW}}^{\mathrm{BSW}}$, to the BSW, in the form,

$S_{\mathrm{SSW}}^{\mathrm{BSW}}=\frac{M_{\mathrm{S}}^{\mathrm{SSW}}}{M^{\mathrm{BSW}}}=\frac{M_{\mathrm{S}}^{\mathrm{SSW}}}{M_{0}^{\mathrm{BSW}}+M_{\mathrm{S}}^{\mathrm{BSW}}}$,

$S_{\mathrm{FW}}^{\mathrm{BSW}}=\frac{M_{\mathrm{S}}^{\mathrm{FW}}}{M^{\mathrm{BSW}}}=\frac{M_{\mathrm{S}}^{\mathrm{FW}}}{M_{0}^{\mathrm{BSW}}+M_{\mathrm{S}}^{\mathrm{BSW}}}$.

Before mixing, the salinities of the two end members are

$S_{\mathrm{A}}^{\mathrm{OW}}=\frac{M_{\mathrm{S}}^{\mathrm{OW}}}{M^{\mathrm{OW}}}$

for the OW part, where $M_{\mathrm{S}}^{\mathrm{OW}}$ is the mass of salt dissolved in the sample mass $M^{\mathrm{OW}}$, and

$S_{\mathrm{A}}^{\mathrm{RW}}=\frac{M_{\mathrm{S}}^{\mathrm{RW}}}{M^{\mathrm{RW}}}$

for the RW part, where $M_{\mathrm{S}}^{\mathrm{RW}}$ is the mass of salt dissolved in the sample mass $M^{\mathrm{RW}}$. Under the plausible assumption that the SSW solute originates from ocean water $\mathrm{OW}, M_{\mathrm{S}}^{\mathrm{SSW}} \approx$ $M_{\mathrm{S}}^{\mathrm{OW}}$, and the FW solute from river discharge, $\mathrm{RW}, M_{\mathrm{S}}^{\mathrm{FW}} \approx$ $M_{\mathrm{S}}^{\mathrm{RW}}$, the relation between the partial salinities before and after the conservative mixing process is given by the mass balance, $S_{\mathrm{FW}}^{\mathrm{BSW}} / S_{\mathrm{A}}^{\mathrm{RW}}+S_{\mathrm{SSW}}^{\mathrm{BSW}} / S_{\mathrm{A}}^{\mathrm{OW}} \approx 1$, i.e.,

$S_{\mathrm{FW}}^{\mathrm{BSW}} \approx S_{\mathrm{A}}^{\mathrm{RW}}\left(1-\frac{S_{\mathrm{SSW}}^{\mathrm{BSW}}}{S_{\mathrm{AW}}^{\mathrm{OW}}}\right)$ 
For the estimation of the riverine salinity $S_{\mathrm{A}}^{\mathrm{RW}}$ from density measurements of Baltic Sea samples, this equation is commonly used under the additional assumption that the SSW end member, North Atlantic surface water, has exactly standard-ocean salinity, $S_{\mathrm{A}}^{\mathrm{OW}} \approx S_{\mathrm{SO}}$ (Millero and Kremling, 1976; Feistel et al., 2010a), which is given in Table A1. The value of $S_{\mathrm{SSW}}^{\mathrm{BSW}}$ can be determined from Chorinity measurements since the amount of halides in FW is zero by definition and the value of $S_{\mathrm{FW}}^{\mathrm{BSW}}$ can then be determined from Eq. (2.11) with the value of $S_{\mathrm{A}}^{\mathrm{BSW}}$, Eq. (2.26), estimated from density measurements.

The mean molar masses of the solutes from the SSW and from the FW, respectively, are defined as

$$
A_{\mathrm{SSW}}=\sum_{a} x_{a}^{\mathrm{SSW}} A_{a}, \quad A_{\mathrm{FW}}=\sum_{a} x_{a}^{\mathrm{FW}} A_{a} .
$$

In the final solution, BSW, the total molality ${ }^{3}$ of the solute is

$m^{\mathrm{BSW}}=\frac{N_{\mathrm{S}}^{\mathrm{SSW}}+N_{\mathrm{S}}^{\mathrm{FW}}}{N_{\mathrm{A}} M_{0}^{\mathrm{BSW}}}=m_{\mathrm{SSW}}^{\mathrm{BSW}}+m_{\mathrm{FW}}^{\mathrm{BSW}}$,

expressed as the sum of the partial molalities, $m_{\mathrm{SSW}}^{\mathrm{BSW}}$ and $m_{\mathrm{FW}}^{\mathrm{BSW}}$, of sea salt from the SSW and from the FW contributions to BSW,

$$
\begin{aligned}
& m_{\mathrm{SSW}}^{\mathrm{BSW}}=\frac{N_{\mathrm{S}}^{\mathrm{SSW}}}{N_{\mathrm{A}} M_{0}^{\mathrm{BSW}}}=\frac{S_{\mathrm{SSW}}^{\mathrm{BSW}}}{A_{\mathrm{SSW}}\left(1-S_{\mathrm{SSW}}^{\mathrm{BSW}}-S_{\mathrm{FW}}^{\mathrm{BSW}}\right)}, \\
& m_{\mathrm{FW}}^{\mathrm{BSW}}=\frac{N_{\mathrm{S}}^{\mathrm{FW}}}{N_{\mathrm{A}} M_{0}^{\mathrm{BSW}}}=\frac{S_{\mathrm{FW}}^{\mathrm{BSW}}}{A_{\mathrm{FW}}\left(1-S_{\mathrm{SSW}}^{\mathrm{BSW}}-S_{\mathrm{FW}}^{\mathrm{BSW}}\right)} .
\end{aligned}
$$

Compared to the molalities, Eqs. (2.19), (2.20), the salinities, Eqs. (2.12), (2.13), have the disadvantage that the salinity measure $S_{\mathrm{SSW}}^{\mathrm{BSW}}$ of salt present with standard composition is (slightly) changing as soon as some anomalous solutes, $M_{\mathrm{S}}^{\mathrm{FW}}$, are added or removed, even if the amount of salt that stems from the SSW, $M_{\mathrm{S}}^{\mathrm{SSW}}$, and the mass of solvent, $M_{0}^{\mathrm{BSW}}$, remain the same.

In general, a formal solute decomposition in the form of Eq. (2.2) is not self-evident. If a seawater sample of a certain molar solute composition $\boldsymbol{x}$ and molality $m$ is given and its original end members are unknown, the decomposition of the solute into a "preformed" part with Reference Composition $\boldsymbol{x}^{\mathrm{RC}}$ and molality $m^{\mathrm{RC}}$, and a residual anomalous "freshwater" part with a resulting composition $\boldsymbol{x}^{\mathrm{FW}}$ and molality $\delta m$ takes the form

$x_{a} m=x_{a}^{\mathrm{RC}} m^{\mathrm{RC}}+x_{a}^{\mathrm{FW}} \delta m$.

Here, the molar fractions are normalised, $\sum_{a} x_{a}=\sum_{a} x_{a}^{\mathrm{RC}}=$ $\sum_{a} x_{a}^{\mathrm{FW}}=1$. These mass-balance equations for the $n$ species

\footnotetext{
${ }^{3}$ Molality $=$ moles of solute per mass of solvent
}

do not possess a unique solution for the $(n+1)$ unknowns $m^{\mathrm{RC}}, \delta m$ and $\boldsymbol{x}^{\mathrm{FW}}$ which fully characterise the end members. Consequently, due to this ambiguity of $m^{\mathrm{RC}}$, the "Preformed Salinity" (Wright et al., 2010a) of an arbitrary seawater sample,

$S_{*}=\frac{M_{0}^{\mathrm{BSW}}}{M^{\mathrm{BSW}}} m^{\mathrm{RC}} \sum_{a} x_{a}^{\mathrm{RC}} A_{a}$,

may take any desired value unless it is subjected to a specified additional condition. One suitable, physically reasonable condition is that $\delta m$ takes a minimum non-negative value and that $m^{\mathrm{RC}}$ and all the freshwater fractions $\boldsymbol{x}^{\mathrm{FW}}$ are also non-negative, $x_{a}^{\mathrm{FW}} \geq 0$. In this case, two chemically well-defined and meaningful end members are associated with the given seawater sample. The molar mass $A_{\mathrm{FW}}$, Eq. (2.17), is positive definite under this condition, and the molality, $m_{\mathrm{FW}}^{\mathrm{BSW}}$, Eq. (2.20), the salinity, $S_{\mathrm{FW}}^{\mathrm{BSW}}$, Eq. (2.13), the mass, $M_{\mathrm{S}}^{\mathrm{FW}}$, and the particle numbers, $N_{a}^{\mathrm{FW}}$, of the anomalous solute are nonnegative. The ideal-solution part of the Gibbs function of any aqueous solution,

$$
\begin{aligned}
& g^{\mathrm{id}}(m, \boldsymbol{x}, T, P)=g^{\mathrm{W}}(T, P) \\
& \quad+\sum_{a} x_{a} m\left[R T \ln \left(x_{a} m\right)+\Gamma_{a}(T, P)\right],
\end{aligned}
$$

possesses a regular and reasonable series expansion with respect to the anomaly if $x_{a}^{\mathrm{FW}} \geq 0$ and $0 \leq x_{a}^{\mathrm{FW}} \delta m \ll x_{a}^{\mathrm{RC}} m^{\mathrm{RC}}$, and the chemical potentials of the RC and the FW solutes are mathematically valid and physically meaningful expressions, Eq. (3.6). Symbols newly introduced in Eq. (2.23) are specified in the glossary, Appendix B.

Alternatively, if for certain reasons the separation (Eq. 2.21) is formally specified in such a way that at least one of $x_{a}^{\mathrm{FW}} \leq 0, x_{a}^{\mathrm{RC}} \leq 0, m^{\mathrm{RC}} \leq 0$ or $m<m^{\mathrm{RC}}$ is implied, some of the previous convenient properties may no longer be valid and a mathematically more cautious treatment of the thermodynamic perturbation is required. In this respect we can distinguish at least three qualitatively different situations, here referred to as modified, alien, and deficient seawater. The distinction between these cases is necessary only if the anomaly is preferably described in terms of an anomalous solute with thermodynamically well-defined concentration and composition values, i.e., if non-negative molar fractions $x_{a}^{\mathrm{FW}}$ and non-negative molalities $m^{\mathrm{RC}}$ and $\delta m$ are relevant for the equations used, and if each of the anomalous concentrations, $x_{a}^{\mathrm{FW}} \delta m$, is assumed to be small compared to that of the parent solution, $x_{a}^{\mathrm{RC}} m^{\mathrm{RC}}$, as exploited in this paper. These conditions are mostly met in the case (a) but partly violated in the cases (b) and (c). Thus, anomalies of the kinds (b) or (c) may require a different Gibbs function approach than the one developed in this paper.

a. Modified seawater is defined by the condition $x_{a}>0$ for each dissolved species $a$ in the RC (i.e., for all species with $x_{a}^{\mathrm{RC}}>0$ ), and $x_{a}=0$ for all species $a$ not included 
in the RC (i.e., for all species with $x_{a}^{\mathrm{RC}}=0$ ). Under these conditions, a nonvanishing anomaly implies that $x_{a} \neq x_{a}^{\mathrm{RC}}$ for at least two of them. This is the simplest case and it is considered exclusively in this paper. It occurs when e.g. riverine freshwater or hydrothermal vents increase the concentration of selected species relative to the parent solution with Reference Composition, or if some species are partially precipitated due to supersaturation at high salinity or high temperature, or biologically depleted. If $m$ is the molality of the given sample, the solute can be uniquely separated into a regular part with Reference Composition and the molality $m^{\mathrm{RC}}<m$, and an anomalous part with the molality $\delta m=m-m^{\mathrm{RC}}$, subject to the conditions

$x_{a} m-x_{a}^{\mathrm{RC}} m^{\mathrm{RC}} \geq 0 \quad \forall a \in \mathrm{RC}$,

$x_{k} m-x_{k}^{\mathrm{RC}} m^{\mathrm{RC}}=0 \quad$ for at least one species $k \in \mathrm{RC}$.

The species $k$ is regarded as the key species which is not present in the anomalous part; its molality specifies the regular part via the RC ratios. In this study of the Baltic Sea, chloride will serve as the key species. Because of the condition (Eq. 2.24), the anomalous part does not contain species with formally negative concentrations and can be modelled physically/chemically in the form of added salt. Usually, $\delta m \ll m^{\mathrm{RC}}$ will be assumed.

b. Alien seawater is defined by the condition $x_{a}>0$ for at least one dissolved species $a$, the alien species, that is not part of the RC (i.e., $x_{a}>0$ for a species for which $x_{a}^{\mathrm{RC}}=0$ ). Two examples of this case are when biologically produced silicate or organic compounds are added to seawater at relevant amounts, and when seawater is acidified to prevent precipitation in technical systems. Compared to the Reference Composition, the responsible physical state space dimension must be expanded to cover the alien species, and the representative point for the RC is then located on the boundary of the positive cone of the expanded space rather that in its interior. On the boundary or in its immediate vicinity, thermodynamic properties possess very special properties such as singularities of chemical potentials or electrolytic limiting laws. Thus, alien species cannot be described theoretically by a small linear deviation from a regular point in the phase space; they require specific nonlinear mathematical expressions such as limiting laws.

c. Deficient seawater is defined by the condition $x_{a}=0$ for at least one species $a$, the deficient species, that is part of the RC (i.e., for a species with $x_{a}^{\mathrm{RC}}>0$ ). The missing constituent may be a volatile or reactive compound such as $\mathrm{CO}_{2}$ or $\mathrm{OH}^{-}$that has disappeared in a certain physical, chemical or technical environment. Although the resulting composition may be very similar to the $\mathrm{RC}$, a procedure like in case (a) is impossible here since it would formally lead to a zero-molality regular part and an anomalous part that contains all of the solute. In this case it may be more reasonable to specify the anomalous part as a small deviation from the RC concentrations some of which are negative. It is clear that this anomalous part can no longer be considered as an "added salt".

As suggested by observational evidence (Feistel et al., 2010a), the Baltic seawater is modelled here as modified seawater, as specified under case (a). The related Preformed Salinity, Eq. (2.22), is the Absolute Salinity of the diluted SSW, denoted here by

$S_{\mathrm{A}}^{\mathrm{SSW}}=\frac{M_{\mathrm{S}}^{\mathrm{SSW}}}{M_{0}^{\mathrm{BSW}}+M_{\mathrm{S}}^{\mathrm{SSW}}}=\frac{m^{\mathrm{RC}} \sum_{a} x_{a}^{\mathrm{RC}} A_{a}}{1+m^{\mathrm{RC}} \sum_{a} x_{a}^{\mathrm{RC}} A_{a}}$.

$S_{\mathrm{A}}^{\mathrm{SSW}}$ differs from the OW end-member salinity, $S_{\mathrm{A}}^{\mathrm{OW}}$, Eq. (2.14), at least due to the dilution with the pure water part of the riverine input and possibly, depending on where and when the BSW sample was collected, due to the riverine contributions to the key species, chloride. We will assume that the dilution effect strongly dominates. The resulting brackish SSW part, the parent solution, can properly be described by the TEOS-10 Gibbs function in terms of $S_{\mathrm{A}}^{\mathrm{SSW}}, T$ and $P$. An expression for the correction to this Gibbs function, proportional to the anomalous solute molality, $\delta m$, is derived from thermodynamic considerations in the following section.

\section{Theoretical formulation of the Gibbs function for Baltic seawater}

In the Baltic Sea, small amounts of anomalous solutes, $N_{a}^{\mathrm{FW}}$, are added to the brackish water body of dilute standard ocean water which consists of $N_{0}^{\mathrm{BSW}}$ water molecules and $N_{a}^{\mathrm{SSW}}$ solute particles. The Gibbs energy of the diluted, anomalyfree parent solution is the sum of the chemical potentials (Feistel and Marion, 2007),

$$
G^{\mathrm{SSW}}=\mu_{0} N_{0}^{\mathrm{BSW}}+\sum_{a} \mu_{a} N_{a}^{\mathrm{SSW}} .
$$

If the composition is slightly modified, the related change of the Gibbs energy is (at the same $T$ and $P$ )

$\mathrm{d} G=\mu_{0} \mathrm{~d} N_{0}+\sum_{a} \mu_{a} \mathrm{~d} N_{a}$,

where the chemical potentials are still those of the parent solution. Equation (3.2) follows as a result of the Gibbs-Duhem equation

$0=N_{0} \mathrm{~d} \mu_{0}+\sum_{a} N_{a} \mathrm{~d} \mu_{a}$. 
Under the condition

$N_{a}^{\mathrm{SSW}} \gg N_{a}^{\mathrm{FW}}$

the Gibbs energy of Baltic seawater,

$G^{\mathrm{BSW}}=G^{\mathrm{SSW}}+\delta G$,

can be described approximately by adding a linear correction term representing the anomaly, corresponding to Eq. (3.2),

$\delta G=\sum_{a} \mu_{a} N_{a}^{\mathrm{FW}}$.

The chemical potentials, $\mu_{a}$, required here depend only on the properties of the parent solution,

$\mu_{a}=\mu_{a}^{0}(T, P)+k T \ln \left(m_{a} \gamma_{a}\right)$.

Here, $\gamma_{a}(\boldsymbol{m}, T, P)$ is the practical activity coefficient of the species $a$, which depends on the set $\boldsymbol{m}=\left\{m_{a}\right\}$ of all molalities of the parent solution,

$m_{a}=\frac{N_{a}^{\mathrm{SSW}}}{N_{\mathrm{A}} M_{0}^{\mathrm{BSW}}}=m_{\mathrm{SSW}}^{\mathrm{BSW}} x_{a}^{\mathrm{RC}}$.

Symbols newly introduced in Eq. (3.7) are specified in the glossary. The particle numbers of the anomalous solutes can be expressed in terms of their mole fractions and their total molalities,

$N_{a}^{\mathrm{FW}}=N_{\mathrm{A}} x_{a}^{\mathrm{FW}} m_{\mathrm{FW}}^{\mathrm{BSW}} M_{0}^{\mathrm{BSW}}$.

In these terms, the Gibbs energy anomaly, Eq. (3.6), reads

$$
\begin{aligned}
\delta G= & M_{0}^{\mathrm{BSW}} m_{\mathrm{FW}}^{\mathrm{BSW}}\left\{R T \ln \left(m_{\mathrm{SSW}}^{\mathrm{BSW}} \gamma_{\mathrm{FW}}^{\mathrm{id}}\right)+\sum_{a} x_{a}^{\mathrm{FW}}\right. \\
& {\left.\left[N_{\mathrm{A}} \mu_{a}^{0}(T, P)+R T \ln \frac{\gamma_{a}}{\gamma_{a}^{\mathrm{id}}}\right]\right\} . }
\end{aligned}
$$

Here, $R=N_{A} k$ is the molar gas constant, and $\gamma_{\mathrm{FW}}^{\mathrm{id}}, \gamma_{a}^{\mathrm{id}}$, related by

$\ln \gamma_{\mathrm{FW}}^{\mathrm{id}}=\sum_{a} x_{a}^{\mathrm{FW}} \ln \left(x_{a}^{\mathrm{RC}} \gamma_{a}^{\mathrm{id}}\right)$

are the limiting values of the activity coefficients at infinite dilution.

Note that the Eq. (3.10) is applicable only to anomalous species, $x_{a}^{\mathrm{FW}}>0$, that are already present in the parent solution, $x_{a}^{\mathrm{RC}}>0$. Otherwise, in the limit $x_{a}^{\mathrm{FW}}>0, x_{a}^{\mathrm{RC}}=0$, Eq. (3.10) possesses a logarithmic singularity for "alien" species $a$ that do not belong to the RC but appear in the anomaly.

Dividing the Gibbs energy by the related mass of the solution, we obtain the expressions for the Gibbs functions of the (diluted) parent solution,

$$
\begin{aligned}
g^{\mathrm{SSW}} & \left(m_{\mathrm{SSW}}^{\mathrm{BSW}}, T, P\right) \\
& =\frac{G^{\mathrm{SSW}}}{M_{0}^{\mathrm{BSW}}+M_{\mathrm{S}}^{\mathrm{SSW}}}=g^{\mathrm{SW}}\left(S_{\mathrm{A}}^{\mathrm{SSW}}, T, P\right),
\end{aligned}
$$

and of Baltic seawater,

$$
\begin{aligned}
& g^{\mathrm{BSW}}\left(m_{\mathrm{SSW}}^{\mathrm{BSW}}, m_{\mathrm{FW}}^{\mathrm{BSW}}, T, P\right) \\
& =\frac{G^{\mathrm{SSW}}+\delta G}{M_{0}^{\mathrm{BSW}}+M_{\mathrm{S}}^{\mathrm{SSW}}+M_{\mathrm{S}}^{\mathrm{FW}}} .
\end{aligned}
$$

Here, $g^{\mathrm{SW}}\left(S_{\mathrm{A}}^{\mathrm{SSW}}, T, P\right)$ is the TEOS-10 Gibbs function of seawater as a function of Absolute Salinity, $S_{\mathrm{A}}^{\mathrm{SSW}}$, Eq. (2.26), of the "preformed" parent solution with Reference Composition (RC) (Millero et al., 2008; Pawlowicz et al., 2010),

$$
S_{\mathrm{A}}^{\mathrm{SSW}}=\frac{M_{\mathrm{S}}^{\mathrm{SSW}}}{M_{0}^{\mathrm{BSW}}+M_{\mathrm{S}}^{\mathrm{SSW}}}=\frac{m_{\mathrm{SSW}}^{\mathrm{BSW}} A_{\mathrm{SSW}}}{1+m_{\mathrm{SSW}}^{\mathrm{BSW}} A_{\mathrm{SSW}}} .
$$

Newly introduced symbols are explained in the glossary. From Eqs. (3.12) and (3.13), in linear approximation with respect to the anomalous solute concentration, the Gibbs function anomaly is

$$
\begin{aligned}
\delta g & =g^{\mathrm{BSW}}-g^{\mathrm{SSW}}=\frac{\delta G-M_{\mathrm{S}}^{\mathrm{FW}} g^{\mathrm{SW}}}{M_{0}^{\mathrm{BSW}}+M_{\mathrm{S}}^{\mathrm{SSW}}+M_{\mathrm{S}}^{\mathrm{FW}}} \\
& =\left(g^{\mathrm{FW}}-g^{\mathrm{SW}}\right) S_{\mathrm{FW}}^{\mathrm{BSW}} .
\end{aligned}
$$

The partial specific Gibbs energy, $g^{\mathrm{FW}}$, of the very dilute anomalous solute in the parent solution is inferred from Eqs. (3.10) and (3.15) to depend only on the parent solution properties, in the form

$$
\begin{gathered}
g^{\mathrm{FW}}\left(S_{\mathrm{A}}^{\mathrm{SSW}}, T, P\right)=\mu_{\mathrm{FW}}^{0}(T, P)+R_{\mathrm{FW}} T \\
{\left[\ln \left(m_{\mathrm{SSW}}^{\mathrm{BSW}} \gamma_{\mathrm{FW}}^{\mathrm{id}}\right)+\ln \frac{\gamma_{\mathrm{FW}}}{\gamma_{\mathrm{FW}}^{\mathrm{id}}}\right],}
\end{gathered}
$$

where $R_{\mathrm{FW}}=R / A_{\mathrm{FW}}$ (Table $\left.\mathrm{A} 1\right)$ is the specific gas constant of the anomalous solute. The constant $\gamma_{\mathrm{FW}}^{\mathrm{id}}$ is the limiting value of $\gamma_{\mathrm{FW}}$ at infinite dilution and is formally introduced here to keep the arguments of the two logarithmic terms dimensionless after their separation; its numerical value is chosen such that the second term disappears at low concentrations. Note that $\gamma_{\mathrm{FW}}$ is defined only up to an arbitrary constant factor which enters the reference state condition, Eq. (4.12), in combination with $\mu_{\mathrm{FW}}^{0}$. The partial Absolute Salinity, $S_{\mathrm{A}}^{\mathrm{SSW}}$, of the salt fraction with Reference Composition in BSW is related to the given molality, $m_{\mathrm{SSW}}^{\mathrm{BSW}}$, by means of Eq. (3.14). The chemical potential, $\mu_{\mathrm{FW}}^{0}$, of the anomalous solute in pure water at infinite dilution is

$\mu_{\mathrm{FW}}^{0}(T, P)=\frac{N_{\mathrm{A}}}{A_{\mathrm{FW}}} \sum_{a} x_{a}^{\mathrm{FW}} \mu_{a}^{0}(T, P)$,

and the mean activity coefficient, $\gamma_{\mathrm{FW}}$, of the anomalous solute in SSW is given by

$\ln \gamma_{\mathrm{FW}}=\sum_{a} x_{a}^{\mathrm{FW}} \ln \left[x_{a}^{\mathrm{RC}} \gamma_{a}\left(m_{\mathrm{SSW}}^{\mathrm{BSW}}, T, P\right)\right]$. 
In Eq. (3.16), the functions $\mu_{\mathrm{FW}}^{0}$ and $\ln \gamma_{\mathrm{FW}}$ are unknown and will be represented by empirical correlations in Sect. 4. The functional form of those correlations is derived from the structure of Eq. (3.16). Once an empirical expression for the function $g^{\mathrm{FW}}$ is determined, the Gibbs function $g^{\mathrm{BSW}}$ of Baltic seawater can be computed from Eq. (3.15), in the form

$$
\begin{aligned}
& g^{\mathrm{BSW}}\left(S_{\mathrm{A}}^{\mathrm{SSW}}, S_{\mathrm{FW}}^{\mathrm{BSW}}, T, P\right)= \\
& \quad\left(1-S_{\mathrm{FW}}^{\mathrm{BSW}}\right) g^{\mathrm{SW}}\left(S_{\mathrm{A}}^{\mathrm{SSW}}, T, P\right)+S_{\mathrm{FW}}^{\mathrm{BSW}} g^{\mathrm{FW}}\left(S_{\mathrm{A}}^{\mathrm{SSW}}, T, P\right) .
\end{aligned}
$$

This equation represents the main result of this section. It expresses the Gibbs function we are looking for, $g^{\mathrm{BSW}}$, in terms of two suitably defined independent salinities, $S_{\mathrm{A}}^{\mathrm{SSW}}$ and $S_{\mathrm{FW}}^{\mathrm{BSW}}$, the salinities associated with the salts from the North Atlantic and from the local riverine inputs. The function $g^{\text {BSW }}$ depends on the known Gibbs function of SSW, $g^{\mathrm{SW}}$, and an unknown function, $g^{\mathrm{FW}}$, that represents the FW properties in the compact form of Eq. (3.16), and will be determined empirically from simulated data in the next section.

The partial Absolute Salinity, $S_{\mathrm{FW}}^{\mathrm{BSW}}$, Eq. (2.13), of the anomalous solute is related to its molality in BSW, $m_{\mathrm{FW}}^{\mathrm{BSW}}$, by

$S_{\mathrm{FW}}^{\mathrm{BSW}}=\frac{m_{\mathrm{FW}}^{\mathrm{BSW}} A_{\mathrm{FW}}}{1+m_{\mathrm{SSW}}^{\mathrm{BSW}} A_{\mathrm{SSW}}+m_{\mathrm{FW}}^{\mathrm{BSW}} A_{\mathrm{FW}}}$.

In terms of the partial salinities $S_{\mathrm{A}}^{\mathrm{SSW}}$ and $S_{\mathrm{FW}}^{\mathrm{BSW}}$, the Absolute Salinity of BSW, $S_{\mathrm{A}}^{\mathrm{BSW}}$, Eq. (2.11), is given by the formula

$S_{\mathrm{A}}^{\mathrm{BSW}}=1-\left(1-S_{\mathrm{FW}}^{\mathrm{BSW}}\right)\left(1-S_{\mathrm{A}}^{\mathrm{SSW}}\right)$.

The salinity variable $S_{\mathrm{A}}^{\mathrm{BSW}}$ is computed from the molar masses of all the dissolved species and is denoted by $S_{\mathrm{A}}^{\text {soln }}$ (the mass fraction of dissolved material in solution) in the nomenclature of Wright et al. (2010a). The function $g^{\mathrm{FW}}$ depends on the concentration of the SSW part, $S_{\mathrm{A}}^{\mathrm{SSW}}$, and the anomalous composition of the FW part but according to Eq. (3.16) it is independent of the concentration, $S_{\mathrm{FW}}^{\mathrm{BSW}}$, of the FW part which is assumed to be very dilute. In the next section, an empirical correlation equation for $g^{\mathrm{FW}}$ will be derived from model data computed using FREZCHEM (Marion and Kargel, 2008).

\section{Fitting the Baltic Gibbs function to FREZCHEM simulation data}

For arbitrary aqueous electrolyte solutions, the related Gibbs function in the form (Feistel and Marion, 2007)

$$
\begin{aligned}
& g\left(S_{\mathrm{A}}, T, P\right)=g^{\mathrm{W}}(T, P)+S_{\mathrm{A}} \Gamma(T, P) \\
& +S_{\mathrm{A}} R_{\mathrm{S}} T\left\{\ln \frac{S_{\mathrm{A}}}{1-S_{\mathrm{A}}}+\psi\left(S_{\mathrm{A}}, T, P\right)\right\}
\end{aligned}
$$

can be estimated from available Pitzer equations for the constituents using the FREZCHEM model. Here, $S_{\mathrm{A}}$ is the Absolute Salinity (mass fraction of dissolved material) of the particular solution, $g^{\mathrm{W}}$ is the Gibbs function of pure water, $\Gamma$ is the partial specific Gibbs energy at infinite dilution, $R_{\mathrm{S}}$ is the specific gas constant of the particular solute, and

$\psi=1-\phi+\ln \frac{\gamma}{\gamma^{\text {id }}}$

is the activity potential, expressed in terms of the osmotic coefficient, $\phi$, and the mean activity coefficient, $\gamma$, of the solution. Infinite dilution is the theoretical asymptotic state of a solution at which the mutual interaction between the solute particles is negligible as the result of their large pairwise separations. Activity coefficients $\gamma$ are defined only up to an arbitrary constant factor; here, $\gamma^{\text {id }}$ is the limiting value to which the particular $\gamma$ is normalized at infinite dilution, commonly, $\gamma^{\text {id }}=1 \mathrm{~kg} \mathrm{~mol}^{-1}$. Any change of this constant is compensated by the conditions, Eq. (4.12), imposed on the freely adjustable coefficients of seawater at the specified reference state (Feistel et al., 2008a).

Using the FREZCHEM model, the absolute salinity, $S_{\mathrm{A}}=S_{\mathrm{A}}^{\mathrm{BSW}}$, the activity potential, $\psi$, the specific volume, $v=(\partial g / \partial P)_{S_{\mathrm{A}}, T}$, and the heat capacity, $c_{P}=$ $-T\left(\partial^{2} g / \partial T^{2}\right)_{S_{\mathrm{A}}, P}$, of Baltic seawater were computed for a number of grid points at given values of $T, P$, the chloride molality, $m_{\mathrm{Cl}}$ (which determines the SSW contribution), and the Calcium molality anomaly, $\delta m_{\mathrm{Ca}}$ (which determines the FW contribution). From these data and Eq. (4.1), an empirical correlation for the partial specific Gibbs energy, $g^{\mathrm{FW}}$, Eq. (3.16), was determined numerically by regression with respect to the anomalies relative to $\mathrm{SSW}$, i.e., relative to $\delta m_{\mathrm{Ca}}=0$.

To relate the given molalities, $m_{\mathrm{Cl}}$ and $\delta m_{\mathrm{Ca}}$, to the arguments, $m_{\mathrm{SSW}}^{\mathrm{BSW}}$ and $m_{\mathrm{FW}}^{\mathrm{BSW}}$, of the Gibbs function (3.19), suitable composition models must be specified. For SSW, the Reference Composition model gives

$m_{\mathrm{Cl}}=x_{\mathrm{Cl}}^{\mathrm{RC}} m_{\mathrm{SSW}}^{\mathrm{BSW}}$.

Therefore, the SSW composition variable in Eq. (3.19) is obtained from $m_{\mathrm{Cl}}$ by Eq. (3.13),

$S_{\mathrm{A}}^{\mathrm{SSW}}=\frac{m_{\mathrm{Cl}} A_{\mathrm{SSW}} / x_{\mathrm{Cl}}^{\mathrm{RC}}}{1+m_{\mathrm{Cl}} A_{\mathrm{SSW}} / x_{\mathrm{Cl}}^{\mathrm{RC}}}$.

In terms of constituents of the $\mathrm{RC}$, the mole fractions of lime dissolved in FW are assumed here to be given by Eq. (2.3). The only purpose of this reaction scheme is its use as a proxy to represent the complex marine carbonate chemistry simulated by FREZCHEM, in order to provide the theoretical Gibbs function model with reasonable molar fractions, Eq. (2.3), and molar masses, Eq. (4.6), of the anomalous solute. The related calcium anomaly of BSW is given by

$\delta m_{\mathrm{Ca}}=x_{\mathrm{Ca}}^{\mathrm{FW}} m_{\mathrm{FW}}^{\mathrm{BSW}}$,

and the related salinity variable in Eq. (3.19) is obtained from $\delta m_{\mathrm{Ca}}$ and $m_{\mathrm{Cl}}$ by Eq. (3.19),

$S_{\mathrm{FW}}^{\mathrm{BSW}}=\frac{\delta m_{\mathrm{Ca}} A_{\mathrm{FW}} / x_{\mathrm{Ca}}^{\mathrm{FW}}}{1+m_{\mathrm{Cl}} A_{\mathrm{SSW}} / x_{\mathrm{Cl}}^{\mathrm{RC}}+\delta m_{\mathrm{Ca}} A_{\mathrm{FW}} / x_{\mathrm{Ca}}^{\mathrm{FW}}}$. 
The total calcium molality in BSW is the sum of the SSW and the FW parts,

$m_{\mathrm{Ca}}=x_{\mathrm{Ca}}^{\mathrm{FW}} m_{\mathrm{FW}}^{\mathrm{BSW}}+x_{\mathrm{Ca}}^{\mathrm{RC}} m_{\mathrm{SSW}}^{\mathrm{BSW}}$.

Derived from the structure of the target function of the regression, Eq. (3.16), we use the polynomial expression (Feistel and Marion, 2007),

$g^{\mathrm{FW}}\left(S_{\mathrm{A}}^{\mathrm{SSW}}, T, P\right)=\sum_{j, k}\left(r_{j k} \ln x+\sum_{i} c_{i j k} x^{i}\right) y^{j} z^{k}$,

where the dimensionless reduced variables are defined by (Feistel, 2008; IAPWS, 2008),

$x=\sqrt{\frac{35 S_{\mathrm{A}}^{\mathrm{SSW}}}{40 S_{\mathrm{SO}}}}, \quad y=\frac{T-T_{\mathrm{SO}}}{40 \mathrm{~K}}, \quad z=\frac{P-P_{\mathrm{SO}}}{100 \mathrm{MPa}}$.

The standard-ocean parameters $S_{\mathrm{SO}}, T_{\mathrm{SO}}$ and $P_{\mathrm{SO}}$ are given in Table A1. Comparing equal powers of $T$ and $P$ of the logarithmic term in Eqs. (3.16) and (4.8) in the limit $x \rightarrow 0$, the coefficients $r_{j k}$ are analytically available from the relation

$\sum_{j, k} r_{j k} y^{j} z^{k} \equiv R_{\mathrm{FW}} T$

to be

$r_{00}=R_{\mathrm{FW}} \times T_{\mathrm{SO}}, \quad r_{10}=R_{\mathrm{FW}} \times 40 \mathrm{~K}$,

$r_{j k}=0$ if $j>1$ or $k>0$.

The coefficients $c_{000}$ and $c_{010}$ are arbitrary and chosen to satisfy reference state conditions which determine the absolute energy and the absolute entropy of the anomalous solute. Here we employ the reference state conditions

$g^{\mathrm{FW}}\left(S_{\mathrm{SO}}, T_{\mathrm{SO}}, P_{\mathrm{SO}}\right)=0$

and

$\frac{\partial}{\partial T} g^{\mathrm{FW}}\left(S_{\mathrm{SO}}, T_{\mathrm{SO}}, P_{\mathrm{SO}}\right)=0$.

From the Gibbs function (3.19) in conjunction with the functional form (4.8) we derive expressions for the available properties $v, c_{\mathrm{P}}$ and $\psi$ in terms of the remaining unknown coefficients, $\boldsymbol{c}=\left\{c_{i j k}\right\}$. These coefficients are then determined numerically by the requirement to minimise the penalty function,

$$
\begin{aligned}
\Omega^{2} & =\sum_{i}\left[\frac{\delta v(\boldsymbol{c})-\delta v_{i}}{\omega_{v}}\right]^{2}+\sum_{i}\left[\frac{\delta c_{P}(\boldsymbol{c})-\delta c_{P, i}}{\omega_{c_{P}}}\right]^{2} \\
& +\sum_{i}\left[\frac{\delta \psi(\boldsymbol{c})-\delta \psi_{i}}{\omega_{\psi}}\right]^{2},
\end{aligned}
$$

in which $\delta v_{i}, \delta c_{P_{i}}$ and $\delta \psi_{i}$ are property anomalies of Baltic seawater relative to the parent solution at the grid points

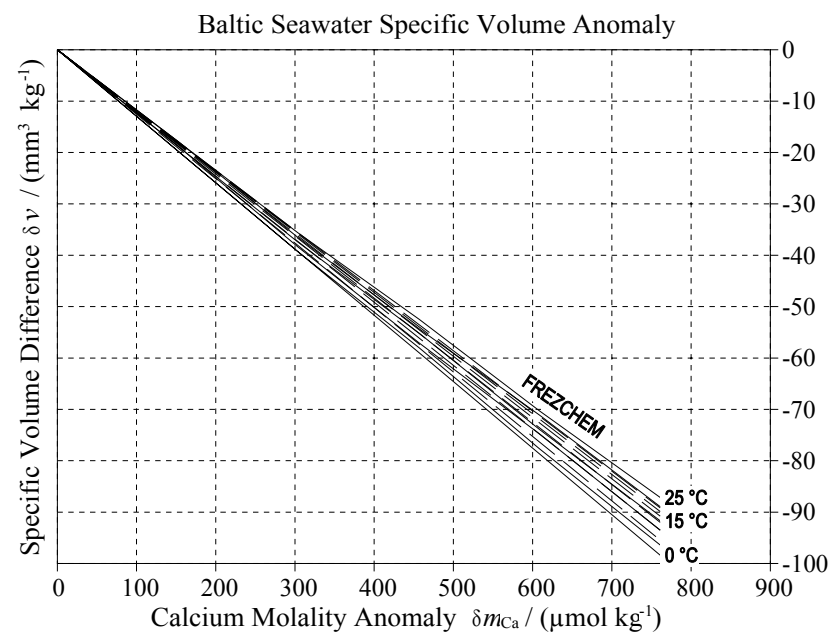

Fig. 2. Specific volume anomaly of Baltic seawater at the standard ocean surface pressure and a typical salinity of $S_{\mathrm{A}}^{\mathrm{SSW}}=$ $10.306 \mathrm{gkg}^{-1}$ for six different temperatures $0-25^{\circ} \mathrm{C}$ as indicated by the curves, computed by the FREZCHEM model and by Millero's Rule (dashed lines, without temperatures indicated). The latter curves are the differences between the specific volumes computed from the TEOS-10 Gibbs function at salinities $S_{\mathrm{A}}^{\mathrm{BSW}}$, Eq. (3.21), and $S_{\mathrm{A}}^{\mathrm{SSW}}$, Eq. (3.19). Experimental uncertainties are considered in the following section.

$i$ of the FREZCHEM simulation results, weighted by estimated uncertainties $\omega$. Selected examples of the data for $\delta v_{i}, \delta c_{P_{i}}$ and $\delta \psi_{i}$ are displayed in Figs. 2, 3 and 4. In our Gibbs function, the original complex chemistry implemented in FREZCHEM is represented in the simplified form represented by the reaction (1.1) in conjunction with the analytical expression (4.8). Since Eq. (4.13) measures the deviation between the two numerical models, the uncertainties $\omega$ cover their numerical round-off and mutual misfit rather than any experimental accuracy. In practice, the $\omega$ values were suitably chosen to allow a reasonably smooth fit. Experimental uncertainties are irrelevant for the regression considered in this section and will be discussed in the subsequent section where the properties of the resulting Gibbs function (4.8) are analysed. The scatter of the FREZCHEM points relative to the fitted Gibbs function are shown in Figs. 5, 6 and 7.

Two earlier studies (Millero and Kremling, 1976; Feistel et al., 2010a) made extensive use of "Millero's Rule" to estimate the Absolute (or total) Salinity of Baltic seawater from measurements. This rule expresses the empirical finding that many aqueous solutions have very similar properties to that of Standard Seawater if only the temperature, the pressure and the mass fraction of dissolved solute are the same, independent of the details of the sample's chemical composition. Under the approximation of Millero's Rule it is claimed in particular that 


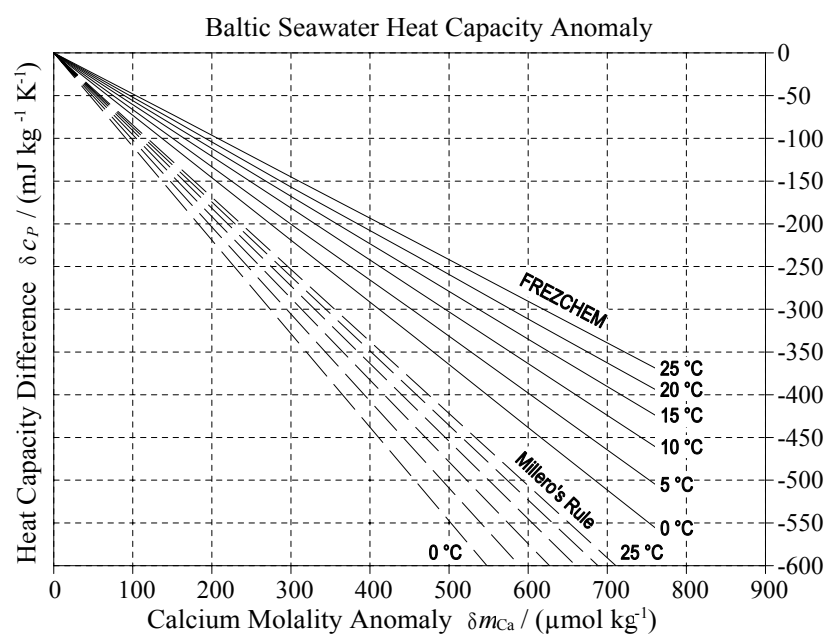

Fig. 3. Heat capacity anomaly of Baltic seawater at the standard ocean surface pressure and a typical salinity of $S_{\mathrm{A}}^{\mathrm{SSW}}=$ $10.306 \mathrm{~g} \mathrm{~kg}^{-1}$ for six different temperatures $0-25^{\circ} \mathrm{C}$ as indicated by the curves, computed by the FREZCHEM model and by Millero's Rule (dashed lines). The latter curves are the differences between the heat capacities computed from the TEOS-10 Gibbs function at salinities $S_{\mathrm{A}}^{\mathrm{BSW}}$, Eq. (3.21), and $S_{\mathrm{A}}^{\mathrm{SSW}}$, Eq. (3.14). Experimental uncertainties are considered in the following section.

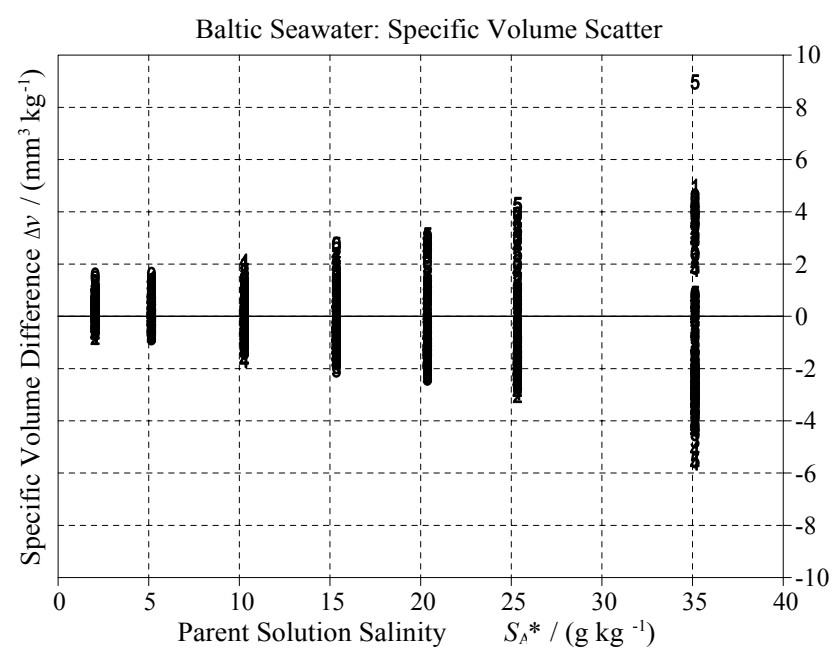

Fig. 5. Scatter of specific volume anomalies computed from FREZCHEM, $\delta v_{i}$, relative to the specific volume anomalies computed from the Gibbs function, $\delta v(\boldsymbol{c})$, Eq. (4.14), at 1260 given data points. The rms deviation of the fit is $1.5 \mathrm{~mm}^{3} \mathrm{~kg}^{-1}$. Symbols $0-5$ indicate the pressures of $0.1 \mathrm{MPa}, 1 \mathrm{MPa}, 2 \mathrm{MPa}, 3 \mathrm{MPa}, 4 \mathrm{MPa}$ and $5 \mathrm{MPa}$, respectively. These residual anomalies should be compared with the total anomalies $\delta v_{i}$ shown in Fig. 2.

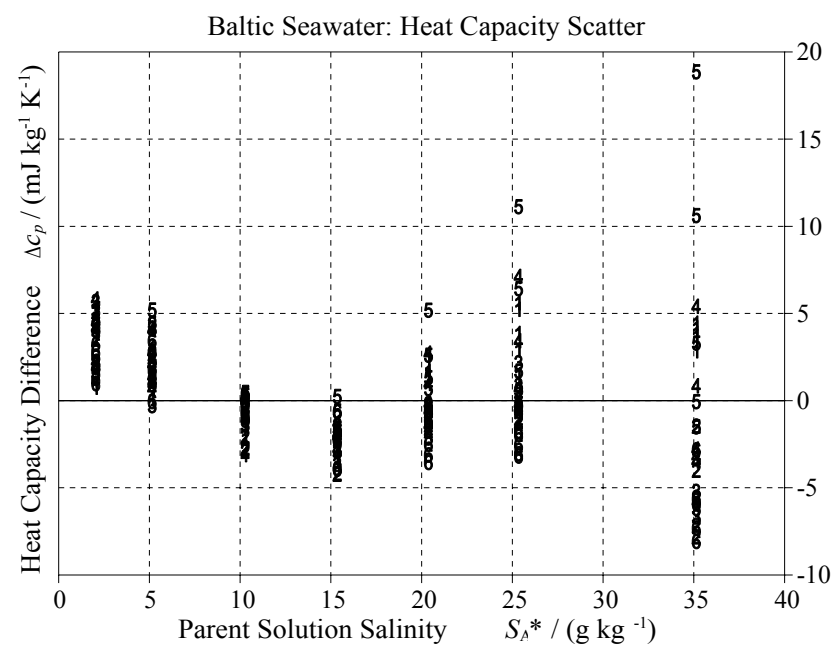

Fig. 6. Scatter of heat capacity anomalies computed from FREZCHEM, $\delta c_{P_{i}}$, relative to the heat capacity anomalies computed from the Gibbs function, $\delta c_{P}(\boldsymbol{c})$, Eq. (4.15), at 210 given data points at atmospheric pressure. The rms deviation of the fit is $3.4 \mathrm{~mJ} /(\mathrm{kg} \mathrm{K})$. Symbols $0-5$ indicate the temperatures of $0-25^{\circ} \mathrm{C}$, respectively. These residual anomalies should be compared with the total anomalies $\delta c_{P_{i}}$ shown in Fig. 3. 


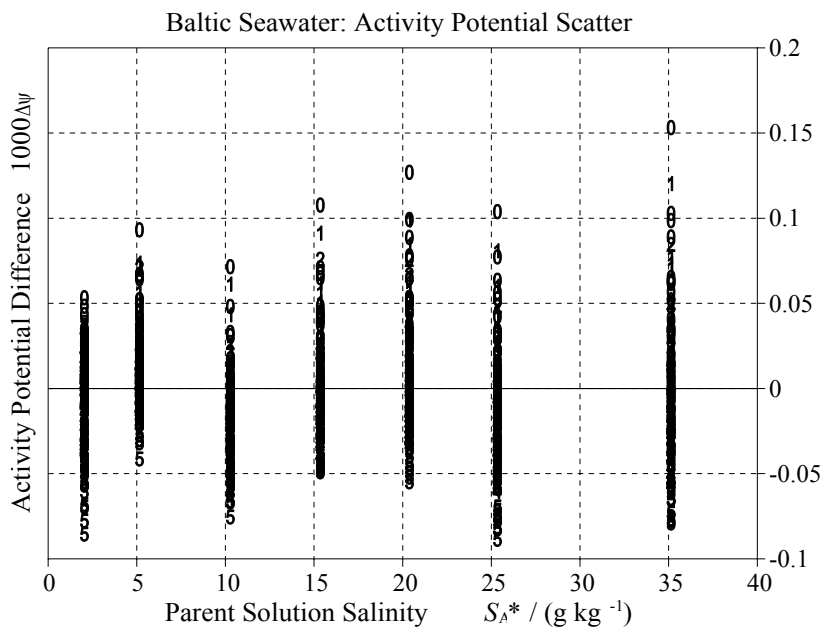

Fig. 7. Scatter of the activity potential anomalies computed from FREZCHEM, $\delta \psi_{i}$, relative to the activity potential anomalies computed from the Gibbs function, $\delta \psi(\boldsymbol{c})$, Eq. (4.33), at 1260 given data points. The rms deviation of the fit is $3.1 \times 10^{-5}$. Symbols $0-5$ indicate the pressures of $0.1 \mathrm{MPa}, 1 \mathrm{MPa}, 2 \mathrm{MPa}, 3 \mathrm{MPa}, 4 \mathrm{MPa}$ and $5 \mathrm{MPa}$, respectively. These residual anomalies should be compared with the total anomalies $\delta \psi_{i}$ shown in Fig. 4.

- Absolute Salinity of anomalous seawater can be computed from its density using the TEOS-10 equation of state, and results in the same value at any temperature or pressure at which the density was measured,

as well as that

- the properties of anomalous seawater can be computed from the TEOS-10 Gibbs function if Absolute Salinity is used as the composition variable,

and finally, the first two rules combined, that

- the properties of anomalous seawater can be estimated by the TEOS-10 functions in terms of SSW properties evaluated at the same density, temperature and pressure.

In this section, we discuss the validity of Millero's Rule and compare the results derived from the FREZCHEM model with those from the TEOS-10 Gibbs function evaluated at the same Absolute Salinity. In the next section, we again discuss the validity of Millero's Rule and compare the results derived from the fitted Gibbs function of Baltic seawater with those from the TEOS-10 Gibbs function evaluated at the same Absolute Salinity or at the same density.

In Figs. 2, 3 and 4, the simulated FREZCHEM data are compared with those estimated from Millero's Rule, i.e., property differences computed from the already available TEOS-10 Gibbs function at the Absolute Salinities $S_{\mathrm{A}}^{\mathrm{BSW}}$ and $S_{\mathrm{A}}^{\mathrm{SSW}}$. The very good agreement visible in Fig. 2 between the simulated density anomalies and those estimated from Millero's Rule depends on two factors. The first factor is how well the rule estimates the results of the FREZCHEM simulation. In other words, how consistent the rule is with the Pitzer equations for the specific volume in the special case of the Baltic seawater composition. The second factor is how well the simple static composition model of the anomaly, Eq. (1.1), used here for the construction of the Gibbs function with intentionally only two representative conservative composition variables, is capable of approximately covering the underlying complicated dynamic solute chemistry implemented in FREZCHEM. If, for example, results were calculated without allowing for the contribution from atmospheric $\mathrm{CO}_{2}$ in the reaction (1.1), then a mismatch between Millero's Rule and FREZCHEM of approximately $30 \%$ occurs in the modified results corresponding to Fig. 2; this difference results from the smaller molar mass of the solute, $A_{\mathrm{FW}}$, Eq. (2.17), and hence the smaller contribution to salinity from the FW source Eq. (4.6), which changes the value of $S_{\mathrm{A}}^{\mathrm{BSW}}$ used for Millero's Rule at a specified value of the Calcium molality anomaly.

The analytical expressions required in Eq. (4.13) for the fit of the anomalous properties are derived from Eqs. (3.15) and (4.8), in the form

$$
\begin{aligned}
\delta v(\boldsymbol{c}) & =\left(\frac{\partial\left(g^{\mathrm{BSW}}-g^{\mathrm{SW}}\right)}{\partial P}\right)_{S_{\mathrm{A}}^{\mathrm{SSW}}, S_{\mathrm{FW}}^{\mathrm{BSW}}, T} \\
& =S_{\mathrm{FW}}^{\mathrm{BSW}}\left(\frac{\partial\left(g^{\mathrm{FW}}-g^{\mathrm{SW}}\right)}{\partial P}\right)_{S_{\mathrm{A}}^{\mathrm{SSW}}, T}
\end{aligned}
$$

and

$$
\begin{aligned}
\delta c_{P}(\boldsymbol{c}) & =-T\left(\frac{\partial^{2}\left(g^{\mathrm{BSW}}-g^{\mathrm{SW}}\right)}{\partial T^{2}}\right)_{S_{\mathrm{A}}^{\mathrm{SSW}}, S_{\mathrm{FW}}^{\mathrm{BSW}}, P} \\
& =-T S_{\mathrm{FW}}^{\mathrm{BSW}}\left(\frac{\partial^{2}\left(g^{\mathrm{FW}}-g^{\mathrm{SW}}\right)}{\partial T^{2}}\right)_{S_{\mathrm{A}}^{\mathrm{SSW}}, P} .
\end{aligned}
$$

The required analytical formula for the activity potential anomaly $\delta \psi(\boldsymbol{c})$ expressed explicitly in terms of the TEOS10 Gibbs function $g^{\mathrm{SW}}$ and the Gibbs function correction, $g^{\mathrm{FW}}$, which depends on the unknown coefficients $\boldsymbol{c}$, is more complicated to obtain. From the Gibbs function for BSW, $g^{\mathrm{BSW}}$, Eq. (4.1), the activity potential is derived,

$$
\begin{gathered}
\psi^{\mathrm{BSW}}\left(S_{\mathrm{A}}^{\mathrm{BSW}}, T, P\right)=\frac{g^{\mathrm{BSW}}-g^{\mathrm{W}}-S_{\mathrm{A}}^{\mathrm{BSW}} \Gamma^{\mathrm{BSW}}}{S_{\mathrm{A}}^{\mathrm{BSW}} R_{\mathrm{BSW}} T} \\
-\ln \frac{S_{\mathrm{A}}^{\mathrm{BSW}}}{1-S_{\mathrm{A}}^{\mathrm{BSW}}},
\end{gathered}
$$

and similarly that of SSW,

$$
\begin{aligned}
\psi^{\mathrm{SSW}}\left(S_{\mathrm{A}}^{\mathrm{SSW}}, T, P\right)=\frac{g^{\mathrm{SW}}-g^{\mathrm{W}}-S_{\mathrm{A}}^{\mathrm{SSW}} \Gamma^{\mathrm{SSW}}}{S_{\mathrm{A}}^{\mathrm{SSW}} R_{\mathrm{SSW}} T} \\
-\ln \frac{S_{\mathrm{A}}^{\mathrm{SSW}}}{1-S_{\mathrm{A}}^{\mathrm{SSW}}} .
\end{aligned}
$$


After some algebraic manipulation of the difference between Eqs. (4.16) and (4.17), the activity potential anomaly, $\delta \psi(c)$, takes the form

$$
\begin{aligned}
& \delta \psi(\boldsymbol{c})=\psi^{\mathrm{BSW}}-\psi^{\mathrm{SSW}} \\
& =\frac{S_{\mathrm{FW}}^{\mathrm{BSW}} A_{\mathrm{BSW}}}{S_{\mathrm{A}}^{\mathrm{BSW}} R T}\left[g^{\mathrm{FW}}-g^{\mathrm{W}}-\frac{A_{\mathrm{SSW}}}{A_{\mathrm{FW}} S_{\mathrm{A}}^{\mathrm{SSW}}}\left(g^{\mathrm{SW}}-g^{\mathrm{W}}\right)\right] \\
& +\frac{A_{\mathrm{SSW}} \Gamma^{\mathrm{SSW}}-A_{\mathrm{BSW}} \Gamma^{\mathrm{BSW}}}{R T}+\ln \left(1-\frac{S_{\mathrm{FW}}^{\mathrm{BSW}}}{S_{\mathrm{A}}^{\mathrm{BSW}}}\right)
\end{aligned}
$$

Here, $A_{\mathrm{BSW}}$ is the molar mass of Baltic sea salt,

$$
A_{\mathrm{BSW}}=\frac{A_{\mathrm{SSW}} m_{\mathrm{SSW}}^{\mathrm{BSW}}+A_{\mathrm{FW}} m_{\mathrm{FW}}^{\mathrm{BSW}}}{m_{\mathrm{SSW}}^{\mathrm{BSW}}+m_{\mathrm{FW}}^{\mathrm{BSW}}},
$$

the Gibbs function of pure water is

$g^{\mathrm{W}}=g^{\mathrm{SW}}(0, T, P)$,

and the partial specific Gibbs energy at infinite dilution is computed from Eq. (4.1) in the mathematical zero-salinity limit,

$\Gamma^{\mathrm{SSW}}(T, P)=\lim _{S \rightarrow 0}\left\{\frac{g^{\mathrm{SW}}(S, T, P)-g^{\mathrm{W}}(T, P)}{S}-R_{\mathrm{SSW}} T \ln S\right\}$.

Since the TEOS-10 Gibbs function is defined as a series expansion in salinity, in the form (Feistel et al., 2010b),

$$
\begin{aligned}
g^{\mathrm{SW}}\left(S_{\mathrm{A}}, T, P\right) & =g^{\mathrm{W}}(T, P)+R_{\mathrm{SSW}} T S_{\mathrm{A}} \ln S_{\mathrm{A}} \\
& +\sum_{i=2}^{7} g_{i}(T, P) S_{\mathrm{A}}^{i / 2},
\end{aligned}
$$

it follows immediately from Eq. (4.21) that $\Gamma^{\mathrm{SSW}}$ is given by

$\Gamma^{\mathrm{SSW}}(T, P) \equiv g_{2}(T, P)$

The function $\Gamma^{\mathrm{BSW}}(T, P)$ in Eq. (4.18) is the coefficient of the linear salinity term of the Gibbs function $g^{\mathrm{BSW}}$ and can be determined by comparison of the two different expressions available for $g^{\mathrm{BSW}}$, on the one hand, Eq. (4.1), in terms of Pitzer equations,

$$
\begin{gathered}
g^{\mathrm{BSW}}=g^{\mathrm{W}}+S_{\mathrm{A}}^{\mathrm{BSW}} \Gamma^{\mathrm{BSW}}+S_{\mathrm{A}}^{\mathrm{BSW}} R_{\mathrm{BSW}} T \\
\left\{\ln \frac{S_{\mathrm{A}}^{\mathrm{BSW}}}{1-S_{\mathrm{A}}^{\mathrm{BSW}}}+\psi^{\mathrm{BSW}}\right\},
\end{gathered}
$$

and on the other hand, Eq. (3.19), in the form of a linear correction to TEOS-10,

$$
\begin{aligned}
g^{\mathrm{BSW}} & =\left(1-S_{\mathrm{FW}}^{\mathrm{BSW}}\right) g^{\mathrm{SW}}\left(S_{\mathrm{A}}^{\mathrm{SSW}}, T, P\right) \\
& +S_{\mathrm{FW}}^{\mathrm{BSW}} g^{\mathrm{FW}}\left(S_{\mathrm{A}}^{\mathrm{SSW}}, T, P\right) .
\end{aligned}
$$

Note that $g^{\text {BSW }}$ in Eqs. (4.24) and (4.25) represent different approximations of the Gibbs function that we want to determine. The Gibbs function given by Eq. (4.24) is nonlinear in the anomaly. For the composition model given, its activity potential $\psi^{\mathrm{BSW}}$ can be computed from complicated systems of Pitzer equations. To derive a simpler correlation function, we estimate $\psi^{\mathrm{BSW}}$ here by means of the Gibbs function, Eq. (4.25), which is linear in the anomaly, $S_{\mathrm{FW}}^{\mathrm{BSW}}$. We consider the series expansions of Eqs. (4.24), (4.25) with respect to salinity $s$ and require that the coefficients of the terms $s^{0}, s$ $\ln s$ and $s^{1}$ are identical in the two equations. As the small expansion parameter we choose $s \equiv S_{\mathrm{A}}^{\mathrm{BSW}}$ under the condition that the composition ratio $r \equiv S_{\mathrm{FW}}^{\mathrm{BSW}} / S_{\mathrm{A}}^{\mathrm{BSW}}$ remains constant in the mathematical limit $s \rightarrow 0$.

In terms of $s$ and $r$, the salinity variables are

$$
\begin{aligned}
& S_{\mathrm{A}}^{\mathrm{BSW}}=s, \quad S_{\mathrm{FW}}^{\mathrm{BSW}}=r s, \quad S_{\mathrm{A}}^{\mathrm{SSW}}=s \frac{1-r}{1-r s}, \\
& m_{\mathrm{SSW}}^{\mathrm{BSW}}=\frac{s}{A_{\mathrm{SSW}}} \frac{1-r}{1-s} .
\end{aligned}
$$

The truncated series expansions are for Eq. (4.24),

$$
g^{\mathrm{BSW}}=g^{\mathrm{W}}+R_{\mathrm{BSW}} T s \ln s+s \Gamma^{\mathrm{BSW}}+O\left(s^{3 / 2}\right),
$$

for Eq. (4.25),

$$
g^{\mathrm{BSW}}=(1-r s) g^{\mathrm{SW}}+r s g^{\mathrm{FW}}
$$

for Eq. (4.22),

$$
\begin{aligned}
g^{\mathrm{SW}} & =g^{\mathrm{W}}+(1-r)\left[R_{\mathrm{SSW}} T \ln (1-r)+g_{2}\right] s \\
& +R_{\mathrm{SSW}} T(1-r) s \ln s+O\left(s^{3 / 2}\right),
\end{aligned}
$$

and for Eq. (3.16),

$$
\begin{aligned}
g^{\mathrm{FW}} & =\mu_{\mathrm{FW}}^{0}+R_{\mathrm{FW}} T \ln \left(\frac{1-r}{A_{\mathrm{SSW}}} \gamma_{\mathrm{FW}}^{\mathrm{id}}\right) \\
& +R_{\mathrm{FW}} T \ln s+O\left(s^{1 / 2}\right) .
\end{aligned}
$$

Note that the limiting laws of $\psi^{\mathrm{BSW}}$ and $\ln \left(\gamma / \gamma^{\mathrm{id}}\right)$ are of the order $O\left(s^{1 / 2}\right)$.

The combination of Eqs. (4.28), (4.29), (4.30) gives

$$
\begin{aligned}
& g^{\mathrm{BSW}}=g^{\mathrm{W}}+R_{\mathrm{BSW}} T s \ln s+ \\
& \quad\left\{(1-r) g_{2}+R_{\mathrm{BSW}} T \ln (1-r)\right. \\
& \left.\quad+r\left(\mu_{\mathrm{FW}}^{0}+R_{\mathrm{FW}} T \ln \frac{\gamma_{\mathrm{FW}}^{\mathrm{id}}}{A_{\mathrm{SSW}}}-g^{\mathrm{W}}\right)\right\} s+O\left(s^{3 / 2}\right) .
\end{aligned}
$$

Here we used the specific gas "constant" $R_{\mathrm{BSW}} \equiv$ $R / A_{\mathrm{BSW}}=r R_{\mathrm{FW}}+(1-r) R_{\mathrm{SSW}}$ which follows from Eqs. (2.11), (2.19), (2.20) and (4.19). The comparison between Eqs. (4.27) and (4.31) results in identities for the coefficients of the terms $s^{0}$ and $s \ln s$. From the coefficient of $s^{1}$ 
we infer the expression

$$
\begin{gathered}
\Gamma^{\mathrm{BSW}}=\frac{S_{\mathrm{SSW}}^{\mathrm{BSW}}}{S_{\mathrm{A}}^{\mathrm{BSW}}} g_{2}+R_{\mathrm{BSW}} T \ln \frac{S_{\mathrm{SSW}}^{\mathrm{BSW}}}{S_{\mathrm{A}}^{\mathrm{BSW}}} \\
+\frac{S_{\mathrm{FW}}^{\mathrm{BSW}}}{S_{\mathrm{A}}^{\mathrm{BSW}}}\left(R_{\mathrm{FW}} T \ln \frac{\gamma_{\mathrm{FW}}^{\mathrm{id}}}{A_{\mathrm{SSW}}}+\mu_{\mathrm{FW}}^{0}-g^{\mathrm{W}}\right) .
\end{gathered}
$$

Note that $\Gamma^{\mathrm{BSW}}(T, P)$ depends on the composition of BSW, in particular on the ratio $r=S_{\mathrm{FW}}^{\mathrm{BSW}} / S_{\mathrm{A}}^{\mathrm{BSW}}$ of the two independent salinity variables.

In Eq. (4.18), we replace $\Gamma^{\mathrm{BSW}}$ by Eq. (4.32) and get the final formula for the required activity potential anomaly, $\delta \psi(\boldsymbol{c})$

$\delta \psi(\boldsymbol{c})=\frac{S_{\mathrm{FW}}^{\mathrm{BSW}}}{S_{\mathrm{A}}^{\mathrm{BSW}} R_{\mathrm{BSW}} T}\left[g^{\mathrm{F}}-\frac{A_{\mathrm{SSW}}}{A_{\mathrm{FW}}}\left(\frac{g^{\mathrm{S}}}{S_{\mathrm{A}}^{\mathrm{SSW}}}-g_{2}\right)\right]$

Here, the saline part of the Gibbs function of SSW is

$g^{\mathrm{S}}\left(S_{\mathrm{A}}^{\mathrm{SSW}}, T, P\right)=g^{\mathrm{SW}}\left(S_{\mathrm{A}}^{\mathrm{SSW}}, T, P\right)-g^{\mathrm{SW}}(0, T, P)$,

or, using Eq. (4.22),

$$
\begin{gathered}
g^{\mathrm{S}}\left(S_{\mathrm{A}}^{\mathrm{SSW}}, T, P\right)=R_{\mathrm{SSW}} T S_{\mathrm{A}}^{\mathrm{SSW}} \ln S_{\mathrm{A}}^{\mathrm{SSW}} \\
+\sum_{i=2}^{7} g_{i}(T, P)\left(S_{\mathrm{A}}^{\mathrm{SSW}}\right)^{i / 2} .
\end{gathered}
$$

Similarly, the saline part of the partial Gibbs function of freshwater solute is defined by

$$
\begin{aligned}
& g^{\mathrm{F}}\left(S_{\mathrm{A}}^{\mathrm{SSW}}, T, P\right)=g^{\mathrm{FW}}\left(S_{\mathrm{A}}^{\mathrm{SSW}}, T, P\right)-\mu_{\mathrm{FW}}^{0}(T, P) \\
& \quad-R_{\mathrm{FW}} T \ln \frac{\gamma_{\mathrm{FW}}^{\mathrm{id}}}{A_{\mathrm{SSW}}},
\end{aligned}
$$

or, using Eq. (3.16),

$$
g^{\mathrm{F}}\left(S_{\mathrm{A}}^{\mathrm{SSW}}, T, P\right)=R_{\mathrm{FW}} T\left[\ln \left(m_{\mathrm{SSW}}^{\mathrm{BSW}} A_{\mathrm{SSW}}\right)+\ln \frac{\gamma_{\mathrm{FW}}}{\gamma_{\mathrm{FW}}^{\mathrm{id}}}\right] \text {. }
$$

Note that in the zero-salinity limit of Eq. (4.33), the singularity $\lim _{S_{\mathrm{A}}^{\mathrm{SSW}} \rightarrow 0} g^{\mathrm{F}}\left(S_{\mathrm{A}}^{\mathrm{SSW}}, T, P\right)$ of Eq. (4.37) cancels exactly with the corresponding singularity of $g^{\mathrm{S}} / S_{\mathrm{A}}^{\mathrm{SSW}}$, Eq. (4.35).

In Eq. (4.33), all terms are known at the FREZCHEM data points except for $g^{\mathrm{F}}$ which depends on the set of coefficients $c=\left\{c_{i j k}\right\}$ to be adjusted by the regression, Eq. (4.13). After this compilation, the reference state conditions, Eq. (4.12), must be satisfied. After setting $c_{000}=0$ and $c_{010}=0$ in $g^{\mathrm{FW}}$, the final values are computed from the equations

$$
c_{000}=-\left.g^{\mathrm{FW}}\left(S_{\mathrm{SO}}, T_{\mathrm{SO}}, P_{\mathrm{SO}}\right)\right|_{c_{000}=0, c_{010}=0}
$$

and

$$
c_{010}=-(40 \mathrm{~K}) \times\left. g_{T}^{\mathrm{FW}}\left(S_{\mathrm{SO}}, T_{\mathrm{SO}}, P_{\mathrm{SO}}\right)\right|_{c_{000}=0, c_{010}=0} .
$$

The results for the coefficients are given in Table 1, and the results of the fit in Table 2. The scatter of the FREZCHEM data points with respect to the resulting partial Gibbs function $g^{\mathrm{FW}}$ is shown in Figs. 5, 6 and 7 for $\delta v, \delta c_{P}$ and $\delta \psi$, respectively. Numerical check values are available from Table A2.

\section{Thermodynamic property anomalies}

Various salinity measures such as Reference Salinity $S_{\mathrm{R}}$, Absolute Salinity, $S_{\mathrm{A}}$, Density Salinity, $S_{\mathrm{D}}$, or Chlorinity Salinity, $S_{\mathrm{Cl}}$, have the same values for SSW but differ from each other for BSW. The estimate of Density Salinity based on inversion of the expression for density in terms of the Gibbs function for SSW at arbitrary values of temperature and pressure is represented by $S_{\mathrm{D}}$, and referred to as "measured" Density Salinity since it is based on whatever the conditions of the direct density measurement are. It is the Absolute Salinity of SSW (here assumed to have Reference Composition) that has the same density as BSW at given temperature and pressure, i.e.,

$g_{P}^{\mathrm{BSW}}\left(S_{\mathrm{A}}^{\mathrm{SSW}}, S_{\mathrm{FW}}^{\mathrm{BSW}}, T, P\right)=g_{P}^{\mathrm{SW}}\left(S_{\mathrm{D}}, T, P\right)$.

In contrast, the true Density Salinity is defined to be strictly conservative and represented by $S_{\mathrm{A}}^{\mathrm{dens}}$ in the nomenclature of Wright et al. (2010a). To ensure that it is independent of temperature and pressure, it is computed using Eq. (5.1) evaluated at $T=298.15 \mathrm{~K}$ and $P=101325 \mathrm{~Pa}$, and is by definition the same for the given sample at any other $T$ or $P$.

Chlorinity Salinity, $S_{\mathrm{Cl}}$, is the Absolute Salinity of SSW that has the same Chlorinity as BSW,

$S_{\mathrm{Cl}}=\frac{m_{\mathrm{SSW}}^{\mathrm{BSW}} A_{\mathrm{SSW}}}{1+m_{\mathrm{SSW}}^{\mathrm{BSW}} A_{\mathrm{SSW}}+m_{\mathrm{FW}}^{\mathrm{BSW}} A_{\mathrm{FW}}}=S_{\mathrm{A}}^{\mathrm{SSW}}\left(1-S_{\mathrm{FW}}^{\mathrm{BSW}}\right)$

Density Salinity and Chlorinity Salinity can be measured in the Baltic Sea; readings are currently related by the approximate empirical relation (Feistel et al., 2010a) in the form of Eq. (2.16),

$$
S_{\mathrm{D}}=S_{\mathrm{Cl}}+130 \mathrm{mg} \mathrm{kg}^{-1} \times\left(1-\frac{S_{\mathrm{Cl}}}{S_{\mathrm{SO}}}\right),
$$

which is based on density measurements made at $20^{\circ} \mathrm{C}$ and Chlorinity determinations at 3 different stations.

Using Eq. (5.2) in the form $S_{\mathrm{Cl}} \approx S_{\mathrm{A}}^{\mathrm{SSW}}$ in Eq. (5.2), we have $S_{\mathrm{D}}$ approximately given as a function of $S_{\mathrm{A}}^{\mathrm{SSW}}$ for typical Baltic seawater conditions,

$S_{\mathrm{D}}=S_{\mathrm{A}}^{\mathrm{SSW}}+130 \mathrm{mg} \mathrm{kg}^{-1} \times\left(1-\frac{S_{\mathrm{A}}^{\mathrm{SSW}}}{S_{\mathrm{SO}}}\right)$.

This empirical relation is used here to conveniently present the comparisons for typical Baltic conditions as a function of 
Table 1. Coefficients $c_{i j k}$ of the partial Gibbs function of Baltic freshwater, $g^{\mathrm{FW}}$, Eq. (4.8), computed from Eqs. (4.12) and (4.38). The logarithmic terms, Eq. (4.11), are $r_{00}=42028.3972160427 \mathrm{~J} \mathrm{~kg}^{-1}$ and $r_{01}=6154.62525587299 \mathrm{~J} \mathrm{~kg}^{-1}$. Two of the 20 coefficients $c_{i j k}$ are computed from the reference state conditions, Eq. (4.38).

\begin{tabular}{llllllllll}
\hline$i$ & $j$ & $k$ & $c_{i j k}$ & Unit & $i$ & $j$ & $k$ & $c_{i j k}$ & Unit \\
\hline 0 & 0 & 0 & +96228.1193989113 & $\mathrm{~J} \mathrm{~kg}^{-1}$ & 1 & 4 & 0 & +1729.0660788551 & $\mathrm{~J} \mathrm{~kg}^{-1}$ \\
0 & 0 & 1 & +10303.6864312721 & $\mathrm{Jkg}^{-1}$ & 2 & 0 & 0 & +1220838.5516502 & $\mathrm{~J} \mathrm{~kg}^{-1}$ \\
0 & 1 & 0 & +13152.6106953709 & $\mathrm{~J} \mathrm{~kg}^{-1}$ & 2 & 1 & 0 & +70762.8545963981 & $\mathrm{~J} \mathrm{~kg}^{-1}$ \\
1 & 0 & 0 & -441934.025099393 & $\mathrm{~J} \mathrm{~kg}^{-1}$ & 2 & 2 & 0 & +16315.4263307828 & $\mathrm{~J} \mathrm{~kg}^{-1}$ \\
1 & 0 & 1 & +17156.5383471054 & $\mathrm{~J} \mathrm{~kg}^{-1}$ & 2 & 3 & 0 & +2273.68918966667 & $\mathrm{~J} \mathrm{~kg}^{-1}$ \\
1 & 0 & 2 & +27859.4906548253 & $\mathrm{~J} \mathrm{~kg}^{-1}$ & 3 & 0 & 0 & -1992184.79639124 & $\mathrm{~J} \mathrm{~kg}^{-1}$ \\
1 & 1 & 0 & -51539.7255022561 & $\mathrm{~J} \mathrm{~kg}^{-1}$ & 3 & 1 & 0 & -31635.7319983778 & $\mathrm{~J} \mathrm{~kg}^{-1}$ \\
1 & 1 & 1 & +25459.1777093084 & $\mathrm{~J} \mathrm{~kg}^{-1}$ & 3 & 2 & 0 & -9480.67775897537 & $\mathrm{~J} \mathrm{~kg}^{-1}$ \\
1 & 2 & 0 & -3508.1908464246 & $\mathrm{~J} \mathrm{~kg}^{-1}$ & 4 & 0 & 0 & +1671565.96767693 & $\mathrm{~J} \mathrm{~kg}^{-1}$ \\
1 & 3 & 0 & -7738.24955854259 & $\mathrm{~J} \mathrm{~kg}^{-1}$ & 5 & 0 & 0 & -549711.375812245 & $\mathrm{~J} \mathrm{~kg}^{-1}$ \\
\hline
\end{tabular}

Table 2. Results of the regression, Eq. (4.8), with respect to properties of Baltic seawater simulated with FREZCHEM.

\begin{tabular}{llllllllll}
\hline Prpty & $\#$ Pts & $\begin{array}{l}m_{\mathrm{Cl}} \\
\frac{\mathrm{mmg}}{\mathrm{kg}}\end{array}$ & $\begin{array}{c}\delta m_{\mathrm{Ca}} \\
\frac{\mathrm{mmol}}{\mathrm{kg}}\end{array}$ & $\begin{array}{l}T \\
\mathrm{~K}\end{array}$ & $\begin{array}{l}P \\
\mathrm{MPa}\end{array}$ & $\omega$ & $\begin{array}{l}\text { r.m.s. } \\
\text { misfit }\end{array}$ & Unit & Eq. \\
\hline$\delta v$ & 1260 & $32-566$ & $0-3$ & $273-298$ & $0.1-5$ & $1 \times 10^{-9}$ & $1.5 \times 10^{-9}$ & $\mathrm{~m}^{3} \mathrm{~kg}^{-1}$ & $(4.14)$ \\
$\delta c_{P}$ & 210 & $32-566$ & $0-3$ & $273-298$ & 0.1 & $2 \times 10^{-3}$ & $3.4 \times 10^{-3}$ & $\mathrm{~J} /(\mathrm{kg} \mathrm{K})$ & $(4.15)$ \\
$\delta \psi$ & 1260 & $32-566$ & $0-3$ & $273-298$ & $0.1-5$ & $2 \times 10^{-5}$ & $3.1 \times 10^{-5}$ & & $(4.33)$ \\
\hline
\end{tabular}

a single salinity variable, $S_{\mathrm{A}}^{\mathrm{SSW}}$, rather than of the two independent arguments, $S_{\mathrm{A}}^{\mathrm{SSW}}$ and $S_{\mathrm{FW}}^{\mathrm{BSW}}$, of the Gibbs function for Baltic seawater, $g^{\mathrm{BSW}}$, Eq. (3.19). From Eqs. (5.1) and (3.19) we obtain the relation

$S_{\mathrm{FW}}^{\mathrm{BSW}}=\frac{g_{P}^{\mathrm{SW}}\left(S_{\mathrm{A}}^{\mathrm{SSW}}, T, P\right)-g_{P}^{\mathrm{SW}}\left(S_{\mathrm{D}}, T, P\right)}{g_{P}^{\mathrm{SW}}\left(S_{\mathrm{A}}^{\mathrm{SSW}}, T, P\right)-g_{P}^{\mathrm{FW}}\left(S_{\mathrm{A}}^{\mathrm{SSW}}, T, P\right)}$,

which is exact by the definition of Density Salinity, $S_{\mathrm{D}}$. Using Eq. (5.5) provides the salinity anomaly $S_{\mathrm{FW}}^{\mathrm{BSW}}$ as a function of any given pair $S_{\mathrm{A}}^{\mathrm{SSW}}$ and $S_{\mathrm{D}}$, and using the approximate relation Eq. (5.4) allows us to conveniently rewrite this expression in terms of the single composition variable $S_{\mathrm{A}}^{\mathrm{SSW}}$. We then use $S_{\mathrm{A}}^{\mathrm{SSW}} \approx S_{\mathrm{Cl}}$ as the control parameter representing the brackish "Baltic Sea salinity", in order to compute arbitrary thermodynamic properties of BSW from Eqs. (5.4), (5.5) and (3.19), and compare them to the properties of the parent solution, SSW, at the same Absolute Salinity, $S_{\mathrm{A}}^{\mathrm{BSW}}$.

Millero's rule suggests that $S_{\mathrm{D}}$ should be a good practical approximation for the Absolute Salinity of BSW, i.e., $S_{\mathrm{D}} \approx S_{\mathrm{A}}^{\mathrm{BSW}}$, Eqs. (2.11), (3.21). In Fig. 8 the difference $S_{\mathrm{A}}^{\mathrm{BSW}}-S_{\mathrm{D}}$ is shown as a function of $T$ and $S_{\mathrm{D}}$. The latter is displayed on the abscissa since $S_{\mathrm{D}}$ is experimentally easily measurable, in contrast to the other salinity measures available from the theoretical model. Note the scale of the vertical axis is $\mathrm{mg} \mathrm{kg}^{-1}=0.001 \mathrm{~g} \mathrm{~kg}^{-1}$.

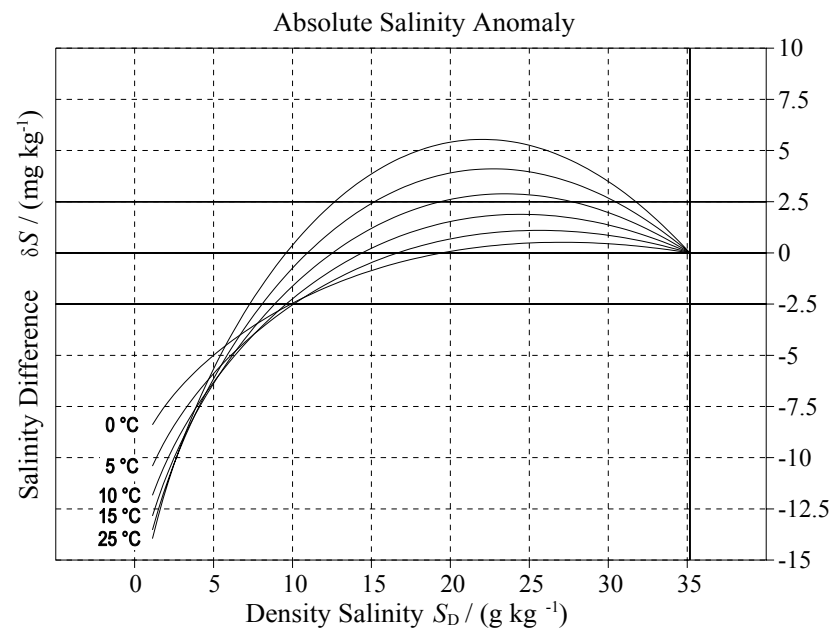

Fig. 8. Difference $\delta S=S_{\mathrm{A}}^{\mathrm{BSW}}-S_{\mathrm{D}}$ between Absolute Salinity, $S_{\mathrm{A}}^{\mathrm{BSW}}$, Eq. (3.21), and Density Salinity, $S_{\mathrm{D}}$, computed from Eq. (5.1) for Baltic seawater at the standard ocean surface pressure and temperatures between 0 and $25^{\circ} \mathrm{C}$. The uncertainty of Density Salinity measurements is $2 \mathrm{~g} \mathrm{~m}^{-3} /(\beta \rho)=2.5 \mathrm{mg} \mathrm{kg}^{-1}$ (Feistel et al., 2010a), indicated by the solid horizontal lines. 


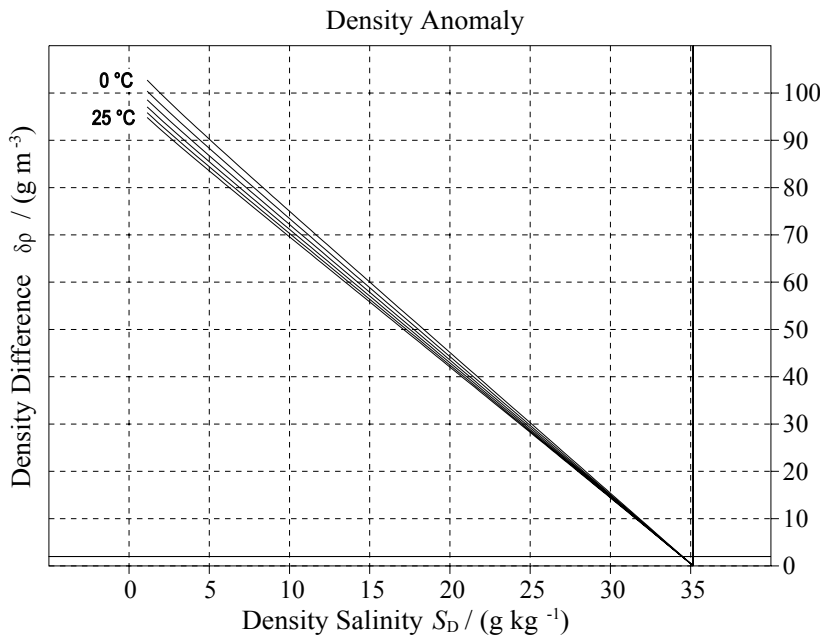

Fig. 9. Difference $\delta \rho$, Eq. (5.6), between the densities with and without the freshwater solute for Baltic seawater at the standard ocean surface pressure and temperatures between 0 and $25^{\circ} \mathrm{C}$. The uncertainty of density measurements is $2 \mathrm{~g} \mathrm{~m}^{-3}$ (Feistel et al., 2010a), indicated by the solid horizontal line.

The density anomaly of the Baltic Sea is shown in Fig. 9 as the difference between the densities with and without the freshwater solute, i.e., of SSW and BSW with the equal chloride molalities (roughly, equal Chlorinities),

$\delta \rho=\frac{1}{g_{P}^{\mathrm{BSW}}\left(S_{\mathrm{A}}^{\mathrm{SSW}}, S_{\mathrm{FW}}^{\mathrm{BSW}}, T, P_{\mathrm{SO}}\right)}-\frac{1}{g_{P}^{\mathrm{BSW}}\left(S_{\mathrm{A}}^{\mathrm{SSW}}, 0, T, P_{\mathrm{SO}}\right)}$,

as a function of Density Salinity. Here, the salinities $S_{\mathrm{D}}$ and $S_{\mathrm{FW}}^{\mathrm{BSW}}$ are computed from the parent solution salinity, $S_{\mathrm{A}}^{\mathrm{SSW}} \approx$ $S_{\mathrm{Cl}}$, using Eqs. (5.4) and (5.5).

Using $\beta \rho \approx 0.8 \times\left(10^{6} \mathrm{~g} \mathrm{~m}^{-3}\right) /\left(10^{6} \mathrm{mg} \mathrm{kg}^{-1}\right)$, it is seen that division of the numerical values of $\delta \rho /\left(\mathrm{g} \mathrm{m}^{-3}\right)$ in Fig. 9 by 0.8 provides an approximate conversion to the units used in Fig. 8 so that comparison of the results in these two figures reveals that the relative errors associated with using $S_{\mathrm{D}}$ in place of $S_{\mathrm{A}}^{\mathrm{BSW}}$ to estimate salinity anomalies due to the addition of calcium carbonate is at most $25 \%$, and only about $2.5 \%$ for a typical brackish salinity value of $S_{\mathrm{A}}^{\mathrm{SSW}} \approx 8 \mathrm{~g} \mathrm{~kg}^{-1}$. Note that the salinity change associated with the added calcium carbonate solute $\left(S_{\mathrm{D}}-S_{\mathrm{A}}^{\mathrm{SSW}}\right)$ is itself a small fraction of the salinity change associated with the addition of fresh water $\left(S_{\mathrm{SO}}-S_{\mathrm{A}}^{\mathrm{SSW}}\right)$. Using Eq. (5.4), the ratio is approximated by $\left(S_{\mathrm{D}}-S_{\mathrm{A}}^{\mathrm{SSW}}\right) /\left(S_{\mathrm{SO}}-S_{\mathrm{A}}^{\mathrm{SSW}}\right) \approx$ $\left(130 \mathrm{mg} \mathrm{kg}^{-1}\right) / S_{\mathrm{SO}} \approx 0.4 \%$.

The Baltic Sea anomaly of the thermal expansion coefficient is shown in Fig. 10 as the difference between the coefficients with and without the freshwater solute, i.e., of SSW and BSW with equal chloride molalities (roughly, equal Chlorinities),

$\delta \alpha=\frac{g_{T P}^{\mathrm{BSW}}\left(S_{\mathrm{A}}^{\mathrm{SSW}}, S_{\mathrm{FW}}^{\mathrm{BSW}}, T, P_{\mathrm{SO}}\right)}{g_{P}^{\mathrm{BSW}}\left(S_{\mathrm{A}}^{\mathrm{SSW}}, S_{\mathrm{FW}}^{\mathrm{BSW}}, T, P_{\mathrm{SO}}\right)}-\frac{g_{T P}^{\mathrm{BSW}}\left(S_{\mathrm{A}}^{\mathrm{SSW}}, 0, T, P_{\mathrm{SO}}\right)}{g_{P}^{\mathrm{BSW}}\left(S_{\mathrm{A}}^{\mathrm{SSW}}, 0, T, P_{\mathrm{SO}}\right)}$,

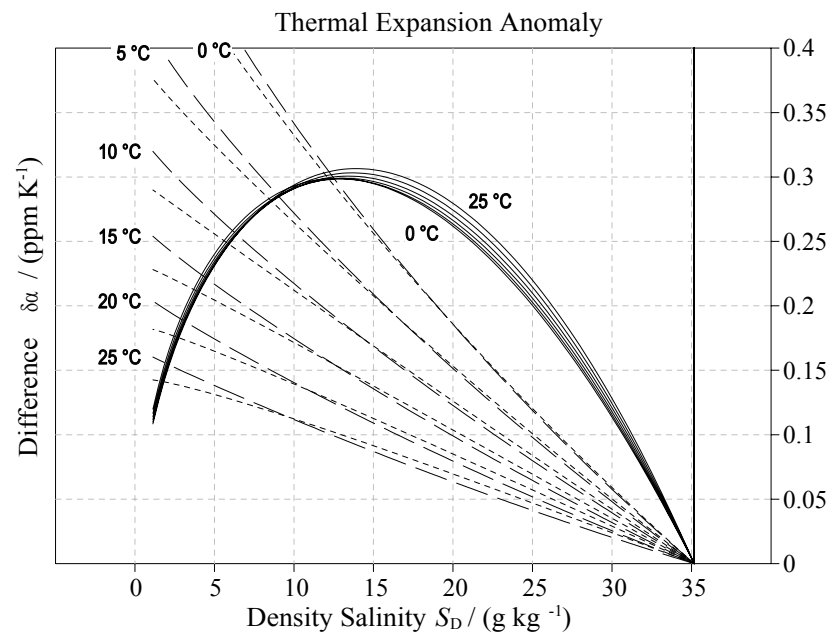

Fig. 10. Difference $\delta \alpha$, Eq. (5.7), between the thermal expansion coefficients (solid lines) with and without the freshwater solute for Baltic seawater at the standard ocean surface pressure and temperatures between 0 and $25^{\circ} \mathrm{C}$, in comparison to estimates from Millero's Rule, $\delta \alpha^{\mathrm{D}}$, based on Density Salinity (dashed lines), Eq. (5.8), and $\delta \alpha^{\mathrm{A}}$, based on Absolute Salinity (dotted lines, temperatures not labelled), Eq. (5.9). For the latter two, the responsible difference between $S_{\mathrm{A}}^{\mathrm{BSW}}$ and $S_{\mathrm{D}}$ is shown in Fig. 8. The estimated experimental uncertainty of the thermal expansion coefficient is $0.6 \mathrm{ppm} \mathrm{K}^{-1}$ (Feistel and Hagen, 1995; IAPWS, 2008) and exceeds the range shown in the figure.

as a function of Density Salinity, computed from Eqs. (5.4) and (5.5). For comparison, the anomaly is estimated by Millero's Rule using Density Salinity $S_{\mathrm{D}}$, Eq. (5.1), from

$\delta \alpha^{\mathrm{D}}=\frac{g_{T P}^{\mathrm{SW}}\left(S_{\mathrm{D}}, T, P_{\mathrm{SO}}\right)}{g_{P}^{\mathrm{SW}}\left(S_{\mathrm{D}}, T, P_{\mathrm{SO}}\right)}-\frac{g_{T P}^{\mathrm{BSW}}\left(S_{\mathrm{A}}^{\mathrm{SSW}}, 0, T, P_{\mathrm{SO}}\right)}{g_{P}^{\mathrm{BSW}}\left(S_{\mathrm{A}}^{\mathrm{SSW}}, 0, T, P_{\mathrm{SO}}\right)}$

and using Absolute Salinity, $S_{\mathrm{A}}^{\mathrm{BSW}}$, Eq. (3.21),

$\delta \alpha^{\mathrm{A}}=\frac{g_{T P}^{\mathrm{SW}}\left(S_{\mathrm{A}}^{\mathrm{BSW}}, T, P_{\mathrm{SO}}\right)}{g_{P}^{\mathrm{SW}}\left(S_{\mathrm{A}}^{\mathrm{BSW}}, T, P_{\mathrm{SO}}\right)}-\frac{g_{T P}^{\mathrm{BSW}}\left(S_{\mathrm{A}}^{\mathrm{SSW}}, 0, T, P_{\mathrm{SO}}\right)}{g_{P}^{\mathrm{BSW}}\left(S_{\mathrm{A}}^{\mathrm{SSW}}, 0, T, P_{\mathrm{SO}}\right)}$.

The uncertainty of the TEOS-10 thermal expansion coefficient is estimated as $0.6 \mathrm{ppm} \mathrm{K}^{-1}$, so the Baltic anomalies are within the uncertainty and can in practice be neglected.

For seawater with varying composition, there are several ways to define the haline contraction coefficient, depending on the particular thermodynamic process by which the composition is changing with salinity. Here we consider the anomalous contraction coefficient which provides the density change with respect to the addition of freshwater solute

$\beta_{\mathrm{FW}}=-\left.\frac{g_{S_{\mathrm{FW}}^{\mathrm{BSW}}}^{\mathrm{BSW}}\left(S_{\mathrm{A}}^{\mathrm{SSW}}, S_{\mathrm{FW}}^{\mathrm{BSW}}, T, P\right)}{g_{P}^{\mathrm{BSW}}\left(S_{\mathrm{A}}^{\mathrm{SSW}}, S_{\mathrm{FW}}^{\mathrm{BSW}}, T, P\right)}\right|_{S_{\mathrm{FW}}^{\mathrm{BSW}}=0}$, 


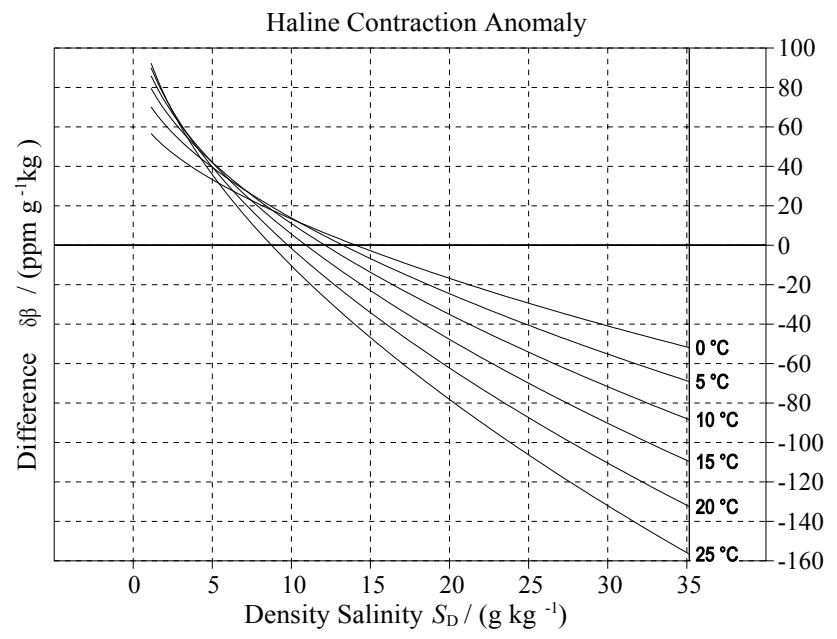

Fig. 11. Difference $\delta \beta$, Eq. (5.12), between the haline contraction coefficients (solid lines) of the parent solution with respect to the addition of FW solute and of SSW solute for Baltic seawater. Values are determined at the standard ocean surface pressure and temperatures between 0 and $25^{\circ} \mathrm{C}$. The standard-ocean value of the haline contraction coefficient is $0.781=781 \mathrm{ppm} \mathrm{g}^{-1} \mathrm{~kg}$. The haline contraction coefficient associated with the addition of calcium carbonate is within $20 \%$ of the haline contraction coefficient for Standard Seawater.

relative to the haline contraction coefficient of SSW,

$\beta=-\frac{g_{S P}^{\mathrm{SW}}\left(S_{\mathrm{A}}^{\mathrm{SSW}}, T, P\right)}{g_{P}^{\mathrm{SW}}\left(S_{\mathrm{A}}^{\mathrm{SSW}}, T, P\right)}$.

Since the Gibbs function, Eq. (3.19), is linear in $S_{\mathrm{FW}}^{\mathrm{BSW}}$, the relevant derivative can be carried out analytically and the anomaly in the haline contraction coefficient can be written as

$\delta \beta=\beta_{\mathrm{FW}}-\beta=1-\frac{g_{P}^{\mathrm{FW}}\left(S_{\mathrm{A}}^{\mathrm{SSW}}, T, P_{\mathrm{SO}}\right)-g_{S P}^{\mathrm{SW}}\left(S_{\mathrm{A}}^{\mathrm{SSW}}, T, P_{\mathrm{SO}}\right)}{g_{P}^{\mathrm{SW}}\left(S_{\mathrm{A}}^{\mathrm{SSW}}, T, P_{\mathrm{SO}}\right)}$.

Calculated values for $\delta \beta$ are shown in Fig. 11.

The Baltic Sea anomaly of the isobaric specific heat is shown in Fig. 12 as the difference between the values with and without the freshwater solute, i.e., of SSW and BSW with the equal chloride molality (roughly, equal Chlorinity),

$$
\begin{aligned}
\delta c_{P} & =-T g_{T T}^{\mathrm{BSW}}\left(S_{\mathrm{A}}^{\mathrm{SSW}}, S_{\mathrm{FW}}^{\mathrm{BSW}}, T, P_{\mathrm{SO}}\right) \\
& +T g_{T T}^{\mathrm{BSW}}\left(S_{\mathrm{A}}^{\mathrm{SSW}}, 0, T, P_{\mathrm{SO}}\right),
\end{aligned}
$$

as a function of Density Salinity, computed from Eqs. (5.4) and (5.5). For comparison, the anomaly is estimated by Millero's rule using Density Salinity $S_{\mathrm{D}}$, Eq. (5.1), from

$\delta c_{P}^{\mathrm{D}}=-T g_{T T}^{\mathrm{SW}}\left(S_{\mathrm{D}}, T, P_{\mathrm{SO}}\right)+T g_{T T}^{\mathrm{BSW}}\left(S_{\mathrm{A}}^{\mathrm{SSW}}, 0, T, P_{\mathrm{SO}}\right)$

and using Absolute Salinity, $S_{\mathrm{A}}^{\mathrm{BSW}}$, Eq. (3.21),

$\delta c_{P}^{\mathrm{A}}=-T g_{T T}^{\mathrm{SW}}\left(S_{\mathrm{A}}^{\mathrm{BSW}}, T, P_{\mathrm{SO}}\right)+T g_{T T}^{\mathrm{BSW}}\left(S_{\mathrm{A}}^{\mathrm{SSW}}, 0, T, P_{\mathrm{SO}}\right)$

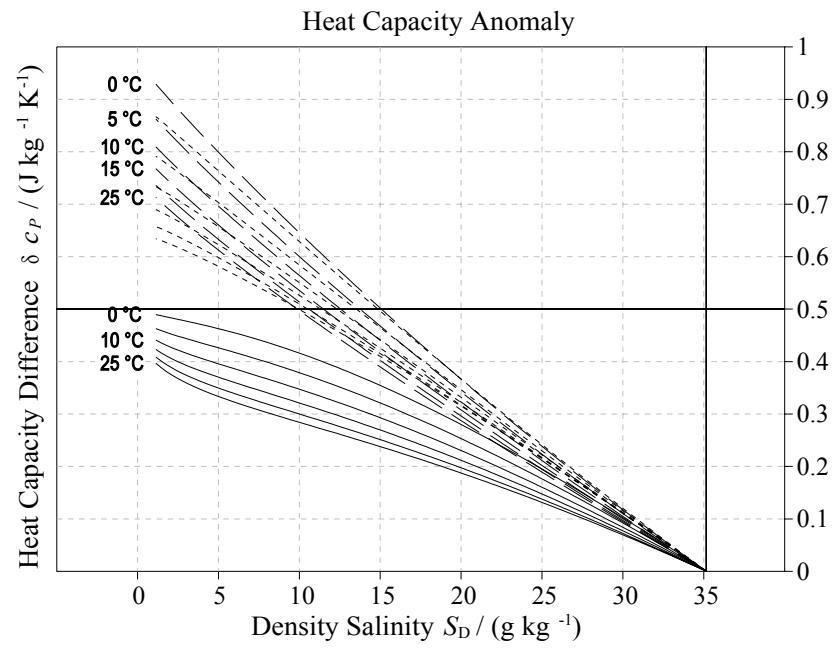

Fig. 12. Difference $\delta c_{P}$, Eq. (5.13), between the specific isobaric heat capacity (solid lines) with and without the freshwater solute for Baltic seawater at the standard ocean surface pressure and temperatures between 0 and $25^{\circ} \mathrm{C}$, in comparison to estimates from Millero's Rule, $\delta c_{P}^{\mathrm{D}}$, based on Density Salinity (dashed lines), Eq. (5.14), and $\delta c_{P}^{\mathrm{A}}$, based on Absolute Salinity (dotted lines, temperatures not labelled), Eq. (5.15). For the latter two, the responsible difference between $S_{\mathrm{A}}^{\mathrm{BSW}}$ and $S_{\mathrm{D}}$ is shown in Fig. 8. The experimental uncertainty of $c_{P}$ relative to pure water is $0.5 \mathrm{~J} \mathrm{~kg}^{-1} \mathrm{~K}^{-1}$, as indicated by the solid horizontal line. A typical value for the heat capacity of water or seawater is $4000 \mathrm{~J} \mathrm{~kg}^{-1} \mathrm{~K}^{-1}$. The changing curvature of the solid curves below $5 \mathrm{~g} \mathrm{~kg}^{-1}$ is probably a numerical edge effect of the regression.

The anomalies of $c_{P}$ remain with the experimental uncertainty of $0.5 \mathrm{~J} \mathrm{~kg}^{-1} \mathrm{~K}^{-1}$, Fig. 12. The errors associated with using Millero's Rule are similar to those associated with simply neglecting the FW solute and are again negligible.

The sound speed $c$ is computed from the Gibbs function $g$ using the formula,

$c=g_{P} \sqrt{\frac{g_{T T}}{g_{T P}^{2}-g_{T T} g_{P P}}}$.

The Baltic Sea anomaly of the speed of sound is shown in Fig. 13 as the difference between the values with and without the freshwater solute, i.e., of SSW and BSW with equal chloride molalities (roughly, equal Chlorinities),

$\delta c=c^{\mathrm{BSW}}\left(S_{\mathrm{A}}^{\mathrm{SSW}}, S_{\mathrm{FW}}^{\mathrm{BSW}}, T, P_{\mathrm{SO}}\right)-c^{\mathrm{BSW}}\left(S_{\mathrm{A}}^{\mathrm{SSW}}, 0, T, P_{\mathrm{SO}}\right)$,

as a function of Density Salinity, computed from Eqs. (5.4) and (5.5). For comparison, the anomaly is estimated by Millero's rule using Density Salinity $S_{\mathrm{D}}$, Eq. (5.1),

$\delta c^{\mathrm{D}}=c^{\mathrm{SW}}\left(S_{\mathrm{D}}, T, P_{\mathrm{SO}}\right)-c^{\mathrm{BSW}}\left(S_{\mathrm{A}}^{\mathrm{SSW}}, 0, T, P_{\mathrm{SO}}\right)$

and using Absolute Salinity, $S_{\mathrm{A}}^{\mathrm{BSW}}$, Eq. (3.21),

$\delta c^{\mathrm{A}}=c^{\mathrm{SW}}\left(S_{\mathrm{A}}^{\mathrm{BSW}}, T, P_{\mathrm{SO}}\right)-c^{\mathrm{BSW}}\left(S_{\mathrm{A}}^{\mathrm{SSW}}, 0, T, P_{\mathrm{SO}}\right)$ 


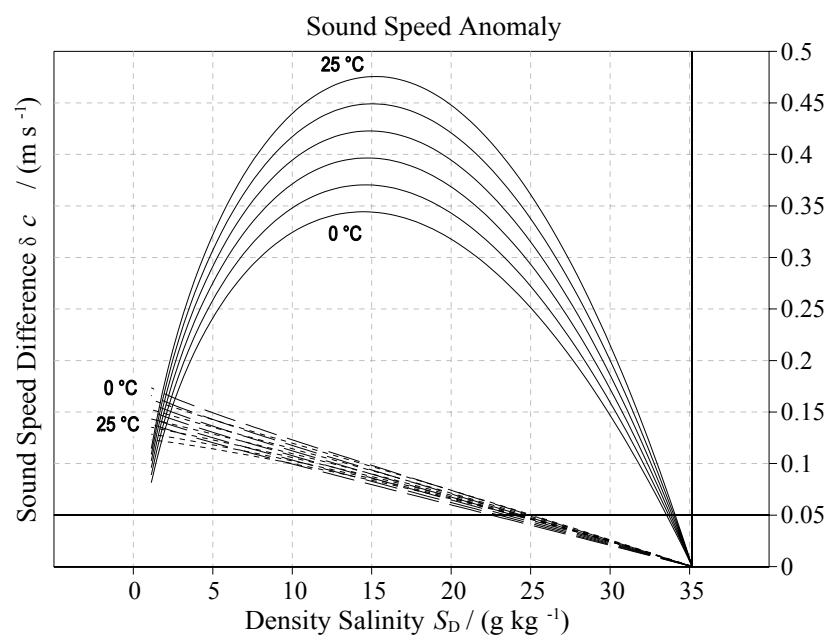

Fig. 13. Difference $\delta c$, Eq. (5.17), between the sound speed (solid lines) with and without the freshwater solute for Baltic seawater at the standard ocean surface pressure and temperatures between 0 and $25^{\circ} \mathrm{C}$, in comparison to estimates from Millero's Rule, $\delta c^{\mathrm{D}}$, based on Density Salinity (dashed lines), Eq. (5.18), and $\delta c^{\mathrm{A}}$, based on Absolute Salinity (dotted lines, temperatures not labelled), Eq. (5.19). For the latter two, the responsible difference between $S_{\mathrm{A}}^{\mathrm{BSW}}$ and $S_{\mathrm{D}}$ is shown in Fig. 8. The experimental uncertainty of $c$ is $0.05 \mathrm{~m} \mathrm{~s}^{-1}$, indicated by the solid horizontal line.

The anomalies of $c$ are much larger than the experimental uncertainty of $0.05 \mathrm{~m} \mathrm{~s}^{-1}$, Fig. 13 and poorly approximated by Millero's Rule. Except at very low salinities, use of Millero's Rule is only slightly better than totally neglecting the influence of the FW solute on sound speed estimates. In Eq. (5.16), the largest contribution to the sound speed anomaly comes from the anomaly of the compressibility, $g_{p p}$, which is of order of magnitude up to $0.07 \%$. Compressibility estimates from FREZCHEM have larger uncertainties than e.g. those of the density or the heat capacity (Feistel and Marion, 2007).

Because of the freely adjustable constants, only relative enthalpies can reasonably be compared between samples that have different compositions. The Baltic Sea anomaly of the relative specific enthalpy is shown in Fig. 14 as the difference of relative enthalpies between the values with and without the freshwater solute, i.e., of SSW and BSW with the equal chloride molalities (roughly, equal Chlorinities),

$$
\begin{aligned}
\delta h & =g^{\mathrm{BSW}}\left(S_{\mathrm{A}}^{\mathrm{SSW}}, S_{\mathrm{FW}}^{\mathrm{BSW}}, T, P_{\mathrm{SO}}\right)-T g_{T}^{\mathrm{BSW}}\left(S_{\mathrm{A}}^{\mathrm{SSW}}, S_{\mathrm{FW}}^{\mathrm{BSW}}, T, P_{\mathrm{SO}}\right) \\
& -g^{\mathrm{BSW}}\left(S_{\mathrm{A}}^{\mathrm{SSW}}, S_{\mathrm{FW}}^{\mathrm{BSW}}, T_{\mathrm{SO}}, P_{\mathrm{SO}}\right)+T_{\mathrm{SO}} g_{T}^{\mathrm{BSW}}\left(S_{\mathrm{A}}^{\mathrm{SSW}}, S_{\mathrm{FW}}^{\mathrm{BSW}}, T_{\mathrm{SO}}, P_{\mathrm{SO}}\right) \\
& -g^{\mathrm{BSW}}\left(S_{\mathrm{A}}^{\mathrm{SSW}}, 0, T, P_{\mathrm{SO}}\right)+T g_{T}^{\mathrm{BSW}}\left(S_{\mathrm{A}}^{\mathrm{SSW}}, 0, T, P_{\mathrm{SO}}\right) \\
& +g^{\mathrm{BSW}}\left(S_{\mathrm{A}}^{\mathrm{SSW}}, 0, T_{\mathrm{SO}}, P_{\mathrm{SO}}\right)-T_{\mathrm{SO}} g_{T}^{\mathrm{BSW}}\left(S_{\mathrm{A}}^{\mathrm{SSW}}, 0, T_{\mathrm{SO}}, P_{\mathrm{SO}}\right)
\end{aligned}
$$

as a function of Density Salinity, computed from Eqs. (5.4) and (5.5). For comparison, the anomaly is estimated by

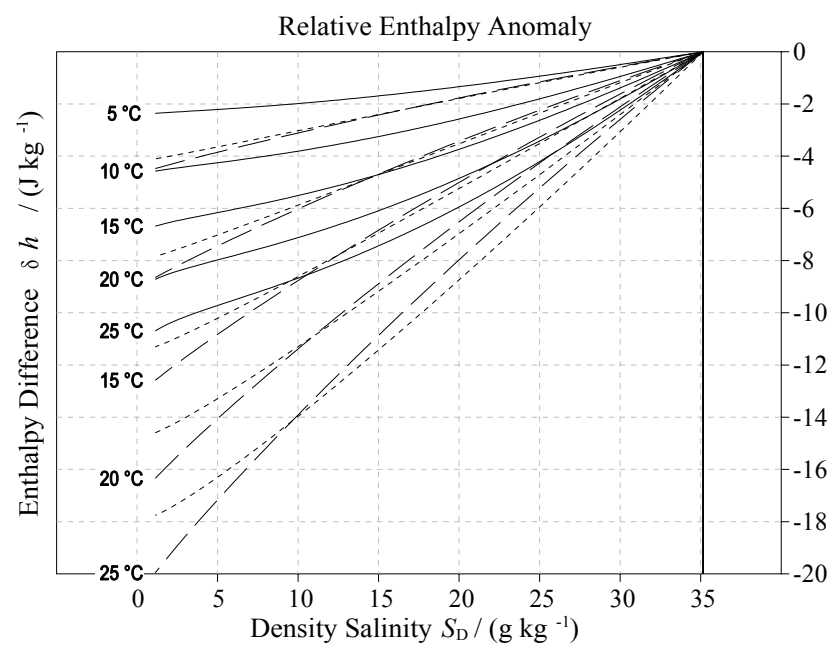

Fig. 14. Difference $\delta h$, Eq. (5.20), between the relative specific enthalpies (solid lines) with and without the freshwater solute for Baltic seawater at the standard ocean surface pressure and temperatures between 5 and $25^{\circ} \mathrm{C}$, in comparison to estimates from Millero's rule, $\delta h^{\mathrm{D}}$, based on Density Salinity (dashed lines, only the $15-25^{\circ} \mathrm{C}$ results are labelled), Eq. (5.21), and $\delta h^{\mathrm{A}}$, based on Absolute Salinity (dotted lines, temperatures not labelled), Eq. (5.22). For the latter two, the responsible difference between $S_{\mathrm{A}}^{\mathrm{BSW}}$ and $S_{\mathrm{D}}$ is shown in Fig. 8. The experimental uncertainty of the relative enthalpies is $0.5 \mathrm{~J} \mathrm{~kg}^{-1} \times t /{ }^{\circ} \mathrm{C}$.

Millero's Rule using Density Salinity $S_{\mathrm{D}}$, Eq. (5.1), from

$$
\begin{aligned}
\delta h^{\mathrm{D}} & =g^{\mathrm{SW}}\left(S_{\mathrm{D}}, T, P_{\mathrm{SO}}\right)-T g_{T}^{\mathrm{SW}}\left(S_{\mathrm{D}}, T, P_{\mathrm{SO}}\right) \\
& -g^{\mathrm{SW}}\left(S_{\mathrm{D}}, T_{\mathrm{SO}}, P_{\mathrm{SO}}\right)+T_{\mathrm{SO}} g_{T}^{\mathrm{SW}}\left(S_{\mathrm{D}}, T_{\mathrm{SO}}, P_{\mathrm{SO}}\right) \\
& -g^{\mathrm{BSW}}\left(S_{\mathrm{A}}^{\mathrm{SSW}}, 0, T, P_{\mathrm{SO}}\right)+T g_{T}^{\mathrm{BSW}}\left(S_{\mathrm{A}}^{\mathrm{SSW}}, 0, T, P_{\mathrm{SO}}\right) \\
& +g^{\mathrm{BSW}}\left(S_{\mathrm{A}}^{\mathrm{SSW}}, 0, T_{\mathrm{SO}}, P_{\mathrm{SO}}\right)-T_{\mathrm{SO}} g_{T}^{\mathrm{BSW}}\left(S_{\mathrm{A}}^{\mathrm{SSW}}, 0, T_{\mathrm{SO}}, P_{\mathrm{SO}}\right),
\end{aligned}
$$

and using Absolute Salinity, $S_{\mathrm{A}}^{\mathrm{BSW}}$, Eq. (3.21),

$$
\begin{aligned}
\delta h^{\mathrm{A}} & =g^{\mathrm{SW}}\left(S_{\mathrm{A}}^{\mathrm{BSW}}, T, P_{\mathrm{SO}}\right)-T g_{T}^{\mathrm{SW}}\left(S_{\mathrm{A}}^{\mathrm{BSW}}, T, P_{\mathrm{SO}}\right) \\
& -g^{\mathrm{SW}}\left(S_{\mathrm{A}}^{\mathrm{BSW}}, T_{\mathrm{SO}}, P_{\mathrm{SO}}\right)+T_{\mathrm{SO}} g_{T}^{\mathrm{SW}}\left(S_{\mathrm{A}}^{\mathrm{BSW}}, T_{\mathrm{SO}}, P_{\mathrm{SO}}\right) \\
& -g^{\mathrm{BSW}}\left(S_{\mathrm{A}}^{\mathrm{SSW}}, 0, T, P_{\mathrm{SO}}\right)+T g_{T}^{\mathrm{BSW}}\left(S_{\mathrm{A}}^{\mathrm{SSW}}, 0, T, P_{\mathrm{SO}}\right) \\
& +g^{\mathrm{BSW}}\left(S_{\mathrm{A}}^{\mathrm{SSW}}, 0, T_{\mathrm{SO}}, P_{\mathrm{SO}}\right)-T_{\mathrm{SO}} g_{T}^{\mathrm{BSW}}\left(S_{\mathrm{A}}^{\mathrm{SSW}}, 0, T_{\mathrm{SO}}, P_{\mathrm{SO}}\right) .
\end{aligned}
$$

For the computation of the freezing temperature of Baltic seawater we need a formula for the chemical potential, $\mu_{W}$, of water in Baltic seawater similar to $\mu_{0}$ in Eq. (3.1), but on a mass rather than on a particle number basis:

$G^{\mathrm{BSW}}=\mu_{\mathrm{W}} M_{0}^{\mathrm{BSW}}+\mu_{\mathrm{SSW}} M_{\mathrm{S}}^{\mathrm{SSW}}+\mu_{\mathrm{FW}} M_{\mathrm{S}}^{\mathrm{FW}}$.

Here, $\mu_{W}$ is defined by

$$
\mu_{\mathrm{W}}=\left(\frac{\partial G^{\mathrm{BSW}}}{\partial M_{0}^{\mathrm{BSW}}}\right)_{M_{\mathrm{S}}^{\mathrm{SSW}}, M_{\mathrm{S}}^{\mathrm{FW}}, T, P} .
$$


We express $G^{\mathrm{BSW}}$ in terms of the required variables, Eqs. (3.13), (3.14) and (3.20),

$g^{\mathrm{BSW}}=\frac{G^{\mathrm{BSW}}}{M_{0}^{\mathrm{BSW}}+M_{\mathrm{S}}^{\mathrm{SSW}}+M_{\mathrm{S}}^{\mathrm{FW}}}$,

$S_{\mathrm{A}}^{\mathrm{SSW}}=\frac{M_{\mathrm{S}}^{\mathrm{SSW}}}{M_{0}^{\mathrm{BSW}}+M_{\mathrm{S}}^{\mathrm{SSW}}}$,

$S_{\mathrm{FW}}^{\mathrm{BSW}}=\frac{M_{\mathrm{S}}^{\mathrm{FW}}}{M_{0}^{\mathrm{BSW}}+M_{\mathrm{S}}^{\mathrm{SSW}}+M_{\mathrm{S}}^{\mathrm{FW}}}$,

and apply the chain rule,

$$
\begin{aligned}
\mu_{\mathrm{W}} & =g^{\mathrm{BSW}}+\left(M_{0}^{\mathrm{BSW}}+M_{\mathrm{S}}^{\mathrm{SSW}}+M_{\mathrm{S}}^{\mathrm{FW}}\right) \\
& \times\left(\frac{\partial g^{\mathrm{BSW}}}{\partial S_{\mathrm{A}}^{\mathrm{SSW}}}\right)_{S_{\mathrm{FW}}^{\mathrm{BSW}}, T, P}\left(\frac{\partial S_{\mathrm{A}}^{\mathrm{SSW}}}{\partial M_{0}^{\mathrm{BSW}}}\right)_{M_{\mathrm{S}}^{\mathrm{SSW}}} \\
& +\left(M_{0}^{\mathrm{BSW}}+M_{\mathrm{S}}^{\mathrm{SSW}}+M_{\mathrm{S}}^{\mathrm{FW}}\right) \\
& \times\left(\frac{\partial g^{\mathrm{BSW}}}{\partial S_{\mathrm{FW}}^{\mathrm{BSW}}}\right)_{S_{\mathrm{A}}^{\mathrm{SSW}}, T, P}\left(\frac{\partial S_{\mathrm{FW}}^{\mathrm{BSW}}}{\partial M_{0}^{\mathrm{BSW}}}\right)_{M_{\mathrm{S}}^{\mathrm{SSW}}, M_{\mathrm{S}}^{\mathrm{FW}},}
\end{aligned}
$$

to obtain the result

$$
\begin{aligned}
\mu_{\mathrm{W}} & =g^{\mathrm{BSW}}-\frac{S_{\mathrm{A}}^{\mathrm{SSW}}}{1-S_{\mathrm{FW}}^{\mathrm{BSW}}}\left(\frac{\partial g^{\mathrm{BSW}}}{\partial S_{\mathrm{A}}^{\mathrm{SSW}}}\right)_{S_{\mathrm{FW}}^{\mathrm{BSW}}, T, P} \\
& -S_{\mathrm{FW}}^{\mathrm{BSW}}\left(\frac{\partial g^{\mathrm{BSW}}}{\partial S_{\mathrm{FW}}^{\mathrm{BSW}}}\right)_{S_{\mathrm{A}}^{\mathrm{SSW}}, T, P} \cdot
\end{aligned}
$$

This general formula is simplified in our case using the linear expression Eq. (3.19), to give:

$\mu_{\mathrm{W}}=g^{\mathrm{SW}}-S_{\mathrm{A}}^{\mathrm{SSW}}\left(g_{S}^{\mathrm{SW}}+\frac{S_{\mathrm{FW}}^{\mathrm{BSW}}}{1-S_{\mathrm{FW}}^{\mathrm{BSW}}} g_{S}^{\mathrm{FW}}\right)$.

At the freezing point, $T_{\mathrm{f}}\left(S_{\mathrm{A}}^{\mathrm{SSW}}, S_{\mathrm{FW}}^{\mathrm{BSW}}, P\right)$, the chemical potential $\mu_{\mathrm{W}}$ equals that of ice, $\mu^{\mathrm{Ih}}$ (IAPWS, 2009b):

$\mu_{\mathrm{W}}\left(S_{\mathrm{A}}^{\mathrm{SSW}}, S_{\mathrm{FW}}^{\mathrm{BSW}}, T_{\mathrm{f}}, P\right)=\mu^{\mathrm{Ih}}\left(T_{\mathrm{f}}, P\right)$.

The Baltic Sea anomaly of the freezing temperature is shown in Fig. 15 as the difference of freezing points between the values with and without the freshwater solute, i.e., of SSW and BSW with the equal chloride molalities (roughly, equal Chlorinities),

$\delta T=T_{\mathrm{f}}\left(S_{\mathrm{A}}^{\mathrm{SSW}}, S_{\mathrm{FW}}^{\mathrm{BSW}}, P_{\mathrm{SO}}\right)-T_{\mathrm{f}}\left(S_{\mathrm{A}}^{\mathrm{SSW}}, 0, P_{\mathrm{SO}}\right)$

as a function of Density Salinity, computed from Eqs. (5.4) and (5.5). For comparison, the anomaly is estimated by Millero's Rule using Density Salinity $S_{\mathrm{D}}$, Eq. (5.1), from

$\delta T^{\mathrm{D}}=T_{\mathrm{f}}\left(S_{\mathrm{D}}, 0, P_{\mathrm{SO}}\right)-T_{\mathrm{f}}\left(S_{\mathrm{A}}^{\mathrm{SSW}}, 0, P_{\mathrm{SO}}\right)$

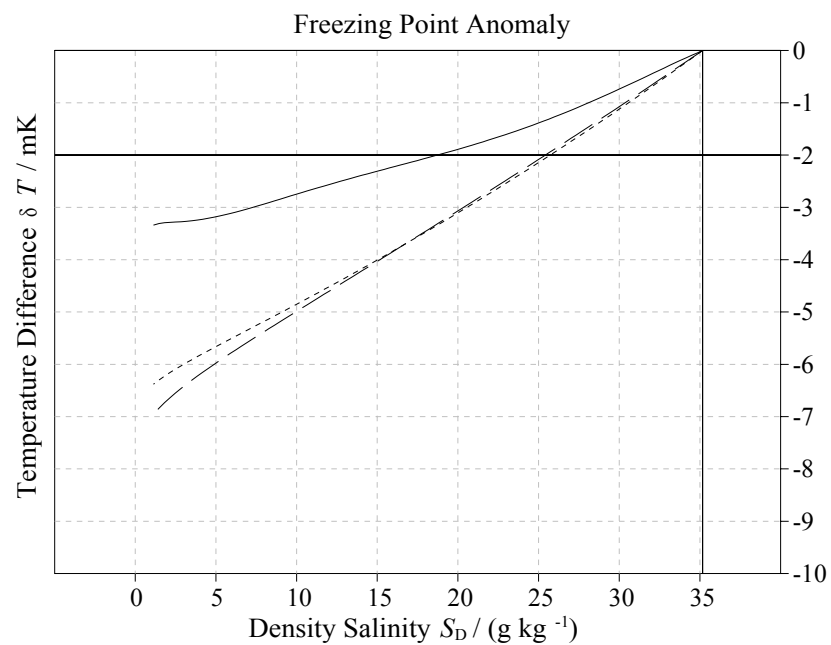

Fig. 15. Difference $\delta T$, Eq. (5.30), between the freezing temperature (solid line) with and without the freshwater solute for Baltic seawater at the standard ocean surface pressure, in comparison to estimates from Millero's Rule, $\delta T^{\mathrm{D}}$, based on Density Salinity (dashed line), Eq. (5.31), and $\delta T^{\mathrm{A}}$, based on Absolute Salinity (dotted line), Eq. (5.32). For the latter two, the responsible difference between $S_{\mathrm{A}}^{\mathrm{BSW}}$ and $S_{\mathrm{D}}$ is shown in Fig. 8. The experimental uncertainty of the freezing temperature of seawater is $2 \mathrm{mK}$, indicated by the solid horizontal line.

and using Absolute Salinity, $S_{\mathrm{A}}^{\mathrm{BSW}}$, Eq. (3.21),

$\delta T^{\mathrm{A}}=T_{\mathrm{f}}\left(S_{\mathrm{A}}^{\mathrm{BSW}}, 0, P_{\mathrm{SO}}\right)-T_{\mathrm{f}}\left(S_{\mathrm{A}}^{\mathrm{SSW}}, 0, P_{\mathrm{SO}}\right)$

The experimental uncertainty of the freezing temperature of seawater is $2 \mathrm{mK}$. The anomaly is of the same order of magnitude and can normally be ignored. Millero's Rule does not provide much improvement over neglecting the anomalies.

The vapour pressure of Baltic seawater, $P^{\mathrm{vap}}\left(S_{\mathrm{A}}^{\mathrm{SSW}}, S_{\mathrm{FW}}^{\mathrm{BSW}}, T\right)$, is computed from the condition that the chemical potential of water in seawater, $\mu_{\mathrm{W}}$, eq. (5.28), equals that of vapour, $g^{\mathrm{V}}$ (IAPWS, 2009a, Feistel et al., 2010b):

$\mu_{\mathrm{W}}\left(S_{\mathrm{A}}^{\mathrm{SSW}}, S_{\mathrm{FW}}^{\mathrm{BSW}}, T, P^{\mathrm{vap}}\right)=g^{\mathrm{V}}\left(T, P^{\mathrm{vap}}\right)$.

The Baltic Sea anomaly of the vapour pressure is shown in Fig. 16 as the difference of pressures between the values with and without the freshwater solute, i.e., of SSW and BSW with the equal chloride molalities (roughly, equal Chlorinities),

$\delta P=P^{\mathrm{vap}}\left(S_{\mathrm{A}}^{\mathrm{SSW}}, S_{\mathrm{FW}}^{\mathrm{BSW}}, T\right)-P^{\mathrm{vap}}\left(S_{\mathrm{A}}^{\mathrm{SSW}}, 0, T\right)$

as a function of Density Salinity, computed from Eqs. (5.4) and (5.5). For comparison, the anomaly is estimated by Millero's Rule using Density Salinity $S_{\mathrm{D}}$, Eq. (5.1), from

$\delta P^{\mathrm{D}}=P^{\mathrm{vap}}\left(S_{\mathrm{D}}, 0, T\right)-P^{\mathrm{vap}}\left(S_{\mathrm{A}}^{\mathrm{SSW}}, 0, T\right)$ 


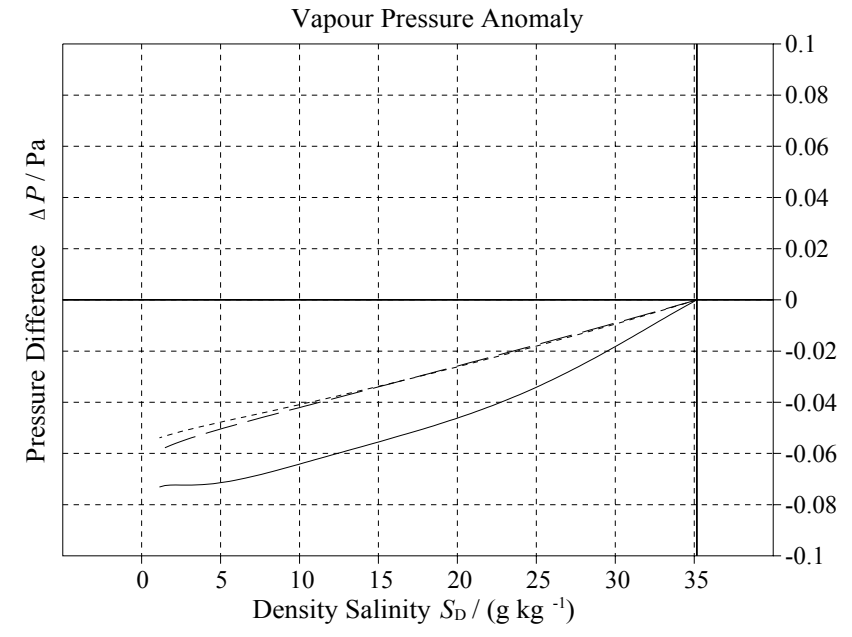

Fig. 16. Difference $\delta P$, Eq. (5.34), between the vapour pressures (solid line) with and without the freshwater solute for Baltic seawater at $20^{\circ} \mathrm{C}$, in comparison to estimates from Millero's Rule, $\delta P^{\mathrm{D}}$, based on Density Salinity (dashed line), Eq. (5.35), and $\delta P^{\mathrm{A}}$, based on Absolute Salinity (dotted line), Eq. (5.36). For the latter two, the responsible difference between $S_{\mathrm{A}}^{\mathrm{BSW}}$ and $S_{\mathrm{D}}$ is shown in Fig. 8 . The related experimental uncertainty is $0.02 \%$ or $0.4 \mathrm{~Pa}$, well beyond the range of this graph.

and using Absolute Salinity, $S_{\mathrm{A}}^{\mathrm{BSW}}$, Eq. (3.21),

$\delta P^{\mathrm{A}}=P^{\mathrm{vap}}\left(S_{\mathrm{A}}^{\mathrm{BSW}}, 0, T\right)-P^{\mathrm{vap}}\left(S_{\mathrm{A}}^{\mathrm{SSW}}, 0, T\right)$.

The anomalies shown in Fig. 16 are a factor of 10 smaller than the uncertainty of the most accurate experimental data (Robinson, 1954; Feistel, 2008).

The "measured" Density Salinity $S_{\mathrm{D}}$ is given by Eq. (5.1) as a function of $S_{\mathrm{A}}^{\mathrm{SSW}}, S_{\mathrm{FW}}^{\mathrm{BSW}}, T$ and $P$. When a sample's temperature is changing, its molalities $m_{\mathrm{Cl}}$ and $\delta m_{\mathrm{Ca}}$ are conservative, and so are the salinities $S_{\mathrm{A}}^{\mathrm{SSW}}$ and $S_{\mathrm{FW}}^{\mathrm{BSW}}$ computed from Eqs. (4.4) and (4.6). On the contrary, Density Salinity, Eq. (5.1), is not strictly conservative unless the thermal expansion coefficient and compressibility of BSW happen to be exactly the same as those for SSW. Figure 17 shows the salinity difference

$$
\begin{aligned}
\Delta S_{\mathrm{D}}(t) & =S_{\mathrm{D}}\left(S_{\mathrm{A}}^{\mathrm{SSW}}, S_{\mathrm{FW}}^{\mathrm{BSW}}, T_{\mathrm{SO}}+t, P_{\mathrm{SO}}\right) \\
& -S_{\mathrm{D}}\left(S_{\mathrm{A}}^{\mathrm{SSW}}, S_{\mathrm{FW}}^{\mathrm{BSW}}, T_{\mathrm{SO}}+25^{\circ} \mathrm{C}, P_{\mathrm{SO}}\right)
\end{aligned}
$$

as a function of the Density Salinity at $25^{\circ} \mathrm{C}$ for typical Baltic anomaly pairs of $S_{\mathrm{A}}^{\mathrm{SSW}}$ and $S_{\mathrm{FW}}^{\mathrm{BSW}}$ computed from Eqs. (5.4) and (5.5). Figure 17 is similar to Fig. 8 in which $S_{\mathrm{FW}}^{\mathrm{BSW}}$ is conservative with respect to the temperature. Density Salinities are less sensitive to temperature changes than density measurements but may need to be stored together with the temperature at which they were determined. Note that the mass fraction of anomalous solute in Baltic seawater is larger than that present anywhere in the deep ocean. For a typical Baltic Sea salinity of $8 \mathrm{~g} \mathrm{~kg}^{-1}$ the mass

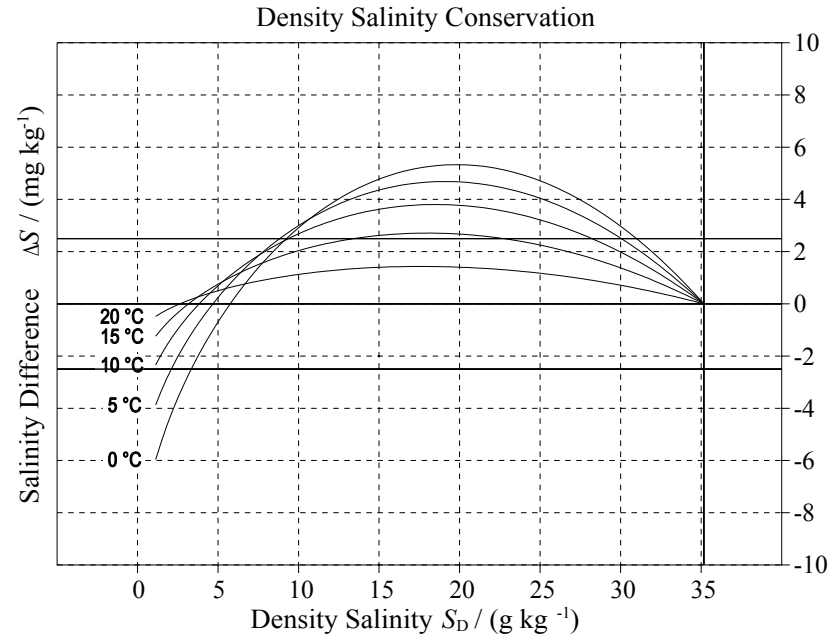

Fig. 17. Difference $\Delta S_{\mathrm{D}}(t)$, Eq. (5.37), between the Density Salinities computed at different temperatures from Eq. (5.1) at the same mass-fraction salinities $S_{\mathrm{A}}^{\mathrm{SSW}}$ and $S_{\mathrm{FW}}^{\mathrm{BSW}}$, as a function of the Density Salinity at $25^{\circ} \mathrm{C}$. The uncertainty of Density Salinity measurements is $2 \mathrm{~g} \mathrm{~m}^{-3} /(\beta \rho)=2.5 \mathrm{mg} \mathrm{kg}^{-1}$ (Feistel et al., 2010a), indicated by solid horizontal lines.

fraction of anomalous solute is approximately $0.004 \times(35-$ 8) $\mathrm{g} \mathrm{kg}^{-1}=0.108 \mathrm{~g} \mathrm{~kg}^{-1}$, about 7 times as large as the maximum mass fraction of anomalous solute in the deep North Pacific where composition anomalies are largest in the open ocean.

Even though the temperature dependence is not very strong, Wright et al. (2010a) define a conservative, "potential" Density Salinity, $S_{\mathrm{A}}^{\mathrm{dens}}$, by the Eq. (5.1) used at the reference point $T=298.15 \mathrm{~K}$ and $P=101325 \mathrm{~Pa}$.

$$
\begin{gathered}
g_{P}^{\mathrm{BSW}}\left(S_{\mathrm{A}}^{\mathrm{SSW}}, S_{\mathrm{FW}}^{\mathrm{BSW}}, T_{\mathrm{SO}}+25^{\circ} \mathrm{C}, P_{\mathrm{SO}}\right) \\
=g_{P}^{\mathrm{SW}}\left(S_{\mathrm{A}}^{\mathrm{dens}}, T_{\mathrm{SO}}+25^{\circ} \mathrm{C}, P_{\mathrm{SO}}\right) .
\end{gathered}
$$

By definition, this value remains the same for a parcel when the temperature or the pressure is changing without exchange of matter. As a consequence, the density deviation

$$
\Delta \rho=\frac{1}{g_{P}^{\mathrm{BSW}}\left(S_{\mathrm{A}}^{\mathrm{SSW}}, S_{\mathrm{FW}}^{\mathrm{BSW}}, T, P\right)}-\frac{1}{g_{P}^{\mathrm{SW}}\left(S_{\mathrm{A}}^{\mathrm{dens}}, T, P\right)}
$$

is not necessarily zero for temperatures different from $25^{\circ} \mathrm{C}$; typical results are shown in Fig. 18. These density errors are relatively small in comparison to the typical Baltic density anomalies of 50-100 $\mathrm{g} \mathrm{m}^{-3}$ that are associated with fresh water solute (Fig. 9).

The anomalies discussed in this section describe the differences between thermodynamic properties of BSW and of SSW if both have the same Absolute Salinity of the SSW part, $S_{\mathrm{A}}^{\mathrm{SSW}}$. For a given sample of BSW, $S_{\mathrm{A}}^{\mathrm{SSW}}$ can for instance be determined from a Chlorinity measurement. This is expensive and time-consuming, cannot be carried out in 
situ and usually requires skilled personnel, in contrast to routine CTD casts that automatically produce in-situ readings of Practical Salinity, $S_{\mathrm{P}}$. Due to the electrolytic conductivity of the freshwater solute, the relation between $S_{\mathrm{A}}^{\mathrm{SSW}}$ and $S_{\mathrm{P}}$ of BSW is influenced by a significant anomaly that cannot be estimated from the Gibbs function $g^{\mathrm{BSW}}$. This problem is addressed in the following section.

\section{Anomalies of Conductivity, Practical Salinity and Reference Salinity}

Conductivity is a non-equilibrium, transport property of seawater and is not available either from the TEOS-10 Gibbs function, or from the FREZCHEM model, which provides only equilibrium thermodynamic properties. Since Practical Salinity, the currently most important solute concentration measure in oceanography, is determined from conductivity measurements, it is important to estimate the effects of the Baltic composition anomaly on measured conductivities. This conductivity effect could reduce or increase the difference between the actual thermodynamic properties of Baltic water and those determined for Standard Seawater diluted to the same conductivity, relative to the differences between the actual thermodynamic properties of Baltic water and those determined for Standard Seawater diluted to the same chloride molality which were discussed previously in Sect. 5 . These property differences for waters of the same conductivity will be discussed in Sect. 7, once we have determined how conductivity is affected by the composition changes present in the Baltic. In addition, predictions of conductivity also allow us to validate at least some of the model calculations against actual observations.

At present, theoretical models of aqueous solution conductivity, based on arbitrary chemical composition, are not accurate enough to study the Baltic (or any other) anomalous seawater directly. However, the composition/conductivity theory of Pawlowicz (2008), which is valid for conductivities in limnological low salinity situations, has been adapted (Pawlowicz, 2009; Pawlowicz et al., 2010) using a linearization about the known characteristics of Standard Seawater to study changes in composition/conductivity/density relationships in seawater, arising from small composition perturbations that originate from biogeochemical processes. This linearization approach, implemented in the numerical model LSEA_DELS, is now used to investigate changes in the relationship between Chlorinity and conductivity-based Reference Salinity, using our idealized model of the Baltic composition anomaly, Eq. (1.1). All considerations in this section refer to conditions at an arbitrary temperature, set to $25^{\circ} \mathrm{C}$ unless otherwise specified, and atmospheric pressure, $P=101325 \mathrm{~Pa}$. However, these parameters are omitted from the formulas for notational simplicity.

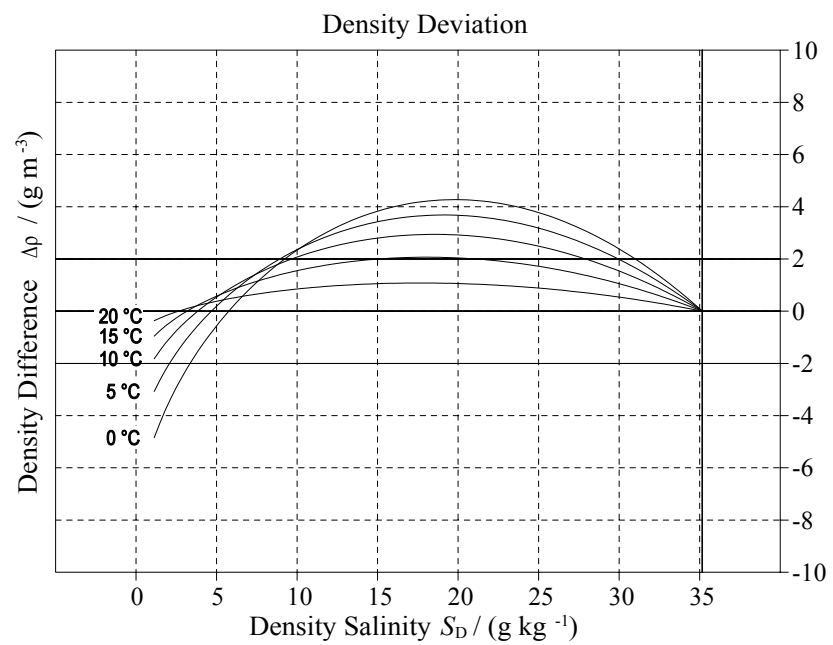

Fig. 18. Deviation (5.37) between the density of Baltic seawater and the density computed from conservative Density Salinity, $S_{\mathrm{A}}^{\text {dens }}$, Eq. (5.38). The experimental uncertainty of density measurements is $2 \mathrm{ppm}$ (Feistel et al., 2010a), indicated by the solid lines.

\subsection{Definitions}

The starting point of simulations is a composition vector $C^{\mathrm{SSW}}$, specifying the molar composition of all constituents in a base seawater. In contrast to the development in Sect. 2, but more straightforwardly linked to the structure of the Gibbs function (3.19), this base seawater is not an "ocean end member" with $S_{\mathrm{P}}=35$. Instead, it is SSW diluted by the addition of pure water so that chloride molality will remain unchanged as the calcium carbonate solute is "added" to create Baltic water. The conductivity $\kappa^{\mathrm{SSW}}=\kappa\left(\boldsymbol{C}^{\mathrm{SSW}}\right)$ and density $\rho^{\mathrm{SSW}}=\rho\left(\boldsymbol{C}^{\mathrm{SSW}}\right)$ of this water depend on the composition, and the true mass fraction of dissolved material (Solution Salinity) will be $S_{\mathrm{A}}^{\mathrm{SSW}}$. Since this water is just a dilution of SSW, the Reference Salinity:

$S_{\mathrm{R}}^{\mathrm{SSW}}=u_{\mathrm{P}} S_{\mathrm{P}}\left(\kappa^{\mathrm{SSW}}\right)$,

based on using the observed conductivity in the algorithm $S_{\mathrm{P}}($.$) specified by the Practical Salinity Scale 1978$, is scaled by an appropriate choice of the constant $u_{\mathrm{P}}$ to give the Solution Salinity $S_{\mathrm{A}}^{\mathrm{SSW}}$. The factor $u_{\mathrm{P}}$ is not exactly the same as $u_{\mathrm{PS}}$ when anomalies are being calculated because LSEA_DELS calculations are based on a SSW composition model that slightly differs from the RC (Wright et al., 2010a).

The composition of Baltic seawater is described by the composition vector $\boldsymbol{C}^{\mathrm{BSW}}$. Exact details of the way in which $\boldsymbol{C}^{\mathrm{BSW}}$ is related to $\boldsymbol{C}^{\mathrm{SSW}}$ are discussed in Section 6.2, but both compositions have the same chloride molality. The composition $\boldsymbol{C}^{\mathrm{BSW}}$ has a Solution Salinity $S_{\mathrm{A}}^{\mathrm{BSW}}$, a conductivity $\kappa^{\mathrm{BSW}}=\kappa\left(\boldsymbol{C}^{\mathrm{BSW}}\right)$ and a density $\rho^{\mathrm{BSW}}=\rho\left(\boldsymbol{C}^{\mathrm{BSW}}\right)$ that will differ from that of the base seawater. All of these parameters can be estimated using LSEA_DELS once the 
compositions are known. The change

$\delta \rho=\rho^{\mathrm{BSW}}-\rho^{\mathrm{SSW}}$

as computed from the model results is then directly comparable to that calculated using Eq. (5.6). This parameter can therefore be used to validate the densities calculated by LSEA_DELS against the Gibbs function (itself based on FREZCHEM model calculations). In addition, the change in Solution Salinity between the original base seawater and the Baltic water is, Eq. (3.21):

$S_{\mathrm{A}}^{\mathrm{BSW}}-S_{\mathrm{A}}^{\mathrm{SSW}} \approx S_{\mathrm{FW}}^{\mathrm{BSW}}$.

The approximation is valid when the amount of solute added is small, as it is in this case.

Typically, conductivity measurements in the ocean are used with SSW parameterizations for different properties under the assumption that the properties of the measured water are well-modelled by the properties of SSW diluted to the same conductivity. Thus we infer a third "reference" water type, described by a composition vector $\boldsymbol{C}_{\mathrm{R}}^{\mathrm{BSW}}$, with Solution Salinity $S_{\mathrm{R}}^{\mathrm{BSW}}$, whose composition is that of SSW diluted by pure water, but whose conductivity matches that of BSW: $\kappa\left(\boldsymbol{C}_{\mathrm{R}}^{\mathrm{BSW}}\right)=\kappa\left(\boldsymbol{C}^{\mathrm{BSW}}\right)$. The Solution Salinity of the reference water is then the Reference Salinity of the Baltic Sea water. The ultimate purpose of the modelling in this section is then to compare the change in the Reference Salinity

$\Delta S_{\mathrm{R}}=S_{\mathrm{R}}^{\mathrm{BSW}}-S_{\mathrm{R}}^{\mathrm{SSW}}$

between Baltic Sea water and diluted Standard Seawater of the same conductivity with the actual Solution Salinity change $S_{\mathrm{FW}}^{\mathrm{BSW}}$ from Eq. (6.3). If the added solute has the same conductivity as that of sea salt, then $\Delta S_{\mathrm{R}}=S_{\mathrm{FW}}^{\mathrm{BSW}}$. If the added solute is not conductive, then $\Delta S_{\mathrm{R}}=0$, irrespective of the value of $S_{\mathrm{FW}}^{\mathrm{BSW}}$.

In addition, the density of this reference water, denoted as the reference density $\rho_{\mathrm{R}}^{\mathrm{BSW}}=\rho\left(\boldsymbol{C}_{\mathrm{R}}^{\mathrm{BSW}}\right)$, will differ from the true density of Baltic water $\rho^{\mathrm{BSW}}$, and the change

$\delta \rho_{\mathrm{R}}=\rho^{\mathrm{BSW}}-\rho_{\mathrm{R}}^{\mathrm{BSW}}$

between the true and reference densities can then be directly compared with measurements of the density anomaly in the Baltic. Previous investigations have suggested that LSEA_DELS calculations for $\Delta S_{\mathrm{R}}$ have an error of between 1 and $10 \%$, depending on the details of the composition anomaly. This uncertainty ultimately arises from uncertainties in the basic chemical data for binary electrolytes from which model parameters for the conductivity algorithm were extracted, as well as inadequacies in the theoretical basis of the model at higher salinities. Errors in the LSEA_DELS density algorithms are themselves much smaller than those for conductivities, but since the Reference Salinity calculation implicitly involves conductivity changes, errors in conductivity will carry over into the density anomaly calculation.
The calculations described above can be carried out at any desired temperature. However, the temperature-dependence of the conductivity and density of seawaters may also vary with the composition anomaly. This implies that the value of $S_{\mathrm{R}}^{\mathrm{BSW}}$ as calculated above may have a slight temperature dependence. For Baltic seawater, this non-conservative effect was shown experimentally to remain within the measurement uncertainty (Feistel and Weinreben, 2008), and neglect of this effect is also supported by numerical experimentation with LSEA_DELS, which suggest the maximum error is less than $0.001 \mathrm{~g} \mathrm{~kg}^{-1}$.

\subsection{Composition anomalies}

Although the Baltic Sea composition anomaly is idealized in this paper as arising from the addition of calcium carbonate, calcium itself is not directly measured in the Baltic. However, anomalies in the Total Alkalinity (TA), defined in LSEA_DELS as

$$
\mathrm{TA}=\left[\mathrm{HCO}_{3}^{-}\right]+2\left[\mathrm{CO}_{3}^{2-}\right]+\left[\mathrm{B}(\mathrm{OH})_{4}^{-}\right]+\left[\mathrm{OH}^{-}\right]-\left[\mathrm{H}^{+}\right]
$$

and Dissolved Inorganic Carbon (DIC), defined as

$\mathrm{DIC}=\left[\mathrm{CO}_{2}\right]+\left[\mathrm{HCO}_{3}^{-}\right]+\left[\mathrm{CO}_{3}^{2-}\right]$,

are known to be approximately equal. In this section, the usual chemical notation of total stoichiometric molalities by brackets [..] is preferred for convenience. Thus we assume for the anomalies

$\delta \mathrm{TA}=\delta \mathrm{DIC}$.

The addition of $\mathrm{Ca}^{2+}$ is then inferred from mass and charge balance considerations:

$\delta m_{\mathrm{Ca}} \equiv\left[\mathrm{Ca}^{2+}\right]=\delta \mathrm{TA} / 2$.

Using Eqs. (6.6)-(6.9), the complete composition at any particular chloride molality can be determined as a function of the molality of the calcium anomaly. This will provide a direct comparison with the Gibbs function described in Sect. 4.

In order to apply these calculations specifically to the Baltic (i.e. as in Sect. 5), we relate some parameter to a function of the chloride salinity $S_{\mathrm{Cl}}$ (or, alternatively, any other salinity measure) in the Baltic. The value of $\delta \mathrm{TA}$ at a chloride salinity of zero, which is taken as an endpoint of linear correlations in mixing diagrams, is estimated from observations to be $1470 \mu \mathrm{mol} \mathrm{kg}^{-1}$ (Feistel et al., 2010a). The TA anomaly in Baltic waters is then

$$
\delta \mathrm{TA}=1470 \mu \mathrm{mol} \mathrm{kg}{ }^{-1} \times\left(1-\frac{S_{\mathrm{Cl}}}{S_{\mathrm{SO}}}\right)
$$

Eqs. (6.8)-(6.10), hereafter denoted as "model-1", then specify the composition $\boldsymbol{C}^{\mathrm{BSW}}$ of Baltic water at all chloride 

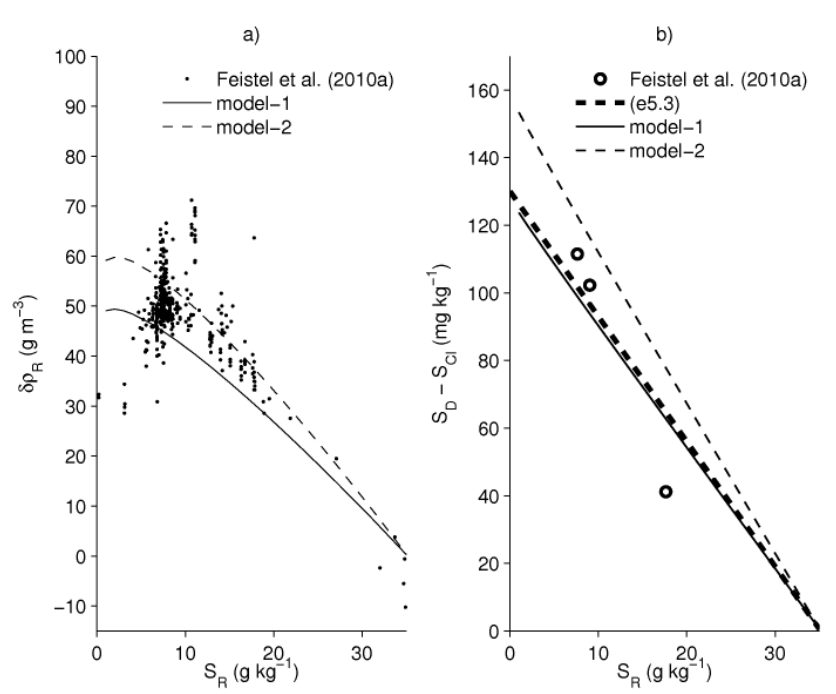

Fig. 19. (a) Comparison between 437 measured density anomalies (Feistel et al., 2010a), with LSEA_DELS model predictions. (b) Comparison of model results with 3 observational estimates of the anomalies between Density Salinity $S_{\mathrm{D}}$ and the Chlorinity Salinity $S_{\mathrm{Cl}}$ (Feistel et al., 2010a) as well as Eq. (5.3), and model predictions.

molalities. However, the composition is only specified in terms of aggregate variables TA and DIC. A carbonate chemistry model within LSEA_DELS, based on equations for the equilibrium chemistry, is used to calculate the complete ionic chemical composition in a new chemical equilibrium. This involves changes to $\mathrm{CO}_{2}, \mathrm{HCO}_{3}^{-}, \mathrm{CO}_{3}^{2-}, \mathrm{B}(\mathrm{OH})_{3}$ and $\mathrm{B}(\mathrm{OH})_{4}^{-}$, as well as to $\mathrm{pH}$ and $p \mathrm{CO}_{2}$. Although the actual compositional perturbation is now somewhat more complex than indicated by Eq. (1.1) almost all of the change that occurs at the $\mathrm{pH}$ of seawater is described by an increase in $\mathrm{HCO}_{3}^{-}$, similar in LSEA_DEL and in FREZCHEM. From Eqn. (1.1), the change in Solution Salinity due to the added mass of dissolved solute is $S_{\mathrm{FW}}^{\mathrm{BSW}} \approx 162.1 \mathrm{~g} \mathrm{~mol}^{-1} \times \delta m_{\mathrm{Ca}}$ (i.e., the molar mass of $\mathrm{Ca}\left(\mathrm{HCO}_{3}\right)_{2}$ times the change in calcium molality, neglecting the change in the mass of solution). The change in Solution Salinity calculated directly from the full chemical compositions used by LSEA_DELS is less than $3 \%$ larger than this value, which is insignificant here in comparison with other uncertainties. This procedure allows us to determine the conductivity and density anomalies at a particular $S_{\mathrm{Cl}}$ within the Baltic.

Later we will discuss whether disagreements between the model predictions and observations of density anomalies arise from inadequacies in LSEA_DELS, or whether they are inherent to the idealized composition anomaly used to model Baltic seawater. For this purpose we introduce a second model for composition anomalies in the Baltic that is slightly more complex. Sulfate is the next largest component of the actual Baltic composition anomaly after calcium carbonate. The sulfate anomaly is estimated (Feistel et al., 2010a) to have a zero-Chlorinity limit of about $166 \mu \mathrm{mol} \mathrm{kg}^{-1}$ (with a considerable uncertainty),

$\delta\left[\mathrm{SO}_{4}^{2-}\right]=166 \mu \mathrm{mol} \mathrm{kg}^{-1} \times\left(1-\frac{S_{\mathrm{Cl}}}{S_{\mathrm{SO}}}\right)$.

With anomalies in both $\mathrm{Ca}^{2+}$ and $\mathrm{SO}_{4}^{2-}$, charge balance considerations now require a modification to Eq. (6.9) to balance the charge associated with the sulfate anomaly,

$\delta\left[\mathrm{Ca}^{2+}\right]-\delta\left[\mathrm{SO}_{4}^{2-}\right]=\delta \mathrm{TA} / 2$,

which will increase the size of the calcium anomaly. The combined calcium carbonate and sulfate anomaly, Eqs. (6.10), (6.11) and (6.12), will be denoted "model-2" for Baltic water.

\subsection{Model validation}

Although the model/data predictions will be shown to be in rough agreement, it is useful at this stage to enumerate possible sources of disagreement. The first potential source of disagreement is the error in density anomaly predictions from the conductivity model, which can themselves be in error by as much as $10 \%$ for a given composition anomaly. The second potential source is the idealization of the composition anomaly, which is only a simplified version of the true Baltic composition anomaly. This error can be investigated by comparing model-1 and model-2 predictions. A third potential source of disagreement is inhomogeneities in the chemical composition of the Baltic, which will tend to scatter results at a particular Chlorinity over a wider range than predicted by measurement uncertainty alone. A final potential source of disagreement is measurement uncertainty in the data itself.

Feistel et al. (2010a) report 437 observations of the density anomaly $\delta \rho_{\mathrm{R}}$ in the Baltic Sea over the years 2006-2008, mostly at salinities of $10-20 \mathrm{~g} \mathrm{~kg}^{-1}$. 66 of these replicate measurements on water were obtained from 11 stations. The observations (Fig. 19a) show a large scatter. Part of this scatter arises from observational error in the density measurements, which can be estimated at about $\pm 9 \mathrm{~g} \mathrm{~m}^{-3}$ (coverage factor 2) from replicate values about the means. However, scatter in excess of this value is present. The additional scatter likely derives from spatial variations in the magnitude and composition of the anomaly. The concentrations of TA in different rivers inflowing into the Baltic can vary by an order of magnitude, and these effects are not always well-mixed within the Baltic. In addition, the solute is subject to various complex chemical processes and interaction with the sediment over the residence time of 20-30 years.

In general, model calculations of $\delta \rho_{\mathrm{R}}$ using either model1 or model-2 are quite consistent with the observations (Fig. 19a), within the limits of observational uncertainty and presumed spatial inhomogeneity. LSEA_DELS predicts an anomaly of zero at $S_{\mathrm{R}}=35.16504 \mathrm{~g} \mathrm{~kg}^{-1}$, rising to 48 and $58 \mathrm{~g} \mathrm{~m}^{-3}$ for model-1 and model-2 anomalies respectively, 
at $S_{\mathrm{R}}=5 \mathrm{~g} \mathrm{~kg}^{-1}$. The scatter in the observations is large enough that it is not clear which of the two models better describes the data. The model- 2 results fall somewhat closer to the raw data at salinities of $15-20 \mathrm{~g} \mathrm{~kg}^{-1}$. On the other hand, although both models predict much larger density differences than are observed at salinities $<5 \mathrm{~g} \mathrm{~kg}^{-1}$, the comparison is better for model-1. It should be noted that the small number of observations in this low-salinity range are from the Gulfs of Bothnia and Finland (Feistel et al., 2010a), Fig. 1, which are not representative of the freshwater inflows as a whole. Hence, complete agreement is not expected. We conclude that spatial inhomogeneities in the composition anomalies are likely the limiting factor in the present model/data comparison, rather than the accuracy of LSEA_DEL itself.

The LSEA_DELS calculations for both model-1 and model-2 anomalies suggest that $\delta \rho_{\mathrm{R}}$ is not a linear function of the salinity, but rather one with a pronounced downward curvature, especially at low salinities. The curvature is large enough that there is little change in predicted anomalies at salinities less than $5 \mathrm{~g} \mathrm{~kg}^{-1}$. This downward curvature is somewhat consistent with the low density anomalies observed for $S_{\mathrm{R}}<5 \mathrm{~g} \mathrm{~kg}^{-1}$, although as just discussed the lack of data makes it unlikely that the observed values are completely representative of mean Baltic values. The curvature in the model results arises because conductivity changes will account for an increasingly large proportion of the total salinity change at low salinities, although this will not become clear until Sect. 6.4.

The $\delta \rho_{\mathrm{R}}$ observations are derived from measurements of density and conductivity. A small number of measurements were also made of density and Chlorinity in 2008 (Feistel et al., 2010a). Comparison of differences between Density Salinity and Chlorinity Salinity from these observations (Fig. 19b) against predictions using model-1 and model-2 anomalies again shows reasonably good agreement, with predictions using model- 1 anomalies closer to the approximate empirical parameterization, Eq. (5.3). In this case, conductivity effects are not involved and the model curves are nearly straight lines, deriving from the straight lines in Eqs. (6.10) and (6.11). Although the expanded uncertainty (coverage factor 2) of the Chlorinity measurements is about $0.5 \%$ (Feistel et al., 2010a), the relationships, Eqs. (6.10), (6.11) are themselves fits to scattered data (again probably reflecting inhomogeneities in the Baltic's chemical composition), so better agreement is not expected.

The LSEA_DELS model calculations for $\delta \rho_{\mathrm{R}}$, Eq. (6.2), using model-1 anomalies can also be compared directly (Fig. 20) against calculations from the Gibbs function, Eq. (5.6), with the Baltic anomaly being modelled using Eq. (5.4). This is a complete intercomparison of not only the density algorithms but also different approaches for specifying the composition anomalies. The two independent calculations agree quite well, with values being within $6 \mathrm{~g} \mathrm{~m}^{-3}$ of each other at all temperatures.

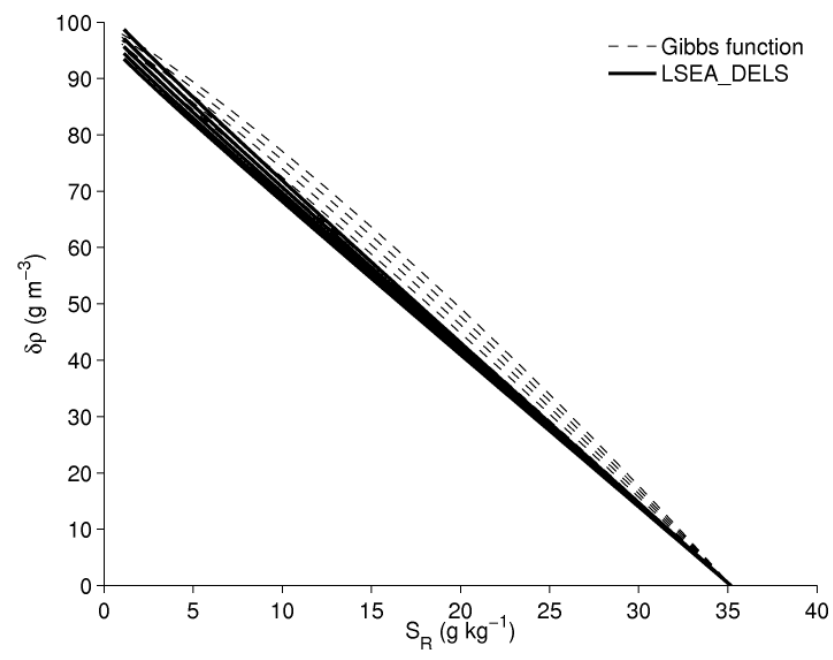

Fig. 20. Comparison of the density anomalies between SSW and Baltic seawater of the same chloride molality, computed by the Gibbs function and by LSEA_DELS. Curves are drawn for temperatures of $0,5,10,15$, and $20^{\circ} \mathrm{C}$, with the highest curves corresponding to the lowest temperatures.

\subsection{Corrections to Practical Salinity required for Gibb function calculations}

The Gibbs function determined in Sect. 4 is a function of chloride molality and the calcium anomaly, or equivalently $S_{\mathrm{A}}^{\mathrm{SSW}}$ and $S_{\mathrm{FW}}^{\mathrm{BSW}}$. In this section we determine a correction factor for conductivity effects as a function of the same parameters using LSEA_DELS with the model-1 parameterization.

First, calculating $\Delta S_{\mathrm{R}}$, Eq. (6.13), for a grid of points in the range $0<S_{\mathrm{Cl}}<35 \mathrm{~g} \mathrm{~kg}^{-1}$ and $0<\delta m_{\mathrm{Ca}}<$ $800 \mu \mathrm{mol} \mathrm{kg}{ }^{-1}$, we find that the calculated change in conductivity-based Reference Salinity, decreases significantly for a fixed $\delta m_{\mathrm{Ca}}$ as the salinity increases (Fig. 21). This reflects a commonly observed phenomenon that the conductivity per mole of charges (the equivalent conductivity), decreases as concentrations increase in solutions where the amount of solute is much less than the amount of solvent (Pawlowicz, 2008). The physical effects which reduce electrolytic conductivity are the relaxation force, electrophoresis and ion association; each of them tends to strengthen with increasing ion concentration (Ebeling et al., 1977, 1979). This change is largest at the lowest concentrations, with the decreases from its infinite dilution endpoint being proportional to $\sqrt{S_{\mathrm{Cl}}}$ in this limit, in accordance with limiting laws.

At lower temperatures, $\Delta S_{\mathrm{R}}$ for a given addition $\delta m_{\mathrm{Ca}}$ is slightly larger than at higher temperatures. However, at all temperatures the changes $\Delta S_{\mathrm{R}}$ are almost perfectly proportional to the magnitude of the composition anomaly. Thus, similar to the Gibbs function anomaly, Eqs. (3.14), (3.19), the salinity change estimate based on conductivity, $\Delta S_{\mathrm{R}}$, can 
Table 3. Coefficients of the correlation function $f$, Eq. (6.14).

\begin{tabular}{cccccc}
\hline$i$ & $j$ & $a i j$ & $i$ & $j$ & $a i j$ \\
\hline 0 & 0 & +0.578390505245625 & 0 & 1 & -0.000180931852871 \\
1 & 0 & -0.089779871747927 & 1 & 1 & -0.000294811756809 \\
2 & 0 & -0.001654733793251 & 2 & 1 & -0.000012798749635 \\
3 & 0 & +0.012951706126954 & 3 & 1 & +0.000079702941453 \\
\hline
\end{tabular}

be accurately expressed as the product of a function, $f$, that depends only on the salinity associated with the base seawater and temperature, and the change in solute mass fraction $S_{\mathrm{FS}}^{\mathrm{BSW}}$,

$$
\Delta S_{\mathrm{R}}=f\left(S_{\mathrm{A}}^{\mathrm{SSW}}, T\right) \times S_{\mathrm{FW}}^{\mathrm{BSW}}
$$

The dependence of $f$ on both $T$ and $S_{\mathrm{Cl}}$ is shown in Fig. 21 but curves corresponding to different values of $\delta m_{\mathrm{Ca}}$ at a fixed temperature are visually indistinguishable at this scale.

As expected, the ratio of $\Delta S_{\mathrm{R}}$ to $S_{\mathrm{FW}}^{\mathrm{BSW}}$ still depends significantly on $S_{\mathrm{A}}^{\mathrm{SSW}}=S_{\mathrm{Cl}} /\left(1-S_{\mathrm{FW}}^{\mathrm{BSW}}\right) \approx S_{\mathrm{Cl}}$, Eq. (5.2), and also shows a slight temperature dependence. The results can be fit to an equation of the form,

$$
f\left(S_{\mathrm{A}}^{\mathrm{SSW}}, T\right)=\sum_{i=0}^{1}\left(a_{0 i}+a_{1 i} \sqrt{\xi}+a_{2 i} \xi \ln \xi+a_{3 i} \xi\right) \tau^{i},
$$

where the reduced variables are $\tau=(T-298.15 \mathrm{~K}) /(1 \mathrm{~K})$ and $\xi=S_{\mathrm{A}}^{\mathrm{SSW}} /\left(1 \mathrm{~g} \mathrm{~kg}^{-1}\right)$, and the coefficients $a_{i j}$ are given in Table 3. Numerical check values are available from Table A2.

The root-mean-square error of this fit is $5.3 \times 10^{-4}$, but note that the model results themselves may be biased by as much as 0.05 (i.e., 10\%). In Sect. 7, Eqs. (6.13) and (6.14) will be used in conjunction with Eq. (3.19) to determine thermodynamic anomalies for waters of a measured conductivity.

Overall, conductivity changes will account for about 30$50 \%$ of the total change in salinity resulting from the presence of the anomaly, with the lower percentages occurring at highest salinities.

It had been shown experimentally that estimates of the Practical Salinity of Baltic seawater are independent of the sample temperature, within reasonable uncertainty (Feistel and Weinreben, 2008). From Eq. (6.13) and Fig. 21 we infer a weak temperature dependence of the Reference Salinity $S_{\mathrm{R}}$ at constant $S_{\mathrm{A}}^{\mathrm{SSW}}$ and $S_{\mathrm{FW}}^{\mathrm{BSW}}$ if $S_{\mathrm{R}}=u_{\mathrm{PS}} \times S_{\mathrm{P}}$ is computed from Practical Salinity $S_{\mathrm{P}}$ of Baltic seawater. Figure 23 shows the deviation from Practical Salinity conservation,

$\delta S_{\mathrm{P}}=\left[f\left(S_{\mathrm{A}}^{\mathrm{SSW}}, T\right)-f\left(S_{\mathrm{A}}^{\mathrm{SSW}}, T_{\mathrm{SO}}+15^{\circ} \mathrm{C}\right)\right] \times S_{\mathrm{FW}}^{\mathrm{BSW}} / u_{\mathrm{PS}}$,

as a function of salinity $S_{\mathrm{A}}^{\mathrm{SSW}}$ and temperature $T$, where $S_{\mathrm{FW}}^{\mathrm{BSW}}$ is estimated from the empirical relations (5.4), (5.5), and the abscissa value from Eq. (6.13), $S_{\mathrm{R}}=S_{\mathrm{A}}^{\mathrm{SSW}}+$
$f\left(S_{\mathrm{A}}^{\mathrm{SSW}}, T\right) S_{\mathrm{FW}}^{\mathrm{BSW}}$. The model results suggest that the measured salinity will vary by no more than 0.001 over a 15 degree temperature change at Practical Salinities of 5 to 10. Experimental evidence (Feistel and Weinreben, 2008) finds that any changes are smaller than this value, i.e., the violation of conservation does not exceed the measurement uncertainty of salinity.

\section{Computation of properties from Practical Salinity readings}

Regular oceanographic practice in Baltic Sea observation (Feistel et al., 2008b) ignores composition anomalies; readings of Practical Salinity are commonly inserted directly into SSW formulas to compute seawater properties. For conductive anomalies such as in the Baltic Sea, using Practical Salinity (or Reference Salinity $S_{\mathrm{R}}$ ) rather than Chlorinity Salinity $S_{\mathrm{Cl}}$ as the input of the Gibbs function can be expected to result in a better approximation of the anomalous property (Lewis, 1981). Nevertheless, the related error in density is known from direct density measurements (Millero and Kremling, 1976; Feistel et al., 2010a). The corresponding errors of other computed properties such as sound speed, freezing point or enthalpy are simply unknown even though they may be relevant for, say, echo sounding or submarine navigation. In this section we first estimate typical errors related to this practice and eventually provide algorithms for their reduction, based on the results of the previous sections.

In Sect. 5, the deviations from SSW properties are discussed for given Density Salinities $S_{\mathrm{D}}$ which are not available from regular CTD measurements. However, our models directly estimate $S_{\mathrm{FW}}^{\mathrm{BSW}}$ and $S_{\mathrm{R}}$ as functions of $S_{\mathrm{A}}^{\mathrm{SSW}}$, so we can easily compute and display pairs $\left(\delta q_{\mathrm{R}}, S_{\mathrm{R}}\right)$ using $S_{\mathrm{A}}^{\mathrm{SSW}}$ as a running dummy variable, where $\delta q_{\mathrm{R}}$ is the error of a property computed from the Gibbs function $g^{\mathrm{BSW}}$ between the salinity pairs $\left(S_{\mathrm{A}}^{\mathrm{SSW}}, S_{\mathrm{FW}}^{\mathrm{BSW}}\right)$, the "true salinity", and $\left(S_{\mathrm{R}}\right.$, $0)$, the "conductivity salinity". At the end of this section we shall invert the relations used in this procedure in order to estimate $S_{\mathrm{A}}^{\mathrm{SSW}}$ and $S_{\mathrm{FW}}^{\mathrm{BSW}}$ from practically measured values of $S_{\mathrm{R}}$ and eventually compute more accurate property estimates from the Gibbs function $g^{\mathrm{BSW}}$, but first we consider a more theoretical approach in which $S_{\mathrm{A}}^{\mathrm{SSW}}$ is treated as if it were measured.

For a given point $\left(S_{\mathrm{A}}^{\mathrm{SSW}}, T, P\right)$, we compute the empirical Baltic Density Salinity anomaly from Eq. (5.4),

$\delta S_{\mathrm{A}}=S_{\mathrm{D}}-S_{\mathrm{A}}^{\mathrm{SSW}} \approx 130 \mathrm{mg} \mathrm{kg}^{-1} \times\left(1-\frac{S_{\mathrm{A}}^{\mathrm{SSW}}}{S_{\mathrm{SO}}}\right)$,

and in turn the anomalous salinity $S_{\mathrm{FW}}^{\mathrm{BSW}}$ from a linear expansion of Eq. (5.5) as a function of $S_{\mathrm{A}}^{\mathrm{SSW}}$,

$S_{\mathrm{FW}}^{\mathrm{BSW}}=-\frac{g_{S P}^{\mathrm{SW}}\left(S_{\mathrm{A}}^{\mathrm{SSW}}, T, P\right)}{g_{P}^{\mathrm{SW}}\left(S_{\mathrm{A}}^{\mathrm{SSW}}, T, P\right)-g_{P}^{\mathrm{FW}}\left(S_{\mathrm{A}}^{\mathrm{SSW}}, T, P\right)} \delta S_{\mathrm{A}}$. 


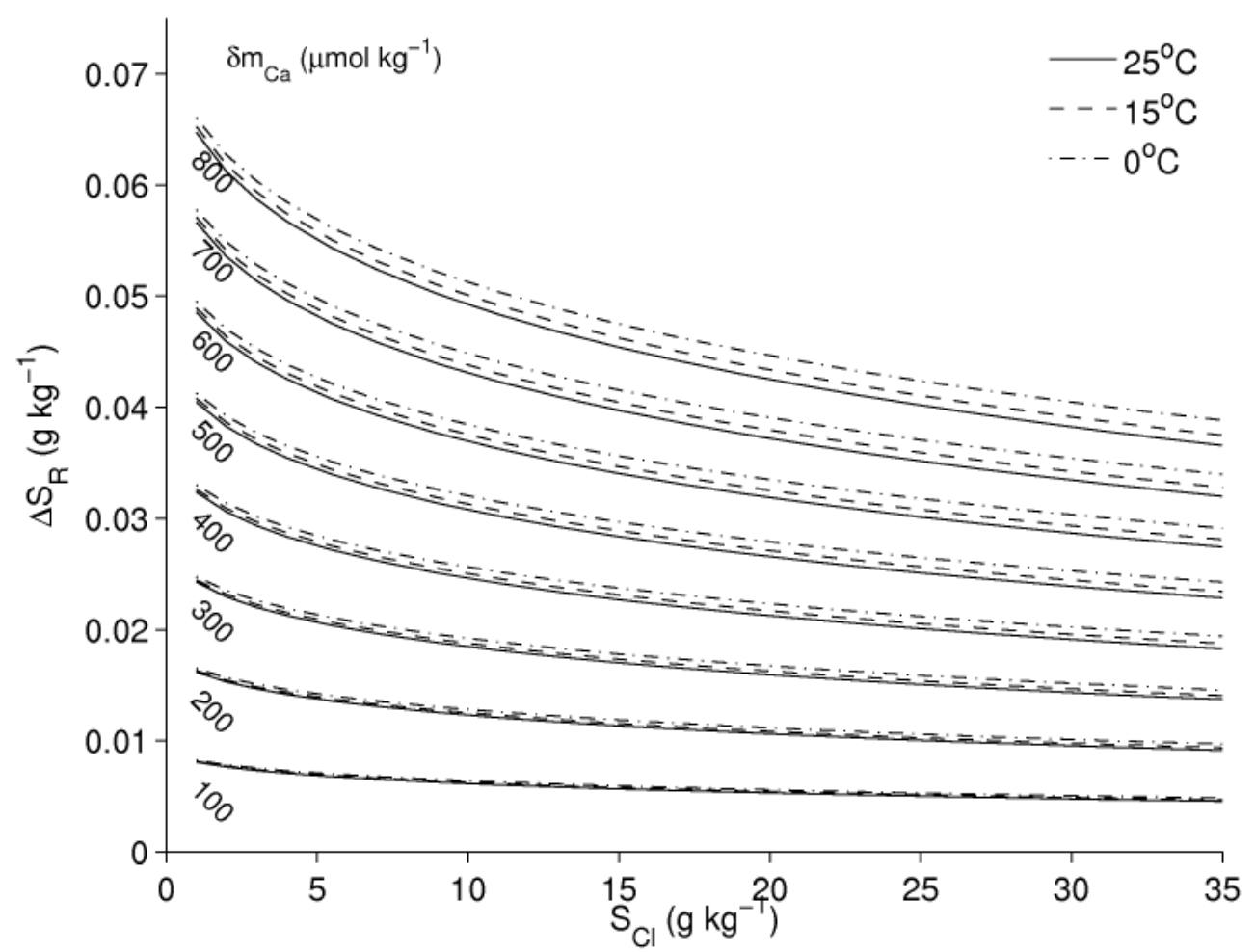

Fig. 21. Anomaly of the Reference Salinity $\Delta S_{\mathrm{R}}$, Eq. (6.13), as a function of $S_{\mathrm{Cl}}$ at different temperatures and anomalies $\delta m_{\mathrm{Ca}}$, estimated using LSEA_DELS.

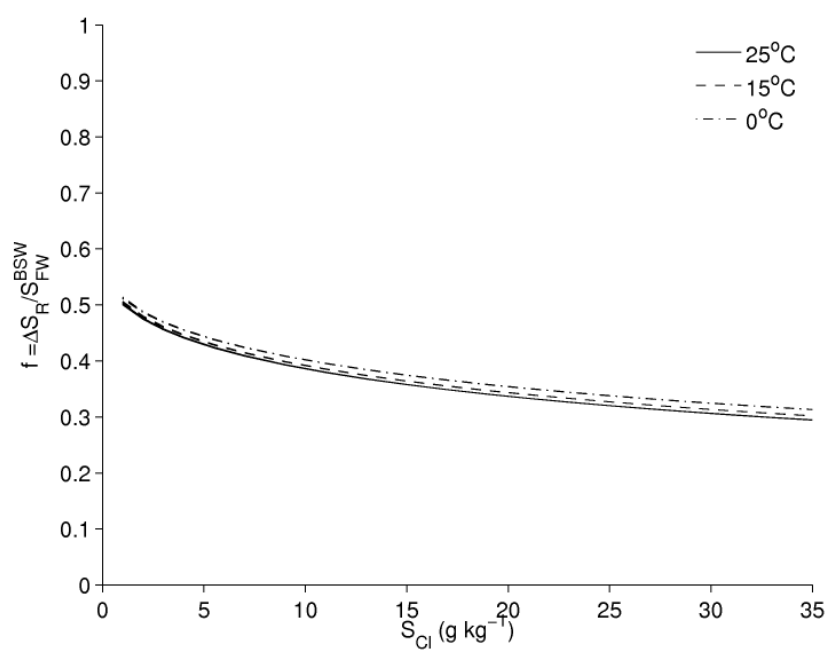

Fig. 22. Ratio $f\left(S_{\mathrm{A}}^{\mathrm{SSW}}, T\right)$ of changes in Reference Salinity and Absolute Salinity, Eq. (6.13).

Reference Salinity is then available from Eqs. (6.4), (6.13) and (6.14) as a function of $S_{\mathrm{A}}^{\mathrm{SSW}}$ and $S_{\mathrm{FW}}^{\mathrm{BSW}}$,

$S_{\mathrm{R}}=S_{\mathrm{A}}^{\mathrm{SSW}}+f\left(S_{\mathrm{A}}^{\mathrm{SSW}}, T\right) S_{\mathrm{FW}}^{\mathrm{BSW}}$.

The anomaly-related error of any considered property $q$ available from the Gibbs function $g^{\mathrm{BSW}}\left(S_{\mathrm{A}}^{\mathrm{SSW}}, S_{\mathrm{FW}}^{\mathrm{BSW}}, T, P\right)$, Eq. (3.19), is calculated as the difference between the best model estimate, $q^{\mathrm{BSW}}$, and the result $q^{\mathrm{SW}}$ obtained using Reference Salinity, $S_{\mathrm{R}}=u_{\mathrm{PS}} \times S_{\mathrm{P}}$, in the TEOS-10 Gibbs function:

$\delta q_{\mathrm{R}}=q^{\mathrm{BSW}}\left(S_{\mathrm{A}}^{\mathrm{SSW}}, S_{\mathrm{FW}}^{\mathrm{BSW}}, T, P\right)-q^{\mathrm{SW}}\left(S_{\mathrm{R}}, T, P\right)$.

The density deviation of the form (7.4),

$\delta \rho_{\mathrm{R}}=\frac{1}{g_{P}^{\mathrm{BSW}}\left(S_{\mathrm{A}}^{\mathrm{SSW}}, S_{\mathrm{FW}}^{\mathrm{BSW}}, T, P_{\mathrm{SO}}\right)}-\frac{1}{g_{P}^{\mathrm{SW}}\left(S_{\mathrm{R}}, T, P_{\mathrm{SO}}\right)}$,

is displayed in Fig. 24. Comparison with experimental data (Feistel et al., 2010a) and with LSEA_DELS results shows reasonable agreement with each, with slightly better agreement with the experimental data. Compared to Fig. 9 or 20, the density anomaly is reduced by almost $50 \%$ as a result of the conductivity of the anomalous salt influencing $S_{\mathrm{R}}$ and representing part of the associated density changes through the second term on the right side of Eq. (7.5). Similarly, the conductivity effect changes the sign of the curvature and significantly reduces the temperature dependence of the density anomaly.

The sound speed deviation of the form (7.4),

$\delta c_{\mathrm{R}}=c^{\mathrm{BSW}}\left(S_{\mathrm{A}}^{\mathrm{SSW}}, S_{\mathrm{FW}}^{\mathrm{BSW}}, T, P_{\mathrm{SO}}\right)-c^{\mathrm{SW}}\left(S_{\mathrm{R}}, T, P_{\mathrm{SO}}\right)$, 


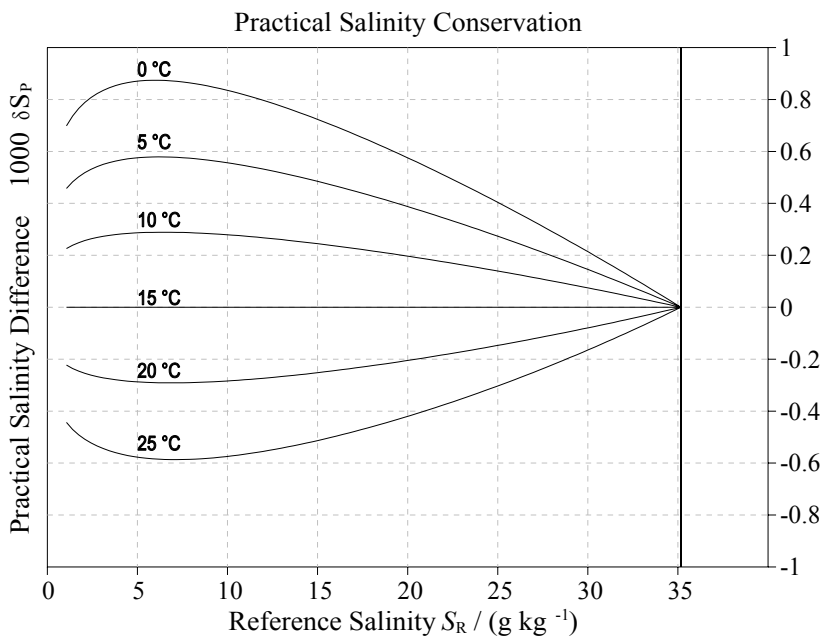

Fig. 23. Temperature dependence, Eq. (6.15), of Practical Salinity relative to $15^{\circ} \mathrm{C}$ of a given sample of Baltic seawater at atmospheric pressure.

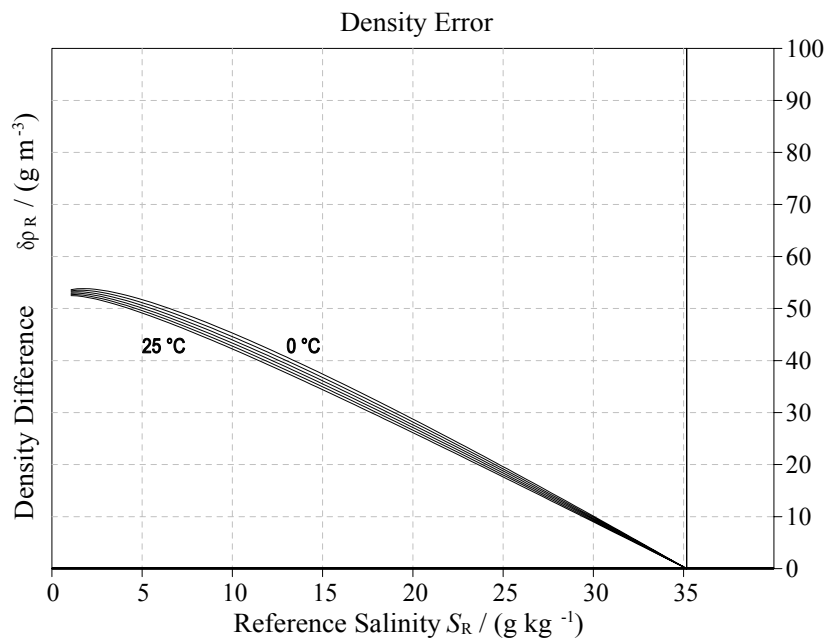

Fig. 24. Error in density, Eq. (7.5), if computed from measured Reference Salinity, using the Gibbs function for SSW. Results are shown for temperatures between 0 and $25^{\circ} \mathrm{C}$ and at atmospheric pressure.

is displayed in Fig. 25. The sound speed formula is given by Eq. (5.16). This figure is very similar to Fig. 13, i.e., the conductivity effect on the sound speed anomaly is only minor.

Consequently, CTD sound speed sensors with a resolution of $1 \mathrm{~mm} \mathrm{~s}^{-1}$ (Valeport, 2010) that are carefully calibrated with respect to SSW can be expected to be capable of measuring Baltic anomalies in situ and to observationally confirm the numerical model results shown here.

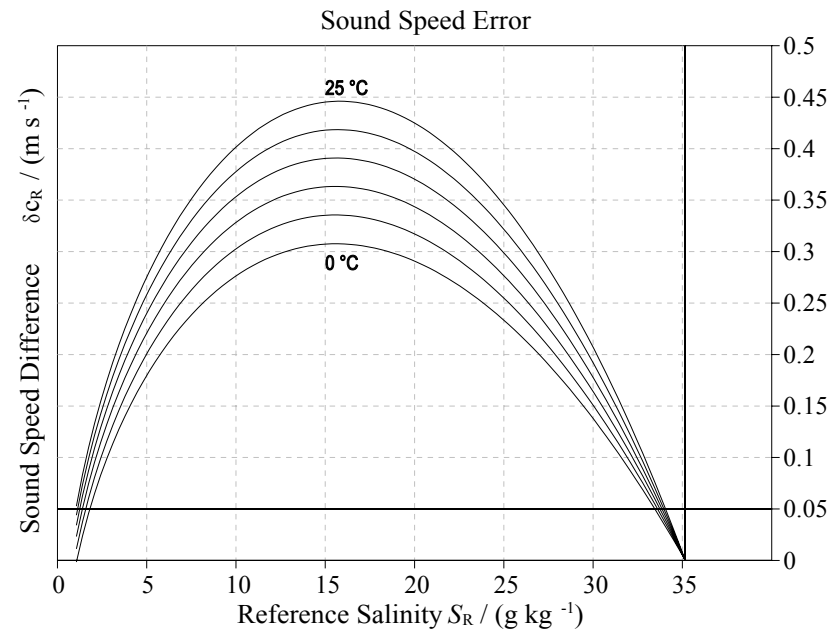

Fig. 25. Error in sound speed, Eq. (7.6), if computed from measured Reference Salinity using the Gibbs function for SSW. Results are shown for temperatures between 0 and $25^{\circ} \mathrm{C}$ and at atmospheric pressure.

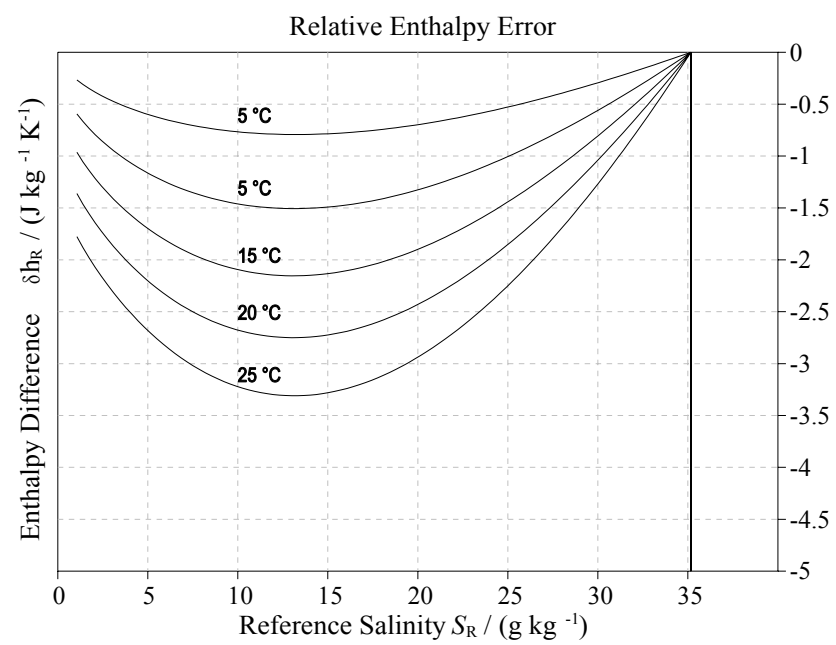

Fig. 26. Error in relative enthalpy, Eq. (7.7), if computed from measured Reference Salinity using the Gibbs function for SSW. Results are shown for temperatures between 1 and $25^{\circ} \mathrm{C}$ and at atmospheric pressure.

The relative enthalpy deviation of the form (7.4),

$$
\begin{aligned}
\delta h_{\mathrm{R}} & =h^{\mathrm{BSW}}\left(S_{\mathrm{A}}^{\mathrm{SSW}}, S_{\mathrm{FW}}^{\mathrm{BSW}}, T, P_{\mathrm{SO}}\right) \\
& -h^{\mathrm{BSW}}\left(S_{\mathrm{A}}^{\mathrm{SSW}}, S_{\mathrm{FW}}^{\mathrm{BSW}}, T_{\mathrm{SO}}, P_{\mathrm{SO}}\right) \\
& -h^{\mathrm{SW}}\left(S_{\mathrm{R}}, T, P_{\mathrm{SO}}\right)+h^{\mathrm{SW}}\left(S_{\mathrm{R}}, T_{\mathrm{SO}}, P_{\mathrm{SO}}\right),
\end{aligned}
$$

is displayed in Fig. 26. Enthalpy is computed from the Gibbs function by $h=g-T g_{T}$. Since $h$ depends on an arbitrary constant, only differences of enthalpies belonging to the same salinities are reasonable to be considered here. Compared to Fig. 14, the enthalpy changes are is almost 
completely captured by the conductivity effect and the enthalpy anomalies are therefore negligible.

The freezing point deviation of the form (7.4),

$\delta T_{\mathrm{R}}=T^{\mathrm{BSW}}\left(S_{\mathrm{A}}^{\mathrm{SSW}}, S_{\mathrm{FW}}^{\mathrm{BSW}}, T, P_{\mathrm{SO}}\right)-T^{\mathrm{SW}}\left(S_{\mathrm{R}}, T, P_{\mathrm{SO}}\right)$,

is displayed in Fig. 27. Freezing temperature is computed from Eq. (5.29). Compared to Fig. 15, the error is reduced by about $80 \%$ due to the conductivity effect and is well below the experimental uncertainty of freezing point measurements.

The above examples show that in some cases it may be desirable to correct for the anomaly or at least to check its significance in the particular case of interest. Even though this may be unnecessary in some situations, we note that there is now a general method for the calculation of the Baltic property anomaly based on the empirical Gibbs and Practical Salinity functions developed in this paper. Two practical situations are considered, (i) only Practical Salinity (plus $T$ and $P$ ) is known for a given sample, and, (ii) a direct density measurement is also available for the sample.

\section{(i) Practical Salinity $S_{\mathrm{P}}$ is known:}

Since no direct information is available on the magnitude of the anomaly, an empirical relation is used for its estimate. The Eqs. (6.4), (6.13), (5.4) and (5.5),

$u_{\mathrm{PS}} \times S_{\mathrm{P}} \equiv S_{\mathrm{R}}=S_{\mathrm{A}}^{\mathrm{SSW}}+f\left(S_{\mathrm{A}}^{\mathrm{SSW}}, T\right) S_{\mathrm{FW}}^{\mathrm{BSW}}$,

$S_{\mathrm{D}}=S_{\mathrm{A}}^{\mathrm{SSW}}+130 \mathrm{mg} \mathrm{kg}^{-1} \times\left(1-\frac{S_{\mathrm{A}}^{\mathrm{SSW}}}{S_{\mathrm{SO}}}\right)$,

and

$S_{\mathrm{FW}}^{\mathrm{BSW}}=\frac{g_{P}^{\mathrm{SW}}\left(S_{\mathrm{A}}^{\mathrm{SSW}}, T, P\right)-g_{P}^{\mathrm{SW}}\left(S_{\mathrm{D}}, T, P\right)}{g_{P}^{\mathrm{SW}}\left(S_{\mathrm{A}}^{\mathrm{SSW}}, T, P\right)-g_{P}^{\mathrm{FW}}\left(S_{\mathrm{A}}^{\mathrm{SSW}}, T, P\right)}$

can be solved in linear approximation of the anomaly, $\delta S_{\mathrm{R}}=S_{\mathrm{R}}-S_{\mathrm{A}}^{\mathrm{SSW}}$. The solution reads

$S_{\mathrm{FW}}^{\mathrm{BSW}}=-130 \mathrm{mg} \mathrm{kg}^{-1}\left(1-\frac{S_{\mathrm{R}}}{S_{\mathrm{SO}}}\right) \frac{g_{S P}^{\mathrm{SW}}}{g_{P}^{\mathrm{SW}}-g_{P}^{\mathrm{FW}}}$

$S_{\mathrm{A}}^{\mathrm{SSW}}=S_{\mathrm{R}}+130 \mathrm{mg} \mathrm{kg}^{-1}\left(1-\frac{S_{\mathrm{R}}}{S_{\mathrm{SO}}}\right) \frac{g_{S P}^{\mathrm{SW}}}{g_{P}^{\mathrm{SW}}-g_{P}^{\mathrm{FW}}} f$

Here, the functions $g$ and $f$ are evaluated at salinity $S_{\mathrm{R}}=$ $u_{\mathrm{PS}} \times S_{\mathrm{P}}$. The constant $u_{\mathrm{PS}}$ is given in Table A1.

The Gibbs function (3.19) with the arguments $S_{\mathrm{A}}^{\mathrm{SSW}}$ and $S_{\mathrm{FW}}^{\mathrm{BSW}}$ can now be used to compute the corrected property.

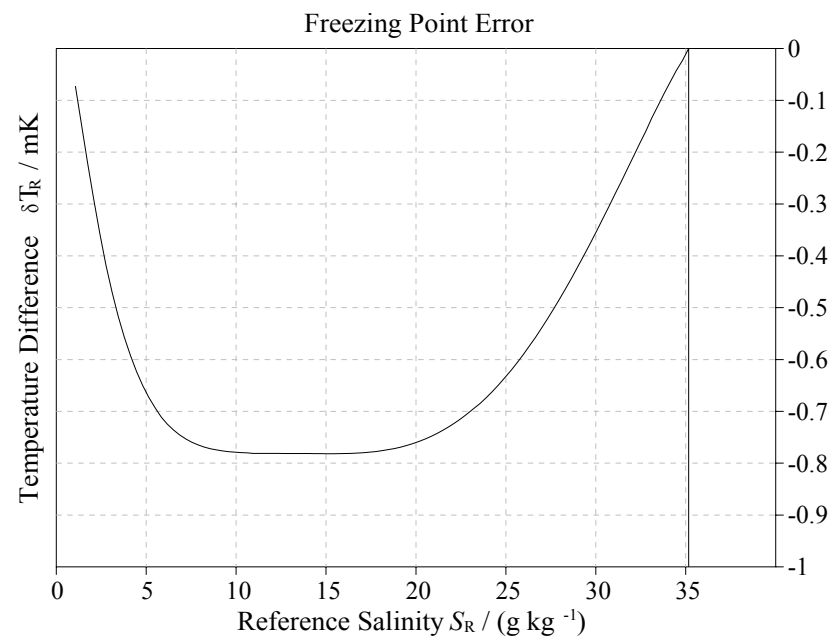

Fig. 27. Error in freezing temperature, Eq. (7.8), if computed from measured Reference Salinity using the Gibbs function for SSW. Results shown correspond to atmospheric pressure.

\section{(ii) Both Practical Salinity $S_{\mathrm{P}}$ and density $\rho$ are known:}

Since density $\rho$ is known, the estimate, Eq. (7.10), is not required here and is replaced by a more reliable value. The remaining equations

$u_{\mathrm{PS}} \times S_{\mathrm{P}} \equiv S_{\mathrm{R}}=S_{\mathrm{A}}^{\mathrm{SSW}}+f\left(S_{\mathrm{A}}^{\mathrm{SSW}}, T\right) S_{\mathrm{FW}}^{\mathrm{BSW}}$,

$S_{\mathrm{FW}}^{\mathrm{BSW}}=\frac{g_{P}^{\mathrm{SW}}\left(S_{\mathrm{A}}^{\mathrm{SSW}}, T, P\right)-\rho^{-1}}{g_{P}^{\mathrm{SW}}\left(S_{\mathrm{A}}^{\mathrm{SSW}}, T, P\right)-g_{P}^{\mathrm{FW}}\left(S_{\mathrm{A}}^{\mathrm{SSW}}, T, P\right)}$,

can be solved in linear approximation of the anomaly, $\delta S_{\mathrm{R}}=S_{\mathrm{R}}-S_{\mathrm{A}}^{\mathrm{SSW}}$. The solution reads

$S_{\mathrm{FW}}^{\mathrm{BSW}}=\frac{g_{P}^{\mathrm{SW}}-\rho^{-1}}{g_{P}^{\mathrm{SW}}-g_{P}^{\mathrm{FW}}+f g_{S P}^{\mathrm{SW}}}$,

$S_{\mathrm{A}}^{\mathrm{SSW}}=S_{\mathrm{R}}-f \frac{g_{P}^{\mathrm{SW}}-\rho^{-1}}{g_{P}^{\mathrm{SW}}-g_{P}^{\mathrm{FW}}+f g_{S P}^{\mathrm{SW}}}$.

The functions $g$ and $f$ are again evaluated at salinity $S_{\mathrm{R}}=$ $u_{\mathrm{PS}} \times S_{\mathrm{P}}$.

The Gibbs function (3.19) with the arguments $S_{\mathrm{A}}^{\mathrm{SSW}}$ and $S_{\mathrm{FW}}^{\mathrm{BSW}}$ can now be used to compute the corrected property. 
Table A1. Numerical constants.

\begin{tabular}{llll}
\hline Symbol & Value & Unit & Comment \\
\hline$u_{\mathrm{PS}}$ & $35.16504 / 35$ & $\mathrm{~g} \mathrm{~kg}^{-1}$ & Practical Salinity conversion \\
$T_{\mathrm{SO}}$ & 273.15 & $\mathrm{~K}$ & Standard ocean temperature \\
$P_{\mathrm{SO}}$ & 101325 & $\mathrm{~Pa}$ & Standard ocean surface pressure \\
$S_{\mathrm{SO}}$ & $35 u_{\mathrm{PS}}$ & $\mathrm{g} \mathrm{kg}^{-1}$ & Standard ocean Reference Salinity \\
$m_{\mathrm{SO}}$ & 1.160581 & $\mathrm{~mol} \mathrm{~kg}^{-1}$ & Standard ocean sea-salt molality \\
$R$ & 8.314472 & $\mathrm{~J} \mathrm{~mol}^{-1} \mathrm{~K}^{-1}$ & Molar gas constant \\
$R_{\mathrm{FW}}$ & $R / A_{\mathrm{FW}}$ & $\mathrm{J} \mathrm{kg}^{-1} \mathrm{~K}^{-1}$ & Specific gas constant of anomalous solute \\
$A_{\mathrm{FW}}$ & 54.03723 & $\mathrm{~g} \mathrm{~mol}^{-1}$ & Molar mass of the Baltic anomalous solute \\
$A_{\mathrm{SSW}}$ & 31.40382 & $\mathrm{~g} \mathrm{~mol}^{-1}$ & Molar mass of Reference-Composition sea salt \\
\hline
\end{tabular}

Table A2. Numerical check values of the Gibbs function anomaly $g^{\mathrm{FW}}$, Eq. (4.8), and of the conductivity function, $f$, Eq. (6.14).

\begin{tabular}{|c|c|c|c|c|}
\hline Quantity & Value & Value & Value & Unit \\
\hline$S_{\mathrm{A}}^{\mathrm{SSW}}$ & 0.030 & 0.005 & 0.005 & $\mathrm{~kg} \mathrm{~kg}^{-1}$ \\
\hline$T^{\mathrm{A}}$ & 273.15 & 298.15 & 273.15 & $\mathrm{~K}$ \\
\hline$P$ & 101325 & 102325 & $5 \times 10^{8}$ & $\mathrm{~Pa}$ \\
\hline$g^{\mathrm{FW}}$ & $-0.677377468 \times 10^{4}$ & $-0.835211586 \times 10^{5}$ & $+0.252089617 \times 10^{6}$ & $\mathrm{~J} \mathrm{~kg}^{-1}$ \\
\hline$g_{S}^{\mathrm{FW}}$ & $+0.145901670 \times 10^{7}$ & $+0.791394921 \times 10^{7}$ & $+0.348699136 \times 10^{8}$ & $\mathrm{~J} \mathrm{~kg}^{-1}$ \\
\hline$g_{T}^{\mathrm{FW}}$ & $-0.268037038 \times 10^{2}$ & $-0.362098912 \times 10^{3}$ & $+0.805202672 \times 10^{3}$ & $\mathrm{~J} \mathrm{~kg}^{-1} \mathrm{~K}^{-1}$ \\
\hline$g_{P}^{\mathrm{FW}}$ & $+0.251267770 \times 10^{-3}$ & $+0.219677073 \times 10^{-3}$ & $+0.114602035 \times 10^{-2}$ & $\mathrm{~m}^{3} \mathrm{~kg}^{-1}$ \\
\hline$g_{T T}^{\mathrm{FW}}$ & $+0.379189354 \times 10^{1}$ & $-0.347691812 \times 10^{1}$ & +0.470491769 & $\mathrm{~J} \mathrm{~kg}^{-1} \mathrm{~K}^{-2}$ \\
\hline$g_{T P}^{\mathrm{FW}}$ & $+0.549912355 \times 10^{-5}$ & $+0.224500779 \times 10^{-5}$ & $+0.224500779 \times 10^{-5}$ & $\mathrm{~m}^{3} \mathrm{~kg}^{-1} \mathrm{~K}^{-1}$ \\
\hline$g_{P P}^{\mathrm{FW}}$ & $+0.481406848 \times 10^{-11}$ & $+0.196533523 \times 10^{-11}$ & $+0.196533523 \times 10^{-11}$ & $\mathrm{~m}^{3} \mathrm{~kg}^{-1} \mathrm{~Pa}^{-1}$ \\
\hline$f$ & +0.324117950 & +0.429079183 & +0.442694939 & \\
\hline
\end{tabular}

\section{Conclusions}

For Baltic seawater with a simplified composition anomaly representing only inputs of calcium carbonate, Eq. (1.1), a Gibbs function is determined based on theoretical considerations and results from FREZCHEM model simulations. The new Gibbs function, Eq. (3.19), combines the TEOS-10 Gibbs function of Standard Seawater (SSW), $g^{\mathrm{SW}}\left(S_{\mathrm{A}}^{\mathrm{SSW}}, T, P\right)$, with an anomalous part, $g^{\mathrm{FW}}\left(S_{\mathrm{A}}^{\mathrm{SSW}}, T, P\right)$, proportional to the Absolute Salinity of the anomalous (freshwater) salt, $S_{\mathrm{FW}}^{\mathrm{BSW}}$, resulting in the form

$$
\begin{aligned}
& g^{\mathrm{BSW}}\left(S_{\mathrm{A}}^{\mathrm{SSW}}, S_{\mathrm{FW}}^{\mathrm{BSW}}, T, P\right)=\left(1-S_{\mathrm{FW}}^{\mathrm{BSW}}\right) g^{\mathrm{SW}}\left(S_{\mathrm{A}}^{\mathrm{SSW}}, T, P\right) \\
& +S_{\mathrm{FW}}^{\mathrm{BSW}} g^{\mathrm{FW}}\left(S_{\mathrm{A}}^{\mathrm{SSW}}, T, P\right) .
\end{aligned}
$$

The Absolute Salinity of the "preformed" SSW part, the parent solution, is denoted by $S_{\mathrm{A}}^{\mathrm{SSW}}$, Eq. (2.26). From the mass balance, the Absolute Salinity of Baltic seawater is given by Eq. (3.21),

$$
\begin{aligned}
S_{\mathrm{A}}^{\mathrm{BSW}} & =1-\left(1-S_{\mathrm{FW}}^{\mathrm{BSW}}\right)\left(1-S_{\mathrm{A}}^{\mathrm{SSW}}\right) \\
& =S_{\mathrm{A}}^{\mathrm{SSW}}+\left(1-S_{\mathrm{A}}^{\mathrm{SSW}}\right) S_{\mathrm{FW}}^{\mathrm{BSW}} .
\end{aligned}
$$

Note that a single salinity variable such as Eq. (8.2) is insufficient for the description of Baltic seawater properties. Rather, the Gibbs function (8.1) takes two separate salinity variables, one for the SSW part and one for the additional anomalous (freshwater-related) part. The anomalous part of the Gibbs function, $g^{\mathrm{FW}}$, is available from the correlation expression (4.8) with regression coefficients reported in Table 1 and numerical check values in Table A2.

Computed from the Baltic Gibbs function, $g^{\mathrm{BSW}}$, various property anomalies are quantitatively displayed in Figs. 8-18 and discussed in relation to Millero's Rule which provides generally reasonable, and sometimes very good estimates although it cannot be assumed a priori to be valid in general. Density Salinity is a good proxy for the actual Absolute Salinity of the Baltic Sea when the composition anomaly is represented by $\mathrm{Ca}^{2+}$ and $2 \mathrm{HCO}_{3}^{-}$, although experimentation 
Table B1. Glossary of formula symbols.

\begin{tabular}{|c|c|c|}
\hline Symbol & Comment & Eq. \\
\hline$a$ & dissolved species name or number & \\
\hline$A_{0}$ & molar mass of water & \\
\hline$A_{a}$ & molar mass of the species $a$ & \\
\hline$A_{\mathrm{BSW}}$ & mean molar mass of the BSW solute & $(4.19)$ \\
\hline$A_{\mathrm{FW}}$ & mean molar mass of the FW solute & $(2.17)$ \\
\hline$A_{\mathrm{SSW}}$ & mean molar mass of the SSW solute & $(2.17)$ \\
\hline$c$ & sound speed & $(5.16)$ \\
\hline$c^{\mathrm{SW}}$ & TEOS-10 sound speed & (5.18) \\
\hline$c^{\mathrm{BSW}}$ & sound speed in BSW & (5.17) \\
\hline$C^{\mathrm{SSW}}$ & composition vector of SSW & $(6.1)$ \\
\hline$C^{\mathrm{BSW}}$ & composition vector of BSW & \\
\hline$c$ & vector of regression coefficients & (4.13) \\
\hline$c_{P}$ & specific isobaric heat capacity & \\
\hline DIC & dissolved inorganic carbon & $(6.7)$ \\
\hline$f$ & anomalous Reference Salinity factor & $(6.13)$ \\
\hline$g$ & Gibbs function & $(4.1)$ \\
\hline$g_{2}$ & TEOS-10 Gibbs function expansion term & $(4.22)$ \\
\hline$g^{\mathrm{BSW}}$ & Gibbs function of Baltic seawater & (3.13) \\
\hline$g^{\mathrm{F}}$ & saline part of the partial Gibbs function of freshwater & $(4.36)$ \\
\hline$g^{\mathrm{FW}}$ & anomalous part of the Gibbs function & (3.16) \\
\hline$g^{\mathrm{id}}$ & Gibbs function at infinite dilution & (2.23) \\
\hline$g^{\mathrm{SW}}$ & TEOS-10 Gibbs function of SSW & (3.12) \\
\hline$g^{S S W}$ & Gibbs function of the SSW part (parent solution) & $(3.12)$ \\
\hline$g^{\mathrm{V}}$ & Gibbs function of water vapour & $(5.33)$ \\
\hline$g^{\mathrm{W}}$ & Gibbs function of liquid water & (2.23) \\
\hline$G^{\mathrm{BSW}}$ & Gibbs energy of BSW & (3.5) \\
\hline$G^{\mathrm{SSW}}$ & Gibbs energy of SSW & $(3.1)$ \\
\hline$k$ & Boltzmann's constant & \\
\hline$m$ & molality, moles of solute per mass of solvent & \\
\hline$m_{a}$ & molality of the species $a$ & $(3.7)$ \\
\hline$m^{\mathrm{BSW}}$ & molality of the solute in the BSW & $(2.18)$ \\
\hline$m_{\mathrm{FW}}^{\mathrm{BSW}}$ & molality of the FW solute in the BSW & $(2.20)$ \\
\hline$m_{\mathrm{SSW}}^{\mathrm{BSW}}$ & molality of the SSW solute in the BSW & (2.19) \\
\hline$m_{\mathrm{Cl}}$ & chloride molality & $(4.3)$ \\
\hline$m_{\mathrm{Ca}}$ & calcium molality & $(4.7)$ \\
\hline$m^{\mathrm{RC}}$ & molality of seawater with RC & \\
\hline$M^{\mathrm{BSW}}$ & mass of the BSW sample & (2.9) \\
\hline$M^{\mathrm{FW}}$ & mass of the FW part & $(2.5)$ \\
\hline$M^{\mathrm{OW}}$ & mass of salt from OW & (2.14) \\
\hline$M^{\mathrm{RW}}$ & mass of salt from RW & (2.15) \\
\hline$M^{\mathrm{SSW}}$ & mass of the SSW sample & $(2.8)$ \\
\hline$M_{0}^{\mathrm{BSW}}$ & mass of water in the BSW & (2.6) \\
\hline$M_{\mathrm{S}}^{\mathrm{BSW}}$ & mass of salt in the BSW & (2.7) \\
\hline$M_{\mathrm{S}}^{\mathrm{FW}}$ & mass of salt in the FW part & $(2.5)$ \\
\hline$M_{\mathrm{S}}^{\mathrm{OW}}$ & mass of salt from OW & (2.14) \\
\hline$M_{\mathrm{S}}^{\mathrm{RW}}$ & mass of salt from RW & $(2.15)$ \\
\hline$M_{\mathrm{S}}^{\mathrm{SSW}}$ & mass of salt in the SSW part & $(2.4)$ \\
\hline$N_{\mathrm{A}}$ & Avogadro's number & \\
\hline$N_{\mathrm{A}}^{\mathrm{BSW}}$ & number of particles of species $a$ in BSW & $(2.2)$ \\
\hline
\end{tabular}

Table B1. Continued.

\begin{tabular}{|c|c|c|}
\hline Symbol & Comment & Eq. \\
\hline$N_{\mathrm{A}}^{\mathrm{FW}}$ & number of particles of species $a$ in FW & $(2.2)$ \\
\hline$N_{\mathrm{A}}^{\mathrm{SSW}}$ & number of particles of species $a$ in SSW & $(2.2)$ \\
\hline$N_{\mathrm{S}}^{\mathrm{BSW}}$ & number of solute particles in BSW & $(2.10)$ \\
\hline$N_{\mathrm{S}}^{\mathrm{FW}}$ & number of solute particles from FW & $(2.2)$ \\
\hline$N_{\mathrm{S}}^{\mathrm{SSW}}$ & number of solute particles in SSW & $(2.2)$ \\
\hline$N_{0}^{\mathrm{BSW}}$ & number of water particles in BSW & $(2.1)$ \\
\hline$N_{0}^{\mathrm{OW}}$ & number of water particles from OW & \\
\hline$N_{0}^{\mathrm{RW}}$ & number of water particles from RW & \\
\hline$N_{0}^{\mathrm{SSW}}$ & number of water particles in the SSW part & $(2.10)$ \\
\hline$N_{a}^{\mathrm{BSW}}$ & number of solute particles of species $a$ in BSW & $(2.1)$ \\
\hline$N_{a}^{\mathrm{FW}}$ & number of solute particles of species $a$ in FW & $(2.2)$ \\
\hline$N_{a}^{\mathrm{OW}}$ & number of solute particles of species $a$ from OW & \\
\hline$N_{a}^{\mathrm{RW}}$ & number of solute particles of species $a$ from RW & \\
\hline$N_{a}^{\mathrm{SSW}}$ & number of solute particles of species $a$ in SSW & $(2.2)$ \\
\hline$N_{\mathrm{S}}^{\mathrm{BSW}}$ & number of solute particles in BSW & $(2.10)$ \\
\hline$N_{\mathrm{S}}^{\mathrm{FW}}$ & number of solute particles in the FW part & $(2.2)$ \\
\hline$N_{\mathrm{S}}^{\mathrm{SSW}}$ & number of solute particles in the SSW part & $(2.2)$ \\
\hline$P$ & absolute pressure & \\
\hline$P_{\mathrm{SO}}$ & standard ocean surface pressure, Table A1 & $(4.9)$ \\
\hline$P^{\text {vap }}$ & vapour pressure & (5.33) \\
\hline$q$ & some quantity & \\
\hline$r$ & formal expansion parameter & $(4.26)$ \\
\hline$R=N_{\mathrm{A}} k$ & molar gas constant & \\
\hline$R_{\mathrm{FW}}=R / A_{\mathrm{FW}}$ & specific gas constant of anomalous solute & (3.16) \\
\hline$R_{\mathrm{S}}$ & specific gas constant of a particular solute & $(4.1)$ \\
\hline$R_{\mathrm{BSW}}$ & specific gas constant of the BSW solute & $(4.24)$ \\
\hline$R_{\mathrm{SSW}}$ & specific gas constant of the SSW solute & $(4.21)$ \\
\hline$s$ & formal expansion parameter & $(4.26)$ \\
\hline$S_{*}$ & preformed salinity & $(2.22)$ \\
\hline$S_{\mathrm{A}}$ & Absolute Salinity & $(4.1)$ \\
\hline$S_{\mathrm{A}}^{\mathrm{BSW}}$ & Absolute Salinity of BSW & $(2.11)$ \\
\hline$S_{\mathrm{A}}^{\text {dens }}$ & "conservative" Density Salinity & $(5.1)$ \\
\hline$S_{\mathrm{A}}^{\text {soln }}$ & alternative nomenclature for $S_{\mathrm{A}}^{\mathrm{BSW}}$ & $(3.21)$ \\
\hline$S_{\mathrm{A}}^{\mathrm{OW}}$ & Absolute Salinity of the OW end member & $(2.14)$ \\
\hline$S_{\mathrm{A}}^{\mathrm{RW}}$ & Absolute Salinity of the RW end member & $(2.15)$ \\
\hline$S_{\mathrm{A}}^{\mathrm{SSW}}$ & Absolute Salinity of the parent solution (SSW) & $(2.26)$ \\
\hline$S_{\mathrm{Cl}}$ & Chlorinity Salinity & $(5.2)$ \\
\hline$S_{\mathrm{D}}$ & "measured" Density Salinity & $(5.1)$ \\
\hline$S_{\mathrm{FW}}^{\mathrm{BSW}}$ & mass fraction of sea salt from $\mathrm{FW}$ in $\mathrm{BSW}$ & (2.13) \\
\hline$S_{\mathrm{R}}^{\mathrm{BSW}}$ & Reference Salinity of BSW & $(6.4)$ \\
\hline$S_{\mathrm{R}}^{\mathrm{SSW}}$ & Reference Salinity of SSW & (6.1) \\
\hline$S_{\mathrm{SSW}}^{\mathrm{BSW}}$ & mass fraction of sea salt from SSW in BSW & $(2.12)$ \\
\hline$S_{\mathrm{P}}$ & Practical Salinity & $(6.1)$ \\
\hline$S_{\mathrm{SO}}$ & standard ocean Reference Salinity, Table A1 & \\
\hline$T$ & Absolute temperature & \\
\hline $\mathrm{TA}$ & Total Alkalinity & $(6.6)$ \\
\hline$T_{\mathrm{f}}$ & freezing temperature & $(5.29)$ \\
\hline$T_{\mathrm{SO}}$ & standard ocean temperature, Table A1 & $(4.9)$ \\
\hline
\end{tabular}


Table B1. Continued.

\begin{tabular}{|c|c|c|}
\hline Symbol & Comment & Eq. \\
\hline$u_{\mathrm{PS}}$ & conversion faction between Practical and Reference Salinity & \\
\hline$u_{\mathrm{P}}$ & conversion faction between Practical and Reference Salinity & $(6.1)$ \\
\hline$v$ & specific volume & \\
\hline$x$ & reduced salinity variable & $(4.9)$ \\
\hline$x$ & vector of molar fractions & \\
\hline$x_{a}^{\mathrm{FW}}$ & mole fraction of solute $a$ in FW & $(2.2)$ \\
\hline$x_{a}^{\mathrm{RC}}$ & mole fraction of solute $a$ in the RC & $(2.2)$ \\
\hline$y$ & reduced temperature variable & $(4.9)$ \\
\hline$z$ & reduced pressure variable & $(4.9)$ \\
\hline$\beta$ & haline contraction coefficient & $(5.11)$ \\
\hline$\beta_{\mathrm{FW}}$ & anomalous haline contraction coefficient with respect to FW & $(5.10)$ \\
\hline$\delta c$ & sound speed anomaly & $(5.17)$ \\
\hline$\delta c^{\mathrm{A}}$ & sound speed anomaly in terms of Absolute Salinity & $(5.19)$ \\
\hline$\delta c^{\mathrm{D}}$ & sound speed anomaly in terms of Density Salinity & $(5.18)$ \\
\hline$\delta c_{P}$ & heat capacity anomaly & $(4.15)$ \\
\hline$\delta c_{P}^{\mathrm{A}}$ & heat capacity anomaly in terms of Absolute Salinity & $(5.15)$ \\
\hline$\delta c_{P}^{\mathrm{D}}$ & heat capacity anomaly in terms of Density Salinity & $(5.14)$ \\
\hline$\delta c_{\mathrm{R}}$ & sound speed deviation & $(7.6)$ \\
\hline$\delta c_{P_{i}}$ & heat capacity deviation FREZCHEM - Gibbs function & $(4.13)$ \\
\hline$\delta g$ & Gibbs function anomaly & $(3.15)$ \\
\hline$\delta G$ & Gibbs energy anomaly & $(3.5)$ \\
\hline$\delta h$ & enthalpy anomaly & $(5.20)$ \\
\hline$\delta h^{\mathrm{A}}$ & enthalpy anomaly in terms of Absolute Salinity & $(5.21)$ \\
\hline$\delta h^{\mathrm{D}}$ & enthalpy anomaly in terms of Density Salinity & $(5.22)$ \\
\hline$\delta h_{\mathrm{R}}$ & enthalpy deviation & $(7.7)$ \\
\hline$\delta m_{\mathrm{Ca}}$ & calcium molality anomaly & $(4.5)$ \\
\hline$\delta P$ & vapour pressure anomaly & $(5.34)$ \\
\hline$\delta P^{\mathrm{A}}$ & vapour pressure anomaly in terms of Absolute Salinity & $(5.36)$ \\
\hline$\delta P^{\mathrm{D}}$ & vapour pressure anomaly in terms of Density Salinity & $(5.35)$ \\
\hline$\delta S_{\mathrm{A}}$ & Absolute Salinity anomaly & $(7.1)$ \\
\hline$\Delta S_{\mathrm{D}}$ & Density Salinity deviation & $(5.37)$ \\
\hline$\delta\left[\mathrm{SO}_{4}\right]$ & sulfate molality anomaly & $(6.11)$ \\
\hline$\delta S_{\mathrm{P}}$ & Practical Salinity anomaly & $(6.11)$ \\
\hline$\Delta S_{\mathrm{R}}$ & Reference Salinity deviation & $(6.4)$ \\
\hline$\delta T$ & freezing temperature anomaly & $(5.30)$ \\
\hline$\delta T^{\mathrm{A}}$ & freezing temperature anomaly in terms of Absolute Salinity & $(5.32)$ \\
\hline$\delta T^{\mathrm{D}}$ & freezing temperature anomaly in terms of Density Salinity & $(5.31)$ \\
\hline$\delta \mathrm{TA}$ & Total Alkalinity anomaly & $(6.10)$ \\
\hline$\delta T_{\mathrm{R}}$ & freezing temperature deviation & $(7.8)$ \\
\hline$\delta v$ & specific volume anomaly & $(4.14)$ \\
\hline$\delta v_{i}$ & specific volume deviation FREZCHEM - Gibbs function & $(4.13)$ \\
\hline$\delta \alpha$ & anomaly of thermal expansion & $(5.7)$ \\
\hline$\delta \alpha^{\mathrm{A}}$ & anomaly of thermal expansion in terms of Absolute Salinity & $(5.9)$ \\
\hline$\delta \alpha^{\mathrm{D}}$ & anomaly of thermal expansion in terms of Density Salinity & $(5.8)$ \\
\hline$\delta \beta$ & anomaly of haline contraction & $(5.12)$ \\
\hline$\delta \rho$ & density anomaly & $(5.6)$ \\
\hline$\delta \rho_{\mathrm{R}}$ & density anomaly due to conductivity & $(6.5)$ \\
\hline$\Delta \rho$ & density deviation & $(5.39)$ \\
\hline$\delta \psi$ & activity potential anomaly & $(4.18)$ \\
\hline$\delta \psi_{i}$ & activity potential deviation FREZCHEM - Gibbs function & $(4.13)$ \\
\hline$\gamma$ & mean activity coefficient & $(4.2)$ \\
\hline$\gamma$ & mean activity coefficient at infinite dilution & $(4.2)$ \\
\hline$\gamma_{a}$ & practical activity coefficient of the species $a$ & $(3.7)$ \\
\hline$\gamma_{a}^{\mathrm{id}}$ & activity coefficient of the species $a$ at infinite dilution & $(3.10)$ \\
\hline$\gamma_{\mathrm{FW}}$ & mean activity coefficient of $\mathrm{FW}$ & $(3.18)$ \\
\hline$\gamma_{\mathrm{FW}}^{\mathrm{id}}$ & mean activity coefficient of FW at infinite dilution & $(3.11)$ \\
\hline$\Gamma$ & partial specific Gibbs energy at infinite dilution & $(4.1)$ \\
\hline$\Gamma$ & partial specific Gibbs energy of species $a$ at infinite dilution & $(2.23)$ \\
\hline$\Gamma^{\mathrm{BSW}}$ & partial specific Gibbs energy of BSW at infinite dilution & $(4.16)$ \\
\hline$\Gamma^{\mathrm{SSW}}$ & partial specific Gibbs energy of SSW at infinite dilution & $(4.17)$ \\
\hline$\kappa^{\mathrm{SSW}}$ & conductivity of SSW & $(6.1)$ \\
\hline$\kappa^{\mathrm{BSW}}$ & conductivity of BSW & \\
\hline$\mu_{0}$ & chemical potential of a water molecule & $(3.1)$ \\
\hline$\mu_{a}$ & chemical potential of the solute particle $a$ & $(3.1)$ \\
\hline$\mu_{a}^{0}$ & absolute chemical potential of the solute particle a & $(3.7)$ \\
\hline$\mu^{\text {Ih }}$ & chemical potential of ice & $(5.29)$ \\
\hline$\mu_{\mathrm{FW}}$ & chemical potential of FW & $(5.23)$ \\
\hline
\end{tabular}

Table B1. Continued.

\begin{tabular}{lll}
\hline Symbol & Comment & Eq. \\
\hline$\mu_{\mathrm{FW}}^{0}$ & chemical potential of the anomalous solute at infinite dilution & $(3.17)$ \\
$\mu_{\mathrm{SSW}}$ & chemical potential of SSW & $(5.23)$ \\
$\mu_{\mathrm{W}}$ & chemical potential of water & $(5.24)$ \\
$\phi$ & osmotic coefficient & $(4.2)$ \\
$\psi^{\mathrm{BSW}}$ & activity potential & $(4.2)$ \\
$\psi^{\mathrm{SSW}}$ & activity potential of BSW & $(4.16)$ \\
$\psi^{\mathrm{SS}}$ & activity potential of SSW & $(4.17)$ \\
$\rho^{\mathrm{SSW}}$ & density of SSW & \\
$\rho^{\mathrm{BSW}}$ & density of BSW & $(6.2)$ \\
$\rho_{\mathrm{R}}^{\mathrm{BSW}}$ & reference density of BSW & $(6.5)$ \\
$\tau$ & reduced temperature & $(6.14)$ \\
$\omega_{i}$ & data uncertainty & $(4.13)$ \\
$\xi$ & reduced absolute salinity & $(6.14)$ \\
\hline
\end{tabular}

shows that these results are somewhat sensitive to the particular composition of the anomaly.

The influence of dissolved calcium that is in charge balance and in chemical equilibrium with the marine carbonate system is estimated from LSEA_DELS simulation results and is effectively represented by the conductivity factor $f\left(S_{\mathrm{A}}^{\mathrm{SSW}}, T\right)$ which correlates the anomalous mass-fraction salinity, $S_{\mathrm{FW}}^{\mathrm{BSW}}$, with Practical Salinity, $S_{\mathrm{P}}$, in the form, Eq. (6.13),

$S_{\mathrm{P}} \times u_{\mathrm{PS}}=S_{\mathrm{A}}^{\mathrm{SSW}}+f\left(S_{\mathrm{A}}^{\mathrm{SSW}}, T\right) \times S_{\mathrm{FW}}^{\mathrm{BSW}}$.

The salinity conversion factor $u_{\mathrm{PS}}$ is given in Table A1. The correlation function $f\left(S_{\mathrm{A}}^{\mathrm{SSW}}, T\right)$ has the mathematical form (6.14) with coefficients given in Table 3 and numerical check values in Table A2. The pressure dependence of $f$ is unknown but is assumed to be of minor relevance for the relatively shallow Baltic Sea compared to the general uncertainties of the models and the scatter of the data employed here.

The above discussion regards the influence of anomalous solute as an addition to the preformed SSW part of the Absolute Salinity. When dealing with field measurements, it is often more convenient to consider anomalies from the Reference-Composition Salinity $S_{\mathrm{R}}=u_{\mathrm{PS}} \times S_{\mathrm{P}}$. In this case, the conductivity effect of the anomalous solute influences the value of $S_{\mathrm{R}}$ and reduces the anomalies in comparison to those computed with respect to estimates based on the preformed Absolute Salinity, $S_{\mathrm{A}}^{\mathrm{SSW}}$, as shown in Figs. 24-27. This conclusion is similar to earlier studies on regional ocean waters (Cox et al., 1967; Lewis, 1981).

For some properties the use of $S_{\mathrm{R}}=S_{\mathrm{P}} \times u_{\mathrm{PS}}$ as the salinity argument of the TEOS-10 Gibbs function (IOC et al., 2010) proves sufficiently accurate for Baltic seawater but may be insufficient in cases such as for density or sound speed, depending on the actual application purposes. In these cases, estimates of $S_{\mathrm{A}}^{\mathrm{SSW}}$ and $S_{\mathrm{FW}}^{\mathrm{BSW}}$ are required for use in the Gibbs function, Eq. (8.1). Two alternative methods, Eqs. (7.12), (7.13) or (7.16), (7.17), are suggested to 
estimate these quantities, the first set of equations requiring only Practical Salinity and temperature as inputs, and the second set additionally requiring density readings.

We note that these estimates result from numerical simulations with the models FREZCHEM (Marion and Kargel, 2008) and LSEA_DELS (Pawlowicz, 2008, 2010) rather than from direct laboratory measurements of Baltic seawater. Observational data (Feistel et al., 2010a) show satisfactory agreement with our simulation results, Fig. 19. The experimentally confirmed conservation of Practical Salinity of Baltic seawater (Feistel and Weinreben, 2008) is also consistent with the LSEA_DELS model prediction, Fig. 23. More detailed comparisons of the FREZCHEM model with SSW properties were discussed previously by Feistel and Marion (2007).

Acknowledgements. The authors thank Bernd Schneider (IOW) for providing his TA/DIC measurements and the editor for helpful suggestions. Matti Pertillä (Finnish Meteorological Institute) provided access to the Baltic-C database of river chemistry measurements (BONUS-IEEG project Baltic-C). The FREZCHEM model of Baltic seawater was developed during a research visit of G.M.M. in Warnemünde; the support by DRI and IOW is gratefully acknowledged. This paper contributes to the tasks of the SCOR/IAPSO WG 127 on Thermodynamics and Equation of State of Seawater.

Edited by: R. Tailleux

\section{References}

Alberty, R. A.: Use of Legendre transforms in chemical thermodynamics, Pure Appl. Chem., 73, 1349-1380, 2001.

Brewer, P. G. and Bradshaw, A.: The effects of the non-ideal composition of seawater on salinity and density, J. Mar. Res., 33, 157-175, 1975.

Chen, C. T. and Millero, F. J.: Precise thermodynamical properties for natural waters covering only the limnological range, Limnol. Oceanogr., 31, 657-662, 1986.

Cockell, C. (Ed.): An Introduction to the Earth-Life System, Cambridge University Press, Cambridge 2008.

Connors, D. N. and Kester, D. R.: Effect of major ion variations in the marine environment on the specific gravity - conductivity chlorinity - salinity relation, Mar. Chem., 2, 301-314, 1974.

Cox, R. A., Culkin, F., and Riley, J. P.: The electrical conductivity/chlorinity relationship in natural seawater, Deep-Sea Res., 14, 203-220, 1967.

Ebeling, W., Feistel, R., Kelbg, G., and Sändig, R.: Generalizations of Onsager's Semiphenomenological Theory of Electrolytic Conductance, J. Non-Equil. Thermody., 3, 11-28, 1977.

Ebeling, W., Feistel, R., and Sändig, R.: Electrolytic Conductance for Gurney-Friedman Models, J. Sol. Chem., 8, 53-82, 1979.

Feistel, R.: On the Physical Chemistry of Seawater with Deviating Ion Composition, Z. Phys. Chem., 204, 27-44, 1998.

Feistel, R.: A Gibbs Function for Seawater Thermodynamics for -6 to $80^{\circ} \mathrm{C}$ and Salinity up to $120 \mathrm{~g} / \mathrm{kg}$, Deep-Sea Res. Pt. I, 55, 1639-1671, 2008.
Feistel, R.: Extended equation of state for seawater at elevated temperature and salinity, Desalination, 250, 14-18, 2010.

Feistel, R. and Hagen, E.: On the Gibbs thermodynamic potential of seawater, Progr. Oceanogr., 36, 249-327, 1995.

Feistel, R. and Marion, G.M.: A Gibbs-Pitzer Function for HighSalinity Seawater Thermodynamics, Prog. Oceanogr., 74, 515539, 2007.

Feistel, R., Nausch, G., and Wasmund, N. (Eds): State and Evolution of the Baltic Sea, 1952-2005. A Detailed 50-Year Survey of Meteorology and Climate, Physics, Chemistry, Biology, and Marine Environment, John Wiley \& Sons, Inc., Hoboken, 2008b.

Feistel, R. and Weinreben, S.: Is Practical Salinity conservative in the Baltic Sea?, Oceanologia, 50, 73-82, http://www.iopan.gda. pl/oceanologia/50_1.html\#A6, 2008.

Feistel, R., Weinreben, S., Wolf, H., Seitz, S., Spitzer, P., Adel, B., Nausch, G., Schneider, B., and Wright, D. G.: Density and Absolute Salinity of the Baltic Sea 2006-2009, Ocean Sci., 6, 3-24, doi:10.5194/os-6-3-2010, 2010a.

Feistel, R., Wright, D. G., Jackett, D. R., Miyagawa, K., Reissmann, J. H., Wagner, W., Overhoff, U., Guder, C., Feistel, A., and Marion, G. M.: Numerical implementation and oceanographic application of the thermodynamic potentials of liquid water, water vapour, ice, seawater and humid air - Part 1: Background and equations, Ocean Sci., 6, 633-677, doi:10.5194/os-6-633-2010, $2010 b$.

Feistel, R., Wright, D. G., Kretzschmar, H.-J., Hagen, E., Herrmann, S., and Span, R.: Thermodynamic properties of sea air, Ocean Sci., 6, 91-141, doi:10.5194/os-6-91-2010, 2010c.

Feistel, R., Wright, D. G., Miyagawa, K., Harvey, A. H., Hruby, J., Jackett, D. R., McDougall, T. J., and Wagner, W.: Mutually consistent thermodynamic potentials for fluid water, ice and seawater: a new standard for oceanography, Ocean Sci., 4, 275-291, doi:10.5194/os-4-275-2008, 2008a.

Forch, C., Knudsen, M., and Sørensen, S. P. L.: Berichte über die Konstantenbestimmungen zur Aufstellung der hydrographischen Tabellen, gesammelt von Martin Knudsen, Det Kongelige Danske Videnskabernes Selskabs Skrifter, 6, 1-152, 1902.

Goodstein, D. L.: States of matter, Prentice-Hall, Inc., Englewood Cliffs, New Jersey, 1975.

IAPWS: IAPWS Certified Research Need - ICRN, Thermophysical Properties of Seawater, The International Association for the Properties of Water and Steam, Lucerne, Switzerland, August 2007, revised 2010, available at: http://www.iapws.org, 2007.

IAPWS: Release on the IAPWS Formulation 2008 for the Thermodynamic Properties of Seawater, The International Association for the Properties of Water and Steam, Berlin, Germany, September 2008, available at: http://www.iapws.org, 2008.

IAPWS: Revised Release on the IAPWS Formulation 1995 for the Thermodynamic Properties of Ordinary Water Substance for General and Scientific Use, The International Association for the Properties of Water and Steam, Doorwerth, The Netherlands, September 2009, available at: http://www.iapws.org, 2009a.

IAPWS: Revised Release on the Equation of State 2006 for $\mathrm{H}_{2} \mathrm{O}$ Ice Ih, The International Association for the Properties of Water and Steam, Doorwerth, The Netherlands, September 2009, available at: http://www.iapws.org, 2009b.

IOC, SCOR and IAPSO: The international thermodynamic equation of seawater - 2010: Calculation and use of thermodynamic properties, Intergovernmental Oceanographic Commission, Manuals 
and Guides No. 56, UNESCO (English), 182 pp., available at: http://www.TEOS-10.org, 2010.

Jacobsen, J. P. and Knudsen, M.: Urnormal 1937 or Primary Standard Sea-Water 1937, ASSOCIATION D'OCÉANOGRAPHIE PHYSIQUE, Union Géodésique et Géophysique Internationale, Publication Scientifique No. 7, 1940.

Knudsen, M. (Hrsg.): Hydrographische Tabellen, G.E.C.Gad, Copenhagen, L. Friedrichsen \& Co., Hamburg, Buchdruckerei Bianco Luno, 1901.

Knudsen, M.: On the Standard-Water used in the hydrographical research until July 1903, Conseil Permanent International pour la l'Exploration de la Mer, Publications de Circonstance No. 2, En Commission Chez Andr. Fred. Høst \& Fils, Copenhague, Juillet, 1903.

Kremling, K: Untersuchungen zur chemischen Zusammensetzung des Meerwassers aus der Ostsee I, Kiel. Meeresforsch., 25, 81104, 1969.

Kremling, K: Untersuchungen zur chemischen Zusammensetzung des Meerwassers aus der Ostsee II, Kiel. Meeresforsch., 26, 120, 1970.

Kremling, K.: New method for measuring density of seawater, Nature, 229, 109-110, 1971.

Kremling, K: Untersuchungen zur chemischen Zusammensetzung des Meerwassers aus der Ostsee III, Kiel. Meeresforsch., 28, 99118, 1972.

Kwiecinski, B.: The relation between the chlorinity and the conductivity in Baltic water, Deep-Sea Res., 12, 113-120, 1965.

Landau, L. D. and Lifschitz, I. M.: Statistische Physik, AkademieVerlag, Berlin, 1987.

Lewis, E. L.: The Practical Salinity Scale 1978 and Its Antecedents, Unesco techn. pap. mar. sci., 37, 13-18, http://unesdoc.unesco. org/images/0004/000479/047932eb.pdf, 1981.

Marion, G. M. and Kargel, J. S.: Cold Aqueous Planetary Geochemistry with FREZCHEM: From Modeling to the Search for Life at the Limits, Springer, Berlin/Heidelberg, 2008.

Millero, F. J.: The physical chemistry of estuaries, in: Marine Chemistry in the Coastal Environment, edited by: Church, T. M., American Chemical Society, 25-55, 1975.

Millero, F. J.: Effect of changes in the composition of seawater on the density-salinity relationship, Deep-Sea Res., 47, 1583-1590, 2000.

Millero, F. J.: History of the Equation of State of Seawater, Oceanography, 23, 18-33, 2010.

Millero, F. J., Feistel, R., Wright, D. G., and McDougall, T. J.: The composition of Standard Seawater and the definition of the Reference-Composition Salinity Scale, Deep-Sea Res. Pt. I, 55, 50-72, 2008.

Millero, F. J., Forsht, D., Means, D., Gieskes, J., and Kenyon, K. E.: The Density of North Pacific Ocean Waters, J. Geophys. Res., 83(C5), 2359-2364, 1978.

Millero, F. J. and Kremling, K.: The densities of Baltic waters, Deep-Sea Res., 23, 1129-1138, 1976.

Nausch, G., Nehring, D., and Nagel, K.: Nutrient concentrations, trends and their relation to eutrophication, in: State and Evolution of the Baltic Sea, 1952-2005. A Detailed 50-Year Survey of Meteorology and Climate, Physics, Chemistry, Biology, and Marine Environment, edited by: Feistel, R., Nausch, G., and Wasmund, N., John Wiley \& Sons Inc., Hoboken, 265-309, 2008.
Omstedt, A., Gustafsson, E., and Wesslander, K.: Modelling the uptake and release of carbon dioxide in the Baltic Sea surface water, Cont. Shelf Res., 29, 870-885, 2009.

Pawlowicz, R.: Calculating the Conductivity of Natural Waters, Limnol. Oceanogr.-Meth., 4, 489-501, 2008.

Pawlowicz, R.: A model for predicting changes in the electrical conductivity, practical salinity, and absolute salinity of seawater due to variations in relative chemical composition, Ocean Sci., 6, 361-378, doi:10.5194/os-6-361-2010, 2010.

Pawlowicz, R., Wright, D. G., and Millero, F. J.: The effects of biogeochemical processes on oceanic conductivity/salinity/density relationships and the characterization of real seawater, Ocean Sci. Discuss., 7, 773-836, doi:10.5194/osd-7-773-2010, 2010.

Perttilä, M.: Baltic-C Meta-data-set: Monthly river discharges into the Baltic Sea, http://www.baltex-research.eu/baltic-c/metadata/ Baltic-C\%20DATA\%20FMI.pdf, 2009.

Poisson, A., Lebel, J., and Brunet, C.: The densities of western Indian Ocean, Red Sea and eastern Mediterranean surface waters, Deep-Sea Res., 28, 1161-1172, 1981.

Reissmann, J. H., Burchard, H., Feistel, R., Hagen, E., Lass, H. U., Mohrholz, V., Nausch, G., Umlauf, L., and Wieczorek, G.: Stateof-the-art review on vertical mixing in the Baltic Sea and consequences for eutrophication, Prog. Oceanogr., 82, 47-80, 2009.

Robinson, R. A.: The vapour pressure and osmotic equivalence of sea water, J. Mar. Biol. Assoc. UK, 33, 449-455, 1954.

Rohde, K.-H.: Untersuchungen über die Calcium- und Magnesiumanomalie in der Ostsee, Beitr. Meereskd., 19, 18-31, 1966.

Schneider, B., Nausch, G., and Pohl, C.: Mineralization of organic matter and nitrogen transformations in the Gotland Sea deep water, Mar. Chem., 119, 153-161, 2010.

Thomas, H. and Schneider, B.: The seasonal cycle of carbon dioxide in Baltic Sea surface waters, J. Marine Syst., 22, 53-67, 1999.

Unesco: The Practical Salinity Scale 1978 and the International Equation of State of Seawater 1980, Unesco techn. pap. mar. sci., 36, 8-25, 1981.

Valeport: Sound Velocity - Direct Measurement vs. CTD Calculation, available at: http://www.valeport.co.uk/Support/ ApplicationNotes/SoundVelocitySensors/CTDvsSV.aspx, 2010.

Wright, D. G., Pawlowicz, R., McDougall, T. J., Feistel, R., and Marion, G. M.: Absolute Salinity, "Density Salinity" and the Reference-Composition Salinity Scale: present and future use in the seawater standard TEOS-10, Ocean Sci. Discuss., 7, 15591625, doi:10.5194/osd-7-1559-2010, 2010a.

Wright, D. G., Feistel, R., Reissmann, J. H., Miyagawa, K., Jackett, D. R., Wagner, W., Overhoff, U., Guder, C., Feistel, A., and Marion, G. M.: Numerical implementation and oceanographic application of the thermodynamic potentials of liquid water, water vapour, ice, seawater and humid air - Part 2: The library routines, Ocean Sci., 6, 695-718, doi:10.5194/os-6-695-2010, 2010 b. 